\title{
Ecological role of mycotoxin zearalenone in interactions among fungi and its enzymatic detoxification
}

\author{
Dissertation \\ zur Erlangung des Doktorgrades \\ der Fakultät für Agrarwissenschaften \\ der Georg-August-Universität Göttingen
}

vorgelegt von

Jan Utermark

geboren in Göttingen

Göttingen im April 2008 
D 7

1. Referent:

2. Korreferent:

Tag der mündlichen Prüfung:
Prof. Dr. Petr Karlovsky

Prof. Dr. Andreas von Tiedemann

22. Mai 2008 



\section{Contents}

Chapter 1: General introduction (Literature review) .......................................

Mycotoxins..................................................................................................

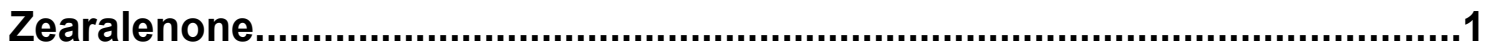

Producing organisms and natural occurrence of zearalenone....................3

Zearalenone biosynthesis in F. graminearum.........................................4

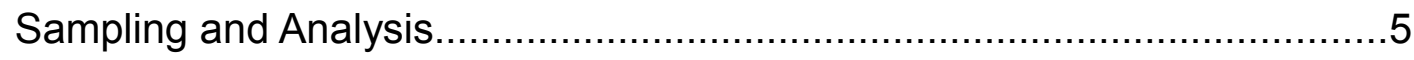

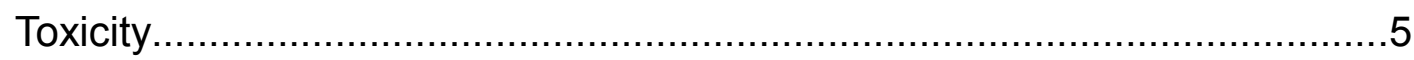

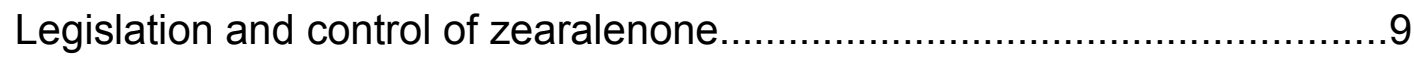

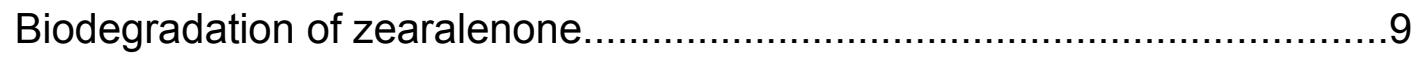

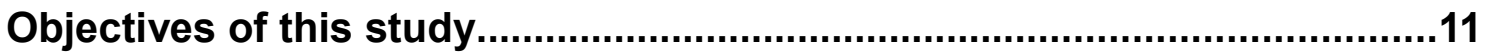

Chapter 2: Role of zearalenone lactonase in protection of

Gliocladium roseum from fungitoxic effects of the

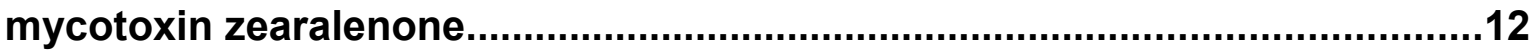

Materials and Methods..............................................................................13

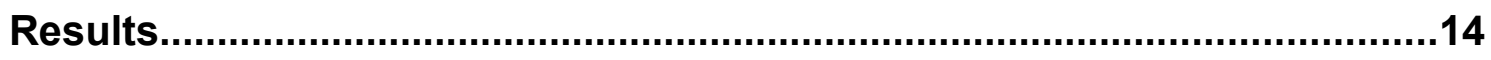

Discussion.............................................................................................. 16

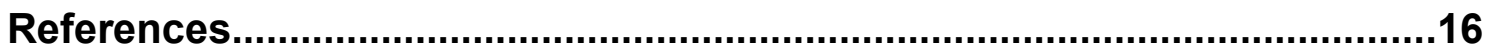

Chapter 3: Phytotoxic effects of zearalenone on growth

of Arabidopsis thaliana and protection by heterologous

expression of zearalenone lactonase...........................................................18

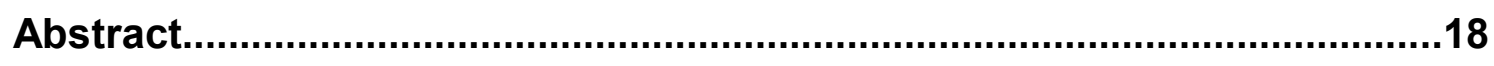

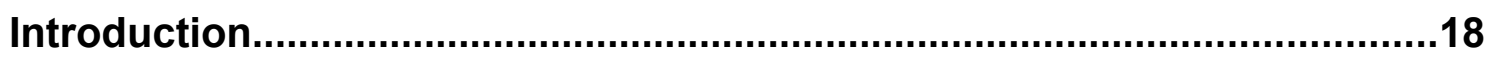

Materials and Methods........................................................................21

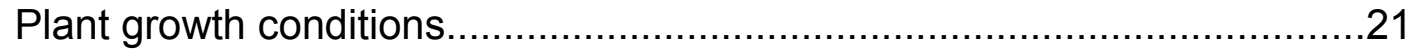

Construction of the zes2 expression vector....................................21

Plant transformation and selection of homozygous transformants.............21 
Analysis of gene integration in chromosomal DNA of $A$. thaliana. .22

In vitro Zes 2 protein activity assay............................................22

Zearalenone analysis................................................................ 22

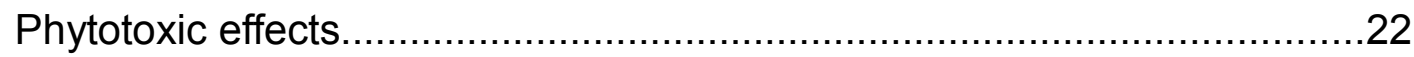

Assessment of cell growth after zearalenone treatment.........................23

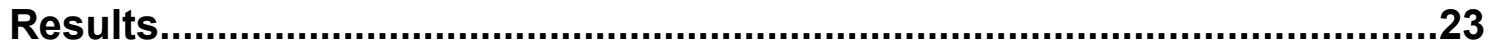

Molecular characterization of zes2-expression in transgenic

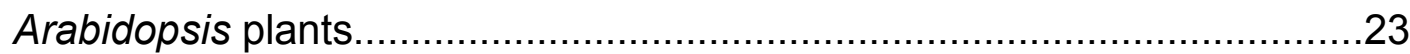

Zearalenone lactonase expression analysis in different plant tissues........24

Zearalenone inhibits morphological development in A. thaliana................26

Tolerance of Arabidopsis leaves to zearalenone and derivatives...............30

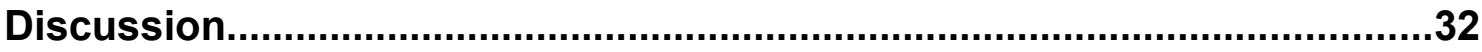

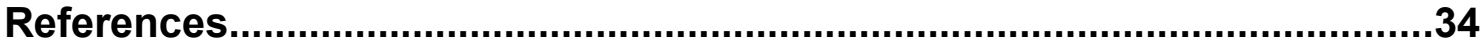

\section{Chapter 4: Genetic transformation of filamentous fungi}

by Agrobacterium tumefaciens............................................................................

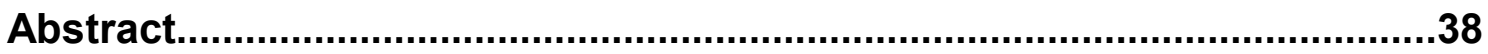

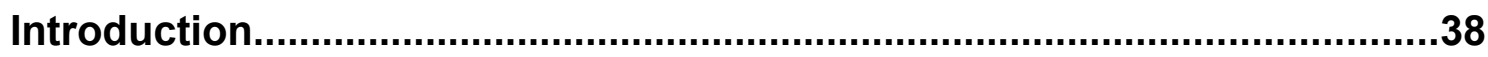

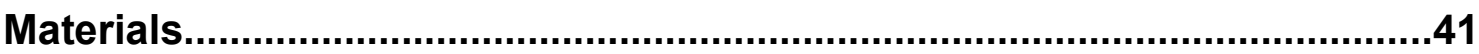

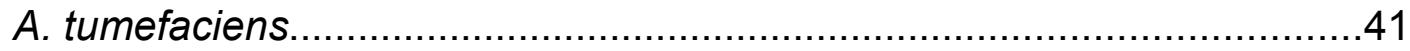

Recipient fungal strains................................................................ 41

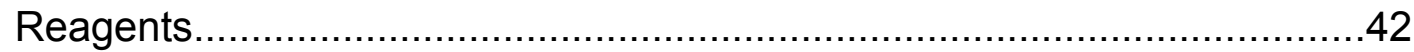

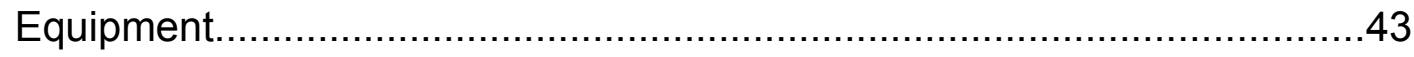

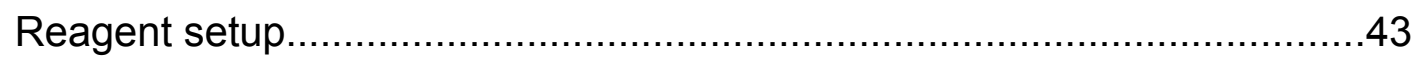

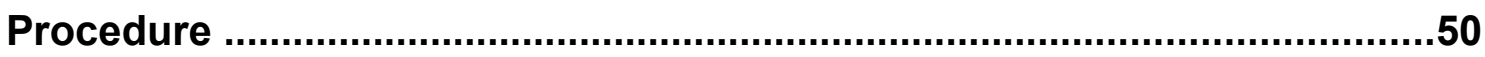

Preparation of fungal recipient...................................................... 50

Preparation A. tumefacies AGL1 as a donor.....................................51

Pre-induction of T-DNA mobilization in A. tumefaciens..........................51

Co-cultivation of $A$. tumefaciens and fungal recipient ...........................52

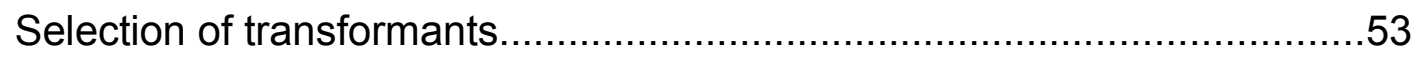

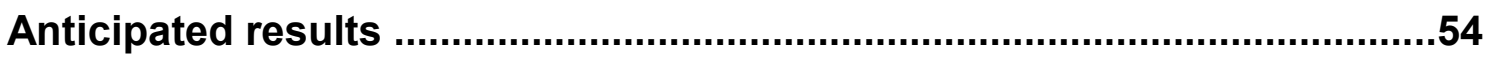


References 55

Chapter 5: Biosensor for zearalenone. .57

Biosensor for mycotoxin zearalenone based on

mycotoxin-sensing mycoparasite Gliocladium roseum..............................57

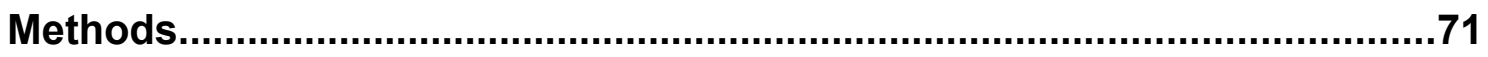

Microbial strains and culture........................................................ 71

Construction of in situ display vectors for zearalenone ...........................71

Generation of a transgenic $G$. roseum strain for

real-time monitoring of zes 2 gene expression...

Analysis targeted replacement of zes 2 in

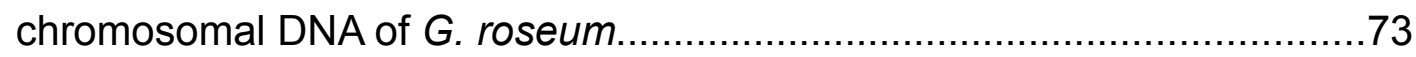

Fluorescence measurement of zearalenone lactonase synthesis.............74

In situ monitoring responses of zearalenone...................................... 74

Extraction of zearalenone and mass spectrometry...........................75

Supplementary information..................................................... 75

References.......................................................................................76

Chapter 6: Quantification of GFP................................................................

Quantification of green fluorescent protein fluorescence

using real-time PCR thermal cycler...........................................................79

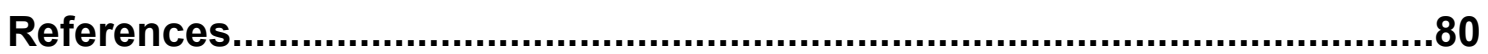

Chapter 7: General discussion..............................................................82

Biological function of mycotoxins in fungal development.........................82

Reduction of zearalenone contamination in

agricultural commodities by enzymatic detoxification...............................84

Biosensors for zearalenone - ready for environmental application?..........85

Luciferase- and GFP-marker in functional genomics in fungi.....................86

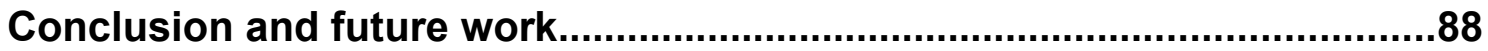

References (cited in introduction and general discussion).......................90 


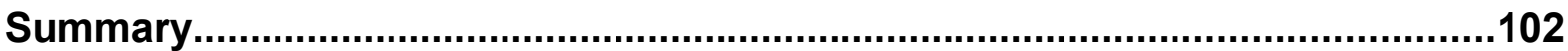

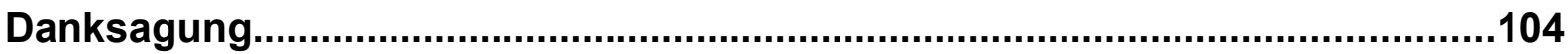

Publications and conference contributions...................................................105

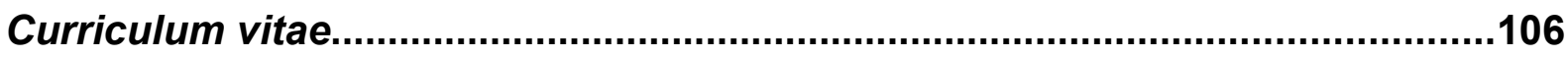




\section{Chapter 1: General introduction (Literature review)}

\section{Mycotoxins}

A large amount of information about mycotoxins has accumulated in the nearly 50 years since the substantial loss of a large number of animals due to mycotoxins (aflatoxin) in feedstuffs in the UK in 1960. This event illustrated the potential threat posed by mycotoxins and initiated modern mycotoxicology (Richard, 2007). The worldwide contamination of cereals and related products with mycotoxins $(25 \%$ of the world's crop production; Rotter et al., 1996) impairs livestock performance and poses a health risk to consumers (D'Mello et al., 1999; Fink-Gremmels, 1999; Placinta et al., 1999). Therefore this area has become a multidisciplinary issue involving analytical chemists, microbiologists, agronomists, agricultural engineers, entomologists, plant pathologists, crop breeders, geneticists, medical and veterinary practitioners and producers (farmers). The combined effort of these groups led to the discovery of many new mycotoxins and knowledge about their involvement in diseases of animals (Bennett and Klich, 2003).

Mycotoxins are a group of structurally heterogeneous secondary metabolites produced by ubiquitous fungi, mainly of the genus Aspergillus, Penicillium, Fusarium, Claviceps, Alternaria, Stachybotrys and Myrothecium. The production of mycotoxins is not essential for fungal growth or reproduction, but is supposed to be a "virulence factor" for some plant pathogens and acts against other microorganisms and higher organisms (Desjardins et al., 1993).

\section{Zearalenone}

Zearalenone was isolated by Stob et al. (1962) and Andrews and Stob (1965; U.S. patent application 3196019) and derives its name from the fungus Giberella zeae (perfect state of Fusarium graminearum) from whose mycelium, contaminating maize (Zea mays), it was first isolated. Urry et al. (1966) carried out a complete characterisation, assigned structure, and named the discovered compound zearalenone. 
So far, five derivatives of zearalenone (Fig. 1) have been characterised. They are: $\alpha-$ and $\beta$-zearalenol, $\alpha$ - and $\beta$-zearalanol and zearalanone.<smiles>C[C@H](CCCCC(=O)O)OC(=O)c1c(O)cc(O)cc1/C=C/CCCCCCO</smiles><smiles>C[C@H](CCCCC(O)O)OC(=O)c1c(O)cc(O)cc1/C=C/CCCCCO</smiles><smiles>C[C@H]1CCC[C@H](O)CCC/C=C/c2cc(O)cc(O)c2C(=O)O1</smiles>
$\beta$-Zearalenol<smiles>C[C@@H](CCCCC(=O)O)OC(=O)c1c(O)cc(O)cc1CCCCCCCO</smiles><smiles>C[C@@H](O)CCCCc1cc(O)cc(O)c1C(=O)O[C@H](C)CCCCC(O)O</smiles><smiles>C[C@H]1CCC[C@H](O)CCCCCc2cc(O)cc(O)c2C(=O)O1</smiles>

B-Zearalanol

Figure 1. Structure of the mycotoxin zearalenone and its derivatives.

Zearalenone, 6-(10-hydroxy-6-oxo-trans-1-un-decenyl)- $\beta$-resorcylic-acid-lactone, is index in chemical abstracts as [S-(E)]-3,4,5,6, 9,10-hexahydro-14,16-dihydroxy-3methyl-1H-2-benzoxacyclotetradecin-1,7(8H) dione or by the CAS number 1792492-4. Zearalenone is a stable compound, both during storage and processing of food and does not degrade at high temperatures (Kuiper-Goodman et al., 1987; Gilbert, 1989; Lauren and Ringrose; 1997).

The resorcylic acid lactone zearalenone is a white crystalline compound with a molecular weight (MW) of 318.36 and a melting point of $164-165^{\circ} \mathrm{C}$. It is naturally fluorescent under ultraviolet (UV) light and its spectrum is characterised by three maxima at $U V_{\max } 236,274$ and $316 \mathrm{~nm}$. This mycotoxin is practically insoluble in water, but is 
readily soluble in many organic solvents (Tab. 1).

Table 1. Solubility of zearalenone in different organic solvents and water (Hidy et al., 1977).

\begin{tabular}{ll}
\hline Solvent & $\mathrm{g}$ zearalenone $/ 100 \mathrm{~g}$ at $25^{\circ} \mathrm{C}$ \\
\hline Acetone & 58 \\
Ethanol & 24 \\
Methanol & 18 \\
Dichloromethane & 17.5 \\
Acetonitrile & 8.6 \\
n-Hexane & 0.05 \\
Water & 0.002 \\
\hline
\end{tabular}

\section{Producing organisms and natural occurrence of zearalenone}

Zearalenone has been isolated from strains of several species belonging to the genus Fusarium, such as: F. graminearum, F. culmorum, F. crookwellense and F. equiseti (Logrieco et al., 2002).

Fusarium is an important genus of fungal pathogens and attacks a wide range of plant species including members of the families Fabaceae, Cucurbitaceae and a wide range of Poaceae (Shaner, 2003). Fusarium species are responsible for devastating diseases in cereal crops such as Fusarium Head Blight (FHB) of wheat and barley or Fusarium ear rot of maize, which can reach epidemic measures (Goswami and Kistler, 2004; Windels, 2000). Fusarium spp. colonise cereals in the field and plant stressors such as draught or over-irritation, insect damage and pesticide exposure may result in a higher susceptibility to fungal infection, whereas the production of mycotoxins may be due to stress or altered conditions for the fungus (Fink-Gremmels, 1999). Surveys on zearalenone occurrence on several commodities are routinely published (Tab. 2 ). 
Table 2. Recent studies on zearalenone contamination of foods and feeds in several countries.

\begin{tabular}{llll}
\hline Commodity & Country & $\begin{array}{l}\text { Zearalenone concen- } \\
\text { tration }(\mathrm{mg} / \mathrm{kg})\end{array}$ & References \\
\hline Wheat & Germany & \pm 0.015 & Schollenberger et al., 2006 \\
Corn & Germany & Up to 0.86 & Schollenberger et al., 2006 \\
Oats & Germany & Up to 0.021 & Schollenberger et al., 2006 \\
Corn & Italy & \pm 0.453 & Pietri et al., 2004 \\
Poultry feed & Slovakia & Up to 0.086 & Labuda et al., 2005 \\
Corn & Morocco & Up to 0.0165 & Zinedine et al., 2006 \\
Corn & Indonesia & Up to 0.52 & Nuryono et al., 2005 \\
Corn flour & Iran & Up to 0.9 & Reza Oveisi et al., 2005 \\
Rice & Korea & Up to 0.047 & Park et al., 2005 \\
\hline
\end{tabular}

\section{Zearalenone biosynthesis in $F$. graminearum}

The polyketide zearalenone is produced by the acetate-polymalonate pathway (Dewick, 2001). 15 polyketide synthase genes were identified in the genomic sequence of F. graminearum (Gaffoor et al., 2005). Gene disruption studies have determined that four tightly linked genes are required for zearalenone biosynthesis (Gaffoor and Trail, 2006). The PKS4 (ZEA2) gene encodes an iterative Type I, reducing, polyketide synthase with six functional domains. The PKS13 (ZEA1) gene also encodes an iterative Type I. Although both PKS4 and PKS13 polyketide synthases are required for zearalenone biosynthesis, their specific roles are unknown. The cluster also contains a gene (ZEB1) that controls oxidization of $\beta$-zearalanol to zearalenone (Kim et al., 2005). 


\section{Sampling and Analysis}

In common with other mycotoxins sampling of food commodities for zearalenone must be carried out to obtain samples representative of the consignment under test. Commonly used extraction solvents are aqueous mixtures of methanol, acetonitrile or ethyl acetate followed by a range of different clean-up procedures.

TLC methods have been used but are now superseded by HPLC with UV or fluorescence detection, GC/ECD, GC/MS and HPLC/MS. Use of immunoaffinity clean up columns with HPLC is becoming used increasingly (Campbell and Armstrong, 2007; Lattanzio et al., 2007). Depending on the method used, concentrations down to and below $5 \mu \mathrm{g} / \mathrm{kg}$ can be measured. In addition, ELISA can be used but this is often less sensitive and can only measure one toxin at a time (Bennett et al., 1994).

\section{Toxicity}

\section{Acute toxicity}

Zearalenone has shown relatively low acute toxicity (oral LD 50 values of $>2-20 \mathrm{~g} / \mathrm{kg}$ body weight) in mice, rats and guinea pigs after oral intake (Flannigan, 1991). Thus, Marasas et al. (1979) reported that a single dose of $20 \mathrm{~g} / \mathrm{kg}$ body weight does not cause death in these species. However it is more toxic by intraperitoneal injection (Hidy et al., 1977).

\section{Carcinogenicity}

Carcinogenic activity of zearalenone is still a matter of discussion (Gao and Yoshizawa, 1997). The National Institute of Health (USA)/National Toxicology Program (NIH/ NTP) considered the results of carcinogenicity assays in rats and mice to be a positive evidence of carcinogenicity. In these studies, there was an increased incidence of pituitary adenomas in both male and female animals, with progression to malignancy, as indicated by the presence of pituitary carcinomas in some of the animals (Kuiper Goodman, 1991).

However, according to IARC (1999), zearalenone is not classifiable as to its carcinogenicity to humans. Whether zearalenone promotes breast cancer (Ahamed et al., 2001; Schoental, 1985; Tomaszewski et al., 1998) rather than reducing mammary tumorigenesis (Hilakivi-Clarke et al., 1999) is heavily contested and further 
studies are required to confirm whether zearalenone should be considered as a potential human carcinogen.

\section{Genotoxicity}

Several genotoxicity assays have been conducted with zearalenone. It was found to be negative in the eukaryotic cell mutation assay with Saccharomyces cerevisae (Creppy, 2002) and it did not induce mutations in Salmonella typhimurium (Ames test). However, zearalenone induced the SOS repair system in some bacterial species (Ghedira et al., 1998) and has been shown a DNA damaging effect in a recombination test with Bacillus subtilis (Ueno and Kubota, 1976). According to Lioi et al. (2004), zearalenone induced DNA-adduct formation in cultures of bovine lymphocytes. Therefore, investigations were undertaken to assess the effect of zearalenone on DNA of female mice and rats after intraperitoneal or oral uptake. These studies clearly demonstrate that zearalenone leads to DNA-adduct formation, chromosomal aberration and polyploidy and therefore approved its genotoxicity (Pfohl-Leszkowicz et al., 1995; Coe et al., 1992).

\section{Immunotoxicity}

In vitro experiments have shown several alterations of immunological parameters (increase of interleukine (IL)-2 and IL-5 production; Eriksen and Alexander, 1998) when testing high concentrations of zearalenone. In other investigations, administration of zearalenone (Pestka et al., 1987; Forsell et al., 1986) and of zearalenols (Pung et al., 1985) did not produce differences between control and treated groups in the serum concentration of immuno globuline $(\lg ) \mathrm{M}, \lg G, \lg A$ and in white blood cell count, which are typical indicators of immunotoxic activity.

\section{Reproductive and developmental toxicity}

Zearalenone induces estrogenic effects in mammals, including early maturity of mammary glands and reproductive organs and an increase in their size. At higher doses zearalenone interferes with conception, ovulation, implantation, fetal development and viability of newborn animals. The most important estrogenic effects of zearalenone are shown in table 3. Estrogenic activity of zearalenone metabolites has also been reported. Pigs are definitely the most sensitive species (Coulombe, 1993). Hy- 
perestrogenism, appearing when zearalenone contamination of corn exceeds $1 \mathrm{mg} / \mathrm{kg}$, shows different characteristics dependent of the age of the swine. Only sexually mature boars are relatively insensitive to zearalenone contamination (Coulombe, 1993; Etiene and Jemmali, 1982; Berger et al., 1981; Ruhr et al., 1983).

The estrogenic effect appear to be mediated via binding of zearalenone or its metabolites to the cytoplasmic estrogen receptor (Er- $\alpha$ and $E r-\beta)$. This has been demonstrated in several in vitro and in vivo experiments (Kuiper et al., 1998). For example, zearalenone and two zearalenone derivatives competed with 17P-estradiol for binding with the cytosolic receptor in rat uterine tissue (Klang et al., 1978). There is some evidence of precocious sexual developments in humans exposed to zearalenone, however these data primarily derive from Puerto Rico and were probably due to the use of a commercial animal growth promoter ( $\alpha-Z A L$, trade name: Ralgro ${ }^{\circledR}$ ) based on zearalenone metabolites and not a consequence of natural exposure (Saenz de Rodriguez et al., 1985). 
Table 3. Estrogenic effects induced by zearalenone in animals.

\begin{tabular}{|c|c|c|}
\hline Species & Estrogenic effect & Reference \\
\hline $\begin{array}{l}\text { Rodents } \\
\text { (rats, mice, } \\
\text { guinea-pigs, } \\
\text { rabbits) }\end{array}$ & $\begin{array}{l}\text { - } \text { increased late fetal deaths } \\
\text { - } \text { infertility or decreased fertility } \\
\text { - } \quad \text { reduced serum testosterone levels } \\
\text { and sperm counts } \\
\text { - } \text { reduced incidence of pregnancy, } \\
\text { altered levels of progesterone } \\
\text { mimic oestrogen actions, delayed va- } \\
\text { ginal opening, persistent oestrus and } \\
\text { sterility }\end{array}$ & $\begin{array}{l}\text { Arora et al.,1983 } \\
\text { Becci et al., 1982a,b } \\
\text { Kaliamurthy et al., } 1997 \\
\text { Long and Diekman, } 1989 \\
\text { Nilsson et al., } 1987 \\
\text { Ito and Ohtsubo, } 1994 \\
\text { Zwierzchowski et al., } 2005\end{array}$ \\
\hline $\begin{array}{l}\text { Turkey } \\
\text { Sows, gilts, } \\
\text { piglets and } \\
\text { boars }\end{array}$ & $\begin{array}{l}\text { - } 20 \% \text { decreased egg production } \\
\text { - } \text { vulvovaginitis, anestrus } \\
\text { one secretion } \\
\text { - } \text { reduced conception rates, litter size, } \\
\text { enlargement of ovaries and uterus } \\
\text { - } \text { swelling of vulva in piglets } \\
\text { - disturbances in the process of devel- } \\
\text { opment and maturation of some of } \\
\text { the ovarian follicles } \\
\text { - depression of serum testosterone } \\
\text { feminization and suppression of li- } \\
\text { bido }\end{array}$ & $\begin{array}{l}\text { Allen et al., } 1983 \\
\text { Etienne et al, } 1994 \\
\text { Vanyi et al., } 1994 \\
\text { Zwierzchowski et al., } 2005 \\
\text { Dacasto et al., } 1995 \\
\text { Diekman and Green, } 1992\end{array}$ \\
\hline $\begin{array}{l}\text { Dairy cows } \\
\text { Cattle }\end{array}$ & $\begin{array}{l}\text { - infertility and reduced milk production } \\
\text { - degeneration of germinal epithelium, } \\
\text { - } 75 \% \text { incidence of sperm degenera- } \\
\text { tion }\end{array}$ & $\begin{array}{l}\text { Weaver et al., } 1986 \\
\text { Vanyi et al., } 1980\end{array}$ \\
\hline
\end{tabular}




\section{Legislation and control of zearalenone}

Due to its adverse effects on mammals, zearalenone is one of the most important mycotoxins from the animal and human health point of view. The increasing awareness of mycotoxin risks is leading to setting guidelines and/or regulatory limits for these mycotoxins. For example, Austria has recommended maximum levels of zearalenone of $60 \mu \mathrm{g} / \mathrm{kg}$ wheat, durum wheat, and rye intended for human consumption. Other countries (Germany, Estonia, Lithuania, Romania, Canada and Slovenia) have also specific regulations setting limits in feed and food. Thus, zearalenone was regulated in the year 2003 by 16 countries (FAO, 2004). A few countries, like Canada and the Netherlands, have applied the "zero tolerance level" approach for one or more matrices (FAO,1997). But the most important fact that hampers the establishment of limits for zearalenone is, that there is no standardised and internationally validated method existing for determination of zearalenone and its metabolites.

\section{Biodegradation of zearalenone}

A variety of microorganisms including bacteria, yeasts, fungi but also plant cell cultures, were found to be able to convert zearalenone to $\alpha$ - and $\beta$ - zearalenol (Palyusik et al., 1980). Firstly, Steele et al. (1976) reported that zearalenone is degraded by F. graminearum. The ability of rumen protozoa to degrade zearalenone was demonstrated by Kiessling et al. (1984). They concluded that protozoa can be considered as the most important ruminal microbial population in zearalenone biodegradation (Kiessling et al., 1984; Hussein and Brasel, 2001). However, this degradation should not be regarded as a detoxification since a-zearalenol (more estrogenic than zearalenone) is the major metabolite obtained.

Recently, zearalenone was found to be degraded by the bacterium Rhodococcus erythropolis (W. Holzapfel, I. Brost, P. Faerber, R. Geisen, H. Bresch, K.D. Jany, M. Mengu, M. Jakobsen, P.S. Steyn, D. Teniola, P. Addo. 2002. World Trade Organization patent application WO02099142). Up to 70\% of the zearalenone concentration was eliminated by this organism but no analysis of culture extracts revealing zearalenone-derived products was reported. Bacterial fermentation of zearalenone contaminated food or feed might reduce zearalenone levels, but it might also convert 
zearalenone to even more potent estrogens (Ryu et al., 2002). Engelhardt et al. (1988) reported that maize suspension cultures were able to convert zearalenone to zearalenone glucoside. However, according to Karlovsky (1999), this transformation also cannot be regarded as a detoxification since the estrogenic activity of these metabolites is similar to that of zearalenone.

In the 1980s El-Sharkawy and Abul-Hajj published a series of important papers on zearalenone transformation by fungi and actinomycetes. They characterized a nonestrogenic substance: zearalenone-4-O- $\beta$-glucoside, produced by Thamnidium elegans and Mucor bainieri (El-Sharkawy and Abul-Hajj, 1987a). In addition, the transformation products of Streptomyces rimosus and Cunninghamella bainieri did not bind to a rat estrogen receptor, indicating a loss of estrogenicity (El-Sharkawy and Abul-Hajj, 1987b). Recently, a few microorganisms with zearalenone detoxification activity have been discovered. Thus, a bio-degradation of zearalenone was reported for the bacterium Pseudomonas Sp. ZEA-1 (Altalhi, 2007) and for the fungi Rhizopus spp. and Mucor spp. (Varga et al., 2005). However, transformation of the toxin to less toxic products without estrogenic effects could not be proven. In contrast, the yeast species Trichosporon mycotoxinivorans is capable of hydrolysing zearalenone into non toxic metabolites (Schatzmayr et al., 2006). Unfortunately, the zearalenone detoxifying enzyme(s) involved is/are currently not available.

Since about twenty years it is known that the mycoparasitic fungus Gliocladium roseum degrades zearalenone enzymatically (El-Sharkawy and Abul-Hajj, 1987). The cleavage of the lactone bond of zearalenone by this fungus indicates a true detoxification because the product is far less estrogenic than zearalenone. The cleavage product, consisting of a mixture of two isomeric hydroxyketones, decarboxylates spontaneously, rendering the reaction irreversible. The entire coding region of zearalenone lactonase gene zes2 has been cloned from this mycoparasite by two research groups (Kakeya et al., 2002; Takahashi-Ando et al., 2002; E. H. Crane, J. T. Gilliam, P. Karlovsky, and J. R. Maddox, 3 October 2002, World Trade Organization patent application 02/ 076205; P. Karlovsky, E. H. Crane, J. T. Gilliam, and J. R. Maddox, U.S. patent application 20030073239). The sequences published independently differ in three amino acids (P. Karlovsky, personal communication). 


\section{Objectives of this study}

The knowledge about the enzymatic detoxification of mycotoxins by fungi is essential for our understanding of their biological function and their fate in nature as well as their role in interactions among organisms. Furthermore, it provides an attractive strategy for the development of biotechnological applications in food as well as feed industry. However, the regulation of these processes has not been investigated so far.

The main objectives of the present study were:

1. Investigation of the role of zearalenone lactonase in protection of $G$. roseum from fungitoxic effects of the mycotoxin zearalenone (Chapter 2).

2. Evaluation of the phytotoxic effects of zearalenone on growth of Arabidopsis thaliana and protection by heterologous expression of zearalenone lactonase (Chapter 3).

3. Development of a technique suitable for the genetic transformation of G. roseum (Chapter 4).

4. Utilisation of the zearalenone-sensing ability of $G$. roseum as basis for a novel kind of biosensors for mycotoxins (Chapter 5).

5. Quantification of green fluorescent protein fluorescence using real-time PCR thermal cycler (Chapter 6). 


\title{
Chapter 2:
}

ApPlied AND EnVironmental Microbiology, Jan. 2007, p. 637-642

0099-2240/07/\$08.00+0 doi:10.1128/AEM.01440-06

Vol. 73 , No. 2

Copyright (C) 2007, American Society for Microbiology. All Rights Reserved.

\section{Role of Zearalenone Lactonase in Protection of Gliocladium roseum from Fungitoxic Effects of the Mycotoxin Zearalenone ${ }^{\nabla}$}

\author{
Jan Utermark and Petr Karlovsky* \\ Molecular Phytopathology and Mycotoxin Research, Goettingen University, Grisebachstrasse 6, D-37077 Goettingen, Germany \\ Received 22 June 2006/Accepted 8 November 2006
}

\begin{abstract}
Zearalenone is a mycotoxin with estrogenic effects on mammals that is produced by several species of Fusarium. We found that zearalenone and its derivatives inhibit the growth of filamentous fungi on solid media at concentrations of $\leq 10 \mu \mathrm{g} / \mathrm{ml}$. The fungitoxic effect declined in the order zearalenone $>\alpha$-zearalenol $>\beta$-zearalenol. The mycoparasitic fungus Gliocladium roseum produces a zearalenone-specific lactonase which catalyzes the hydrolysis of zearalenone, followed by a spontaneous decarboxylation. The growth of $G$. roseum was not inhibited by zearalenone, and the lactonase may protect $G$. roseum from the toxic effects of this mycotoxin. We inactivated zes2, the gene encoding zearalenone lactonase in $G$. roseum, by inserting a hygromycin resistance cassette into the coding sequence of the gene by means of Agrobacterium tumefaciens-mediated genetic transformation. The zes 2 disruption mutants could not hydrolyze the lactone bond of zearalenone and were more sensitive to zearalenone. These data are consistent with a hypothesis that resorcylic acid lactones exemplified by zearalenone act to reduce growth competition by preventing competing fungi from colonizing substrates occupied by zearalenone producers and suggest that they may play a role in fungal defense against mycoparasites.
\end{abstract}

Zearalenone [6-(10-hydroxy-6-oxo-trans-1-undecenyil)-resorcylic acid lactone] is a mycotoxin produced by several species of Fusarium, most notably Fusarium graminearum and Fusarium culmorum. Zearalenone and its derivatives exert estrogenic and anabolic effects on mammals. Carryover of zearalenone from infected grain to feedstuff causes reproductive problems in pigs, sheep, and other farm animals, including precocious sexual development, vulva enlargement, pseudopregnancy, loss of embryos, and reduced litter size $(10,14,24)$. When digested with grain-based food, zearalenone may cause hyperestrogenism in children (33). Apart from its estrogenicity, zearalenone is genotoxic in mice and is a suspected carcinogen $(5,15,30)$. The intake of zearalenone by some human populations is close to the estimated tolerable limits (9), and the amount of zearalenone allowed in grain, feedstuff, and food is regulated in several countries (1). Current ecological and economic constraints on grain production encourage minimum tillage practices and reduced fungicide application, so infection of cereal plants with Fusarium spp. is increasing and contamination with mycotoxins is becoming a more serious threat to grain production.

One promising strategy for reducing zearalenone contamination is enzymatic degradation. The only commercial product on the market claimed to enzymatically detoxify zearalenone is the feed additive Mycofix Plus (Biomin GmbH, Herzogenburg, Austria). There are no published laboratory data demonstrating the hydrolysis of zearalenone by Mycofix Plus or by its active component, and such activity was not detected by us (21). The recently discovered yeast species Trichosporon mycotoxinivorans (27) degrades zearalenone and is expected to provide future versions of Mycofix Plus with genuine zearalenone-hydrolyzing activity.

* Corresponding author. Mailing address: Molecular Phytopathology and Mycotoxin Research, Grisebachstrasse 6, D-37077 Goettingen, Germany. Phone: 49-551-391-2919. Fax: 49-551-391-2919. E-mail: pkarlov@gwdg.de.

${ }^{\nabla}$ Published ahead of print on 17 November 2006.
Another fungus with proven zearalenone-degrading activity is Gliocladium roseum (8), and a zearalenone lactonase gene has been cloned from this mycoparasite by two research groups (19, 34; E. H. Crane, J. T. Gilliam, P. Karlovsky, and J. R. Maddox, 3 October 2002, World Trade Organization patent application 02/ 076205; P. Karlovsky, E. H. Crane, J. T. Gilliam, and J. R. Maddox, U.S. patent application 20030073239). The sequences published independently differ in three amino acids (P. Karlovsky, unpublished data). The biological function of zearalenone esterase, as well as the function of zearalenone itself, is unknown.

The objectives of this work were (i) to demonstrate the growth inhibition of filamentous fungi by zearalenone and (ii) to evaluate the effect of disruption of the zes 2 gene of $G$. roseum on the ability of the fungus to hydrolyze zearalenone and the resistance of $G$. roseum to zearalenone. Our working hypothesis is that zearalenone acts as an agent of interference competition (active protection of substrate from colonization by competitors) and that the zearalenone-specific lactonase of $G$. roseum protects the fungus from the fungitoxic effect of the mycotoxin. We suggest a biological function for zearalenone production and an ecological role for this fungal metabolite in a nonagricultural setting.

\section{MATERIALS AND METHODS}

Microbial strains. G. roseum DSM62726 was obtained from the Deutsche Sammlung von Mikroorganismen und Zellkulturen (Braunschweig, Germany). Agrobacterium tumefaciens AGL1 (23) was used for fungal transformation. Escherichia coli DH5 $\alpha$ (16) was used as the host for the construction and maintenance of plasmid vectors.

The fungal and protoctist species used in the investigation of the effect of zearalenone on growth rate and colony morphology were Epicoccum purpurascens AvT206, Cladosporium herbarum AvT264, and Alternaria alternata AvT64 (provided by A. von Tiedemann, Goettingen University, Goettingen, Germany); Sporotrichium thermophile $\mathrm{H} 98$ and Thermoascus aurantiacus $\mathrm{H} 103$ (provided by Jean Wagner, Hohenheim University, Stuttgart, Germany); Phytophthora nicotianae DSM1829 (Deutsche Sammlung von Mikroorganismen und Zellkulturen GmbH, Braunschweig, Germany); Stagonospora avenae H121, Stagonospora 
TABLE 1. PCR primers used in this study

\begin{tabular}{|c|c|c|c|}
\hline Template & Name & Sequence $\left(5^{\prime}-3^{\prime}\right)^{a}$ & $\begin{array}{l}\text { Product size } \\
\text { (bp) }\end{array}$ \\
\hline \multirow[t]{2}{*}{ zes 2 coding sequence } & OL500 & TACATACATATGCGCATTCGCAGCACAA & \multirow[t]{2}{*}{820} \\
\hline & OL501 & AAGAGAAAGATCTTCAAAGATACTTCTGCGTA & \\
\hline \multirow[t]{2}{*}{ zes2 $3^{\prime}$ and upstream sequences } & OL505 & AAGACAGAGCTCAACCAACCAGCCAGAAGTTAGA & \multirow[t]{2}{*}{960} \\
\hline & OL506 & AAGACAAAGCTTGGTCCAGTAGCTTTGTTGGCA & \\
\hline \multirow[t]{2}{*}{ hph } & HygBu & AAAAGTTCGACAGCGTCTCC & \multirow[t]{2}{*}{930} \\
\hline & HygBd & CGGCGAGTACTTCTACACAGC & \\
\hline
\end{tabular}

${ }^{a}$ Underlined recognition sequences for restriction enzymes: OL505, SacI; OL506, HindIII; OL507, KpnI; OL508, XbaI.

nodorum $\mathrm{Sn} 80$, and $F$. graminearum $\mathrm{HOH} 587$ (provided by Hanno Wolf, Hohenheim University, Stuttgart, Germany); Septoria avenae f. sp. tritici ATCC 26371 (American Type Culture Collection, Manassas, VA); and Phytophthora parasitica P6623 (provided by Arthur de Cock, Centraalbureau voor Schimmelcultures, Utrecht, The Netherlands)

Culture conditions and media. GM7 medium (20) was prepared by dissolving $3 \mathrm{~g}$ L-asparagine, $1 \mathrm{~g} \mathrm{KH}_{2} \mathrm{PO}_{4}, 0.5 \mathrm{~g} \mathrm{MgSO}_{4} \cdot 7 \mathrm{H}_{2} \mathrm{O}, 50 \mathrm{mg} \mathrm{CaCl}, 10 \mathrm{mg} \mathrm{FeCl} 3$. $7 \mathrm{H}_{2} \mathrm{O}, 1 \mathrm{mg}$ thiamine, and $20 \mathrm{~g}$ glucose in 1 liter of distilled water; the $\mathrm{pH}$ was adjusted to 5.6. Media were sterilized by autoclaving and solidified with $1.5 \%$ agar. A. tumefaciens was grown in LB medium (31) supplemented with kanamycin, rifampin, and carbenicillin at 50,50 , and $25 \mu \mathrm{g} / \mathrm{ml}$, respectively. Induction medium (IM) for A.tumefaciens was prepared as described by de Groot et al. (7). Malt extract agar (MEA) and Czapek-Dox agar were purchased from Difco (Detroit, Mich.) and prepared according to the manufacturer's instructions. Synthetic nutrient-poor agar was prepared as described by Gerlach and Nirenberg (12)

Chemicals. Zearalenone was obtained from Fermentek Ltd. (Jerusalem, Israel) in a purity of $99 \%$. $\alpha$ - and $\beta$-zearalenol were purchased from Sigma-Aldrich (Steinheim, Germany). Stock solutions of zearalenone and its derivatives were made in ethanol at a concentration of $10 \mathrm{mg} / \mathrm{ml}$ and kept at $-20^{\circ} \mathrm{C}$. All other chemicals were of "pro analysis" quality (analytical grade)

General DNA isolation and manipulation methods. Total DNA of $G$. roseum was isolated by using a modified cetyltrimethylammonium bromide protocol (4). Plasmid DNA isolation, restriction enzyme digestion, ligation, PCR, and DNA electrophoresis in agarose gels were performed according to standard protocols (31).

Construction of the zes 2 disruption vector. The cassette used for the disruption of zes2 was constructed by inserting a hygromycin resistance gene into the coding sequence of zes2. Flanking regions consisting of $960 \mathrm{bp}$ (upstream sequence and $3^{\prime}$ part of the zes 2 coding region) and 1,064 bp ( $5^{\prime}$ part of the zes 2 coding region and the downstream sequence) were amplified with primers (Table 1) derived from the genomic DNA of G. roseum (GenBank accession no. AB076037) and containing recognition sequences for SacI/HindIII (upstream and $3^{\prime}$ regions) and $\mathrm{KpnI} / \mathrm{XbaI}$ ( $5^{\prime}$ and downstream regions). PCR amplification was performed with 35 cycles of $96^{\circ} \mathrm{C}$ for $30 \mathrm{~s}, 61^{\circ} \mathrm{C}$ for $30 \mathrm{~s}$, and $72^{\circ} \mathrm{C}$ for $50 \mathrm{~s}$ with a final extension at $72^{\circ} \mathrm{C}$ for $5 \mathrm{~min}$. The hygromycin $\mathrm{B}$ resistance cassette contained the hygromycin phosphotransferase gene from E. coli $(h p h)$ under the control of the gpdA promoter and the $\operatorname{trpC}$ terminator from $A$. nidulans isolated as a 4-kb KpnI-HindIII fragment from binary vector pPK2 (6). The resistance cassette was fused with the 1,064-bp KpnI-XbaI PCR fragment carrying the 5' part and downstream region of zes2 inserted between the HindIII and XbaI sites of pUC57 (GenBank accession no. Y14837). The resistance cassette connected to the $3^{\prime}$ and downstream regions of zes2 was isolated as a 5-kb HindIII/ $\mathrm{XbaI}$ fragment and joined in a tri-fragment ligation with the SacI/HindIII-digested PCR product of the amplified upstream and $3^{\prime}$ parts of zes2 and SacI/XbaI-digested binary vector $\mathrm{pPK} 2$ to yield pZG05 (Fig. 1). The length of the T-DNA, from the left border to the right border, was $\sim 6.5 \mathrm{~kb}$. The vector was introduced into $A$. tumefaciens AGL1 by electroporation (26) with a pulse of $2.5 \mathrm{kV}$ in a $2-\mathrm{mm}$ cuvette, which was bridged with a resistance of $400 \Omega$ and a capacitance of $25 \mu \mathrm{F}$.

Southern hybridization. Disruption of zes2 in the genome of $G$. roseum after $A$. tumefaciens-mediated transformation was evaluated by Southern hybridization with a PCR-generated, digoxigenin-labeled zes2 fragment as the probe. The probe was amplified from the genomic DNA of G. roseum by using dUTP conjugated with digoxigenin (Roche Diagnostics GmbH, Penzberg, Germany) and primers OL 500 and OL501 (Table 1), generating a product of $820 \mathrm{bp}$. Six micrograms of HindIII- digested genomic DNA from putative transformants was resolved in a $0.8 \%$ agarose gel and blotted on Hybond N+ nylon membrane (Amersham Biosciences Europe $\mathrm{GmbH}$, Freiburg, Germany). Hybridization and detection of the digoxigenin-labeled probe with streptavidin-phosphatase complex and chemiluminescence substrate CDP-star was performed according to the manufacturer's (Roche Diagnostics $\mathrm{GmbH}$ ) instructions. Alternatively, chemifluorescence of dephosphorylated dimethylacridinone phosphate (Molecular Probes, Eugene, OR) was used to localize the probe, and fluorescent signals were recorded with a laser scanner (Typhoon 8600; Amersham Biosciences Europe GmbH).

A. tumefaciens-mediated transformation of $G$. roseum. A. tumefaciens carrying the pZG05 disruption vector was grown with shaking $(220 \mathrm{rpm})$ at $28^{\circ} \mathrm{C}$ overnight. Cells were washed with IM, transferred to fresh IM containing $0.2 \mathrm{mM}$ acetosyringone, and grown to an optical density at $660 \mathrm{~nm}$ of 0.15 . The culture was shaken at $28^{\circ} \mathrm{C}$ until its optical density doubled. One hundred microliters of A. tumefaciens culture and a suspension of $1 \times 10^{6}$ G. roseum spores in $100 \mu \mathrm{l}$ water were mixed and spread on a cellophane membrane overlying the IM agar supplemented with $0.2 \mathrm{mM}$ acetosyringone. After coincubation for $48 \mathrm{~h}$, the membranes were transferred to agar plates with GM7 medium containing 250 $\mu \mathrm{g} / \mathrm{ml}$ hygromycin B to select transformants and $200 \mu \mathrm{M}$ cefotaxime to prevent the growth of $A$. tumefaciens.

HPLC-mass spectrometric analysis of zearalenone and its conversion products. Reverse-phase high-performance liquid chromatography (HPLC) with a diode array and mass spectrometric detectors was used. The column was a Polaris $\mathrm{C}_{18}$-A ( $5 \mu \mathrm{m}, 150$ by $2 \mathrm{~mm}$; Varian, Darmstadt, Germany), the mobile

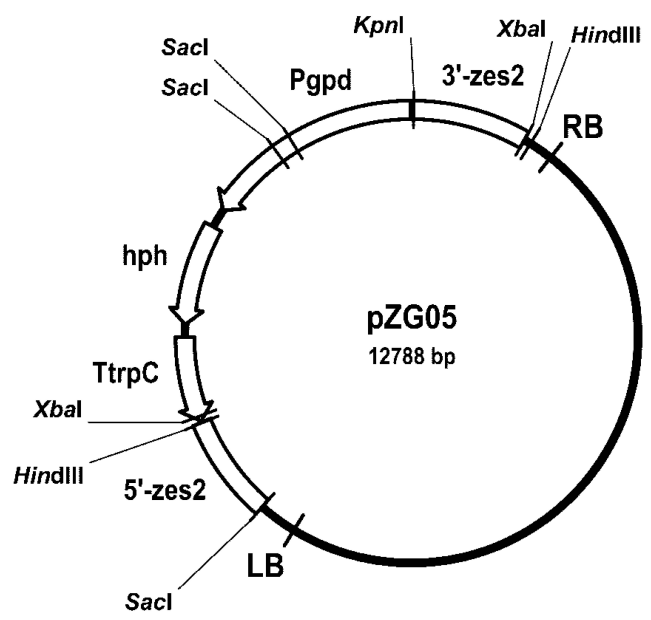

FIG. 1. Physical map of zes2 disruption vector pZG05. Pgpd, promoter region from $g p d$ gene; TtrpC, termination region from $\operatorname{tr} C$ gene (both from Aspergillus nidulans); LB and RB, left and right boundaries of T-DNA, respectively. 


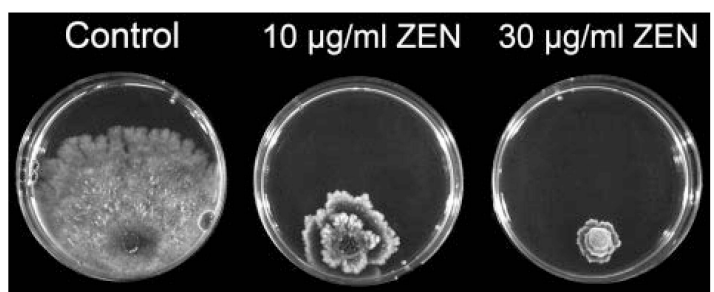

FIG. 2. Inhibition of $S$. fimicola growth by zearalenone. $S$. fimicola was inoculated into petri dishes filled with MEA alone (control) or with MEA amended with zearalenone (ZEN) at $10 \mu \mathrm{g} / \mathrm{ml}$ and 30 $\mu \mathrm{g} / \mathrm{ml}$. Zearalenone was added to agar medium cooled to $60^{\circ} \mathrm{C}$ as a methanol stock solution. The final concentration of methanol was set to $5 \%$ in all three media. Inoculated plates were incubated at $20^{\circ} \mathrm{C}$ for 7 days under a 16-h light, 8-h dark cycle.

phase was $55 \%$ methanol- $-45 \%$ water-5\% acetonitrile, the flow rate was 0.2 $\mathrm{ml} / \mathrm{min}$, the column temperature was $40^{\circ} \mathrm{C}$, detection was done with a diode array detector (absorbance at 200 to $800 \mathrm{~nm}$ ), and mass spectrometry was done by electrospray in positive mode (scan for a mass/charge ratio of 250 to 500 ). Preparation of samples was done by extracting culture supernatants with ethyl acetate and removing the solvent on a rotary evaporator. The residue was dissolved in the mobile phase.

Examination of the effect of zearalenone and its derivatives on fungal growth. MEA was autoclaved, cooled to $60^{\circ} \mathrm{C}$, and amended with zearalenone and its derivatives by adding appropriate amounts of stock solutions in methanol. The concentration of methanol was adjusted to $5 \%$ in all media, including controls. We have not observed any effect of methanol at this concentration on the growth of $G$. roseum. For qualitative assays, fungal strains were inoculated on solidified media by placing agar blocks overgrown with mycelium onto the agar close to the margin of the petri dish. Inoculated plates were incubated for 7 days at $20^{\circ} \mathrm{C}$ under a long-day light regimen ( $16 \mathrm{~h}$ light, $8 \mathrm{~h}$ dark). For quantitative assays, round, mycelium-covered agar blocks cut with a cork borer ( $6 \mathrm{~mm}$ diameter) out of agar plates were placed in the middle of petri dishes with solid medium. Plates were incubated at $24^{\circ} \mathrm{C}$ in the dark, and colony diameter was measured every $48 \mathrm{~h}$. Two values measured in perpendicular directions were recorded at each time point.

\section{RESULTS}

Inhibition of fungal growth by zearalenone. Zearalenone strongly inhibits the growth of Sordaria fimicola (Fig. 2). An inhibitory effect is detectable at a zearalenone concentration as low as $2 \mu \mathrm{g} / \mathrm{ml}$. An additional 10 species of filamentous fungi and fungus-like protoctists were inoculated onto MEA plates

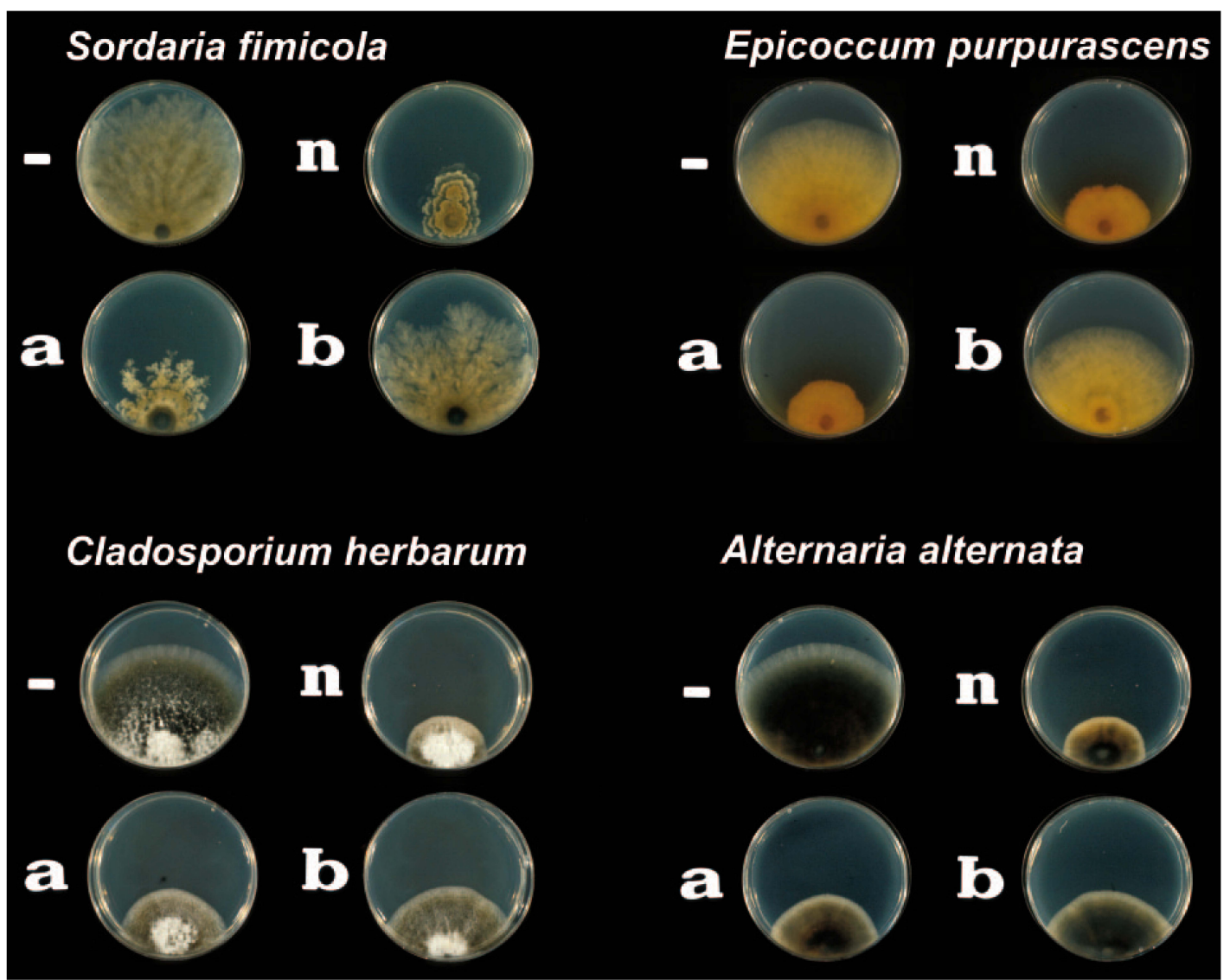

FIG. 3. Effects of zearalenone derivatives on fungi. The fungal species specified were inoculated onto petri dishes filled with MEA alone (-) and medium amended with zearalenone (n), $\alpha$-zearalenol (a), and $\beta$-zearalenol (b) at $20 \mu \mathrm{g} / \mathrm{ml}$. Mycotoxins were added to agar medium cooled to $60^{\circ} \mathrm{C}$ as a methanol stock solution. The final concentration of methanol was set to $5 \%$ in all media. Inoculated plates were incubated at $20^{\circ} \mathrm{C}$ for 7 days under a 16-h light, 8-h dark cycle. 


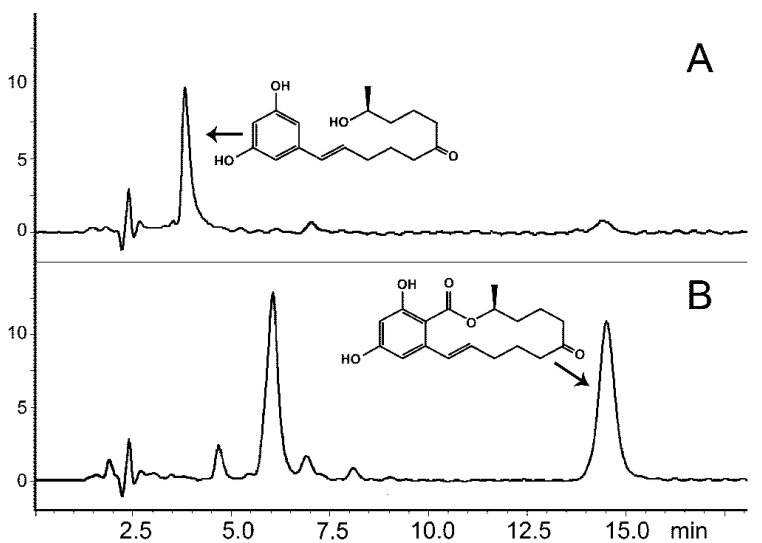

FIG. 4. HPLC analyses of the products of zearalenone degradation by $G$. roseum. Products of the transformation of zearalenone by wildtype G. roseum (A) and a zes 2 disruption mutant (B) were separated by HPLC and detected by $A_{236}$. The structure of zearalenone is drawn adjacent to the zearalenone peak in chromatogram B, and the structure of the hydrolyzed and decarboxylated degradation product of zearalenone (8) is drawn adjacent to the corresponding peak of chromatogram A. A large peak at the elution time of approximately 6 min corresponds to a putative unknown transformation product of zearalenone.

with zearalenone. With the exception of $G$. roseum, the growth of all of the species tested was inhibited by zearalenone at $\geq 10$ $\mu \mathrm{g} / \mathrm{ml}$. Growth of G. roseum was not inhibited by zearalenone on agar media. The zearalenone derivative $\alpha$-zearalenol had growth inhibitory effects on S. fimicola similar to those of zearalenone, but $\beta$-zearalenone was less fungitoxic (Fig. 3). Growth in medium with zearalenone and zearalenols altered the morphology of $S$. fimicola colonies and pigment production by $E$. purpurascens (Fig. 3). Similarly, growth inhibition of $C$. herbarum by zearalenone derivatives declined in the order zearalenone $>\alpha$-zearalenol $>\beta$-zearalenol (Fig. 3). In liquid media, even the growth (dry weight) of the zearalenone producer $F$. graminearum was slightly inhibited by zearalenone at $20 \mu \mathrm{g} / \mathrm{ml}$ (data not shown).

Disruption of zearalenone lactonase production in G. roseum by insertion of a resistance cassette into the zes 2 gene. $G$. roseum spores $\left(10^{6}\right)$ were subjected to transformation with $A$. tumefaciens. They were plated on GM7 plates supplemented with $250 \mu \mathrm{g} / \mathrm{ml}$ hygromycin $\mathrm{B}$, and $23 \mathrm{Hyg}^{\mathrm{r}}$ colonies were selected for further analysis.

A time series of HPLC chromatograms was generated for each sample and assigned to one of two classes. The first class (Fig. 4 A) contained chromatograms of the wild-type strain and 11 putative transformants. Zearalenone was rapidly replaced with a conversion product eluting from the column at $3.8 \mathrm{~min}$. The UV spectrum of the product possessed three maxima with a relative distance similar to that of the maxima of zearalenone and a hypsochromic shift of $20 \mathrm{~nm}$. The mass of the molecular ion $[M+1]$ corresponding to this product was 293 , which was 26 units less than the molecular mass of zearalenone. These data confirm the identity of the product as a hydrolysis product of zearalenone (acquisition of 18 mass units) which underwent spontaneous decarboxylation (loss of 44 mass units). We con-

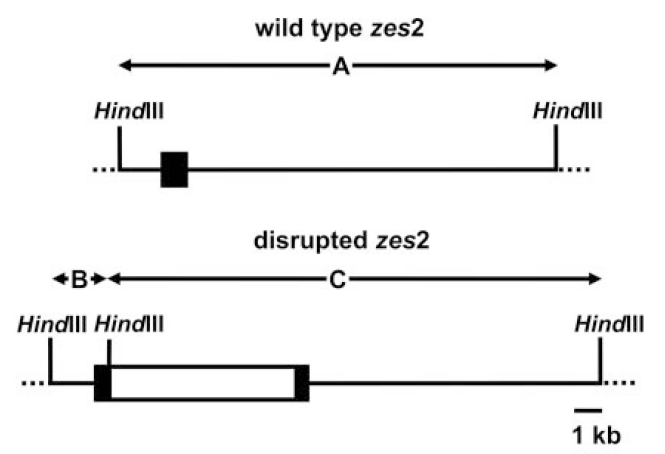

$\begin{array}{lllllllllll}M & 1 & 2 & 3 & 4 & 5 & 6 & 7 & 8 & 9 & 10\end{array}$

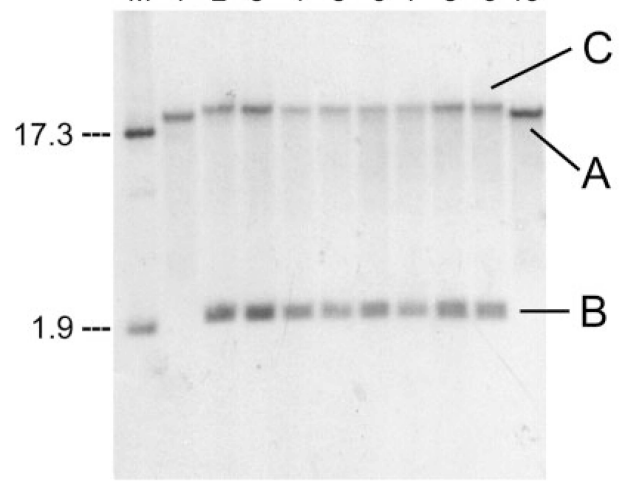

FIG. 5. Southern hybridization analysis of zes2 disruption mutants of $G$. roseum. The upper panel shows a scheme of the insertional mutagenesis of zes2. A Southern blot is presented in the lower panel. Genomic DNA was digested with HindIII, separated on a $0.8 \%$ agarose gel, and hybridized with an 820-bp fragment of zes2. Lane M, size marker (in kilobases); lanes 1 and 10, untransformed wild-type strain; lanes 2 to 9 , eight putative zes 2 disruption mutants.

cluded that these transformants retained a zearalenone lactonase activity identical to that of the wild type, having the hygromycin resistance cassette integrated ectopically.

The second class contained chromatograms of 12 samples (Fig. 4B). The conversion of zearalenone was much slower, leaving a substantial part of the exogenous zearalenone unchanged after 2 weeks of incubation. The conversion product eluted from the column with a retention time of $6 \mathrm{~min}$, which indicates that it is more polar than zearalenone (retention time, $14.6 \mathrm{~min})$. The absorption spectrum of the product(s) corresponding to this peak was indistinguishable from the UV spectrum of zearalenone, indicating that the aromatic ring and its functional groups remained unchanged. The mass of the putative molecular ion $[\mathrm{M}+1]$ was 16 units higher than the mass of the molecular ion of zearalenone, suggesting that the product was an oxidized derivative of zearalenone.

Analysis of the zes2 locus in G. roseum transformants. Hygromycin-resistant colonies were checked by PCR for the presence of the hygromycin phosphotransferase gene (primers $\mathrm{HygBu}$ and HygBd, Table 1) and the absence of the intact zes2 coding region. For the latter purpose, primers within the coding sequence of zes 2 flanking the hygromycin cassette in pZG05 were used (OL500 and OL501, Table 1). Among 23 
TABLE 2. Effect of zearalenone on growth of G. roseum zes 2 mutants

\begin{tabular}{lcc}
\hline \multirow{2}{*}{ G. roseum strain } & \multicolumn{2}{c}{ Growth rate $\left(\mathrm{mm} /\right.$ day) $^{a}$} \\
\cline { 2 - 3 } & $\begin{array}{c}\text { Czapek-Dox } \\
\text { medium }\end{array}$ & $\begin{array}{c}\text { Czapek-Dox medium with } \\
20 \mu \mathrm{g} \text { zearalenone/ml }\end{array}$ \\
\hline Wild type & $1.37 \pm 0.70$ & $1.46 \pm 0.080$ \\
zes2-1 & $1.44 \pm 0.11$ & $0.78 \pm 0.044$ \\
zes2-2 & $1.55 \pm 0.14$ & $0.58 \pm 0.53$ \\
zes2-3 & $1.54 \pm 0.088$ & $0.67 \pm 0.087$ \\
\hline
\end{tabular}

${ }^{a}$ Agar plates were incubated at $24^{\circ} \mathrm{C}$ in darkness for 12 days. Radial growth was recorded in two perpendicular directions, and means \pm standard deviations of six measurements are given.

putative transformants examined by PCR, 11 contained both the hygromycin cassette and the intact zes 2 sequence, indicating ectopic integration of the vector. These transformants metabolized zearalenone in the same manner as the wild-type strain (Fig. 4A). Twelve hygromycin-resistant strains lost the amplification product originating from the intact zes 2 gene, indicating that they had undergone a double recombination event. All of these transformants exhibited type B zearalenone metabolism (Fig. 4).

Eight potential mutants with zes 2 disrupted were examined by Southern blotting and hybridization. Genomic DNA was digested with HindIII (Fig. 5), which does not cut zes2 but does have a single recognition sequence in the hygromycin resistance cassette. The sum of fragments from the zes 2 disruption mutants equals the sum of the zes 2 fragment from the wild-type strain plus the length of the hygromycin resistance cassette. The size of the fragment detected in the wild-type strains was estimated to be $15.6 \mathrm{~kb}$, and the putative transformants produced fragments of $17.5 \mathrm{~kb}$ and $2.1 \mathrm{~kb}$. The difference $(4.0 \mathrm{~kb})$ is approximately the size of the resistance cassette $(4 \mathrm{~kb})$, which is consistent with the hypothesis that the transformants identified were true gene replacements.

Effect of zearalenone on the growth of zes 2 disruption mutants. The growth of the zes 2 mutant was retarded by zearalenone at $20 \mu \mathrm{g} / \mathrm{ml}$, while the wild type was unaffected (Table 2). Ectopic transformants behaved indistinguishably from the wild type (data not shown). Colonies of wild-type $G$. roseum grown on agar plates containing Czapek-Dox medium with zearalenone at $20 \mu \mathrm{g} / \mathrm{ml}$ exhibited a fluffy phenotype indistinguishable from that of colonies grown without zearalenone, while the zes 2 mutants grew as compact colonies with a reduced amount of aerial mycelium.

\section{DISCUSSION}

The observation that $G$. roseum has a lactonase activity that can hydrolyze zearalenone and the high substrate specificity of the enzyme (37) both suggest that zearalenone plays a role in the interaction of this mycoparasite with Fusarium species. Our finding of inhibition of the growth of many filamentous fungi by zearalenone supports the hypothesis that zearalenone helps Fusarium spp. reduce or inhibit the growth of many fungi. Decreased growth by the zes 2 disruption mutants of $G$. roseum in the presence of zearalenone further supports this hypothesis. The protection of a substrate colonized by zearalenoneproducing Fusarium spp. against competitors appears to be limited to fungi, since zearalenone does not affect the growth of bacteria (3) although it induces the SOS repair system in some bacterial species (13).

In spite of their economic importance and their impact on the health of humans and farm animals, the biological function of many mycotoxins remains unknown. Zearalenone was the first mycotoxin of Fusarium spp. for which a biological function was hypothesized. Nelson et al. suggested in the 1970s that zearalenone controls sexual development in Gibberella zeae $(29,38,39,40)$. This hypothesis persists (22) even though there are several lines of evidence that contradict it, including a lack of correlation between zearalenone synthesis and perithecium production $(11,36)$ and the fact that $F$. culmorum makes large amounts of zearalenone but does not reproduce sexually. $(F$. culmorum strains that have lost zearalenone synthesis would outgrow zearalenone producers if zearalenone did not increase their fitness by a mechanism unrelated to sexual reproduction.) Our results provide another argument to retire the sex hormone hypothesis: if zearalenone acts as an agent of interference competition, it is unlikely to control sexual reproduction. This does not, however, exclude the possibility that zearalenone exerts subtle effects on the physiology of its producers.

The existence of a functional gene encoding zearalenonespecific lactonase in G. roseum and the inducibility of this gene by zearalenone (37) indicate that the interaction of the mycoparasite with fungi producing zearalenone or similar resorcylic lactones is frequent enough to exert selection pressure for the maintenance of detoxifying lactonase. This enzyme may be one reason why Gliocladium spp. are among the most frequently found and effective fungal antagonists of $F$. culmorum in wheat (35). To address the ecological role of zearalenone in detail, the effect of zearalenone and its degradation on fungal fitness needs to be evaluated in mixed cultures and microcosms. The zes 2 mutants described here and known non-zearalenone-producing mutants of $F$. graminearum $(11,22)$ should facilitate these studies. The results will be relevant for the assessment of the ecological impact of a large-scale release of genetically modified crops expressing zearalenone lactonase $(17,18)$.

Many filamentous fungi and yeasts convert zearalenone to a mixture of $\alpha$ - and $\beta$-zearalenol $(2,25,28,32,41)$. $\beta$-Zearalenone production may be regarded as detoxification because this derivative has much less of an effect on fungal growth than zearalenone does (Fig. 3). Neither wild-type G. roseum nor its zes 2 mutants reduced zearalenone to zearalenols in detectable amounts.

\section{ACKNOWLEDGMENTS}

We thank Susanne Frick, Leibniz Institute of Plant Biochemistry (Halle/Saale, Germany), for providing A. tumefaciens AGL1; Hanno Wolf for providing $S$. fimicola; John-Bryan Speakman (BASF) and Helgard H. Nirenberg (BBA, Berlin, Germany) for taxonomic characterization of fungal isolates; Ursula Hettwer for help with HPLC; A. von Tiedemann, H. Wolf, A. de Cock, and J. Wagner for providing microbial strains; and Claudia Nordmann for technical assistance.

J. Utermark was supported by a grant from Niedersachsen Israel Funds.

\section{REFERENCES}

1. Anonymous. 2005. Commission regulation (EC) no. 856/2005 amending regulation (EC) no. 466/2001 as regards to Fusarium toxins. Off. J. Eur. Union 143:3-8. 
2. Boeswald, C., G. Engelhardt, H. Voegl, and P. R. Wallnoefer. 1995. Metabolism of the Fusarium mycotoxins zearalenone and deoxynivalenol by yeast strains of technological relevance. Nat. Toxins 3:138-144.

3. Boutibonnes, P. 1978. A preliminary report about antibacterial properties of the mycotoxin zearalenone. Pharmacology 4:491-492.

4. Brandfass, C., and P. Karlovsky. 2006. Simultaneous detection of Fusarium culmorum and F. graminearum in plant material by duplex PCR with melting curve analysis. BMC Microbiol. 6:4.

5. Coe, J. E., K. G. Ishak, J. M. Ward, and M. J. Ross. 1992. Tamoxifen prevents induction of hepatic neoplasia by zeranol, an estrogenic food contaminant. Proc. Natl. Acad. Sci. USA 89:1085-1089.

6. Covert, S., P. Kapoor, M. Lee, A. Briley, and C. J. Nairn. 2001. Agrobacterium tumefaciens-mediated transformation of Fusarium circinatum. Mycol. Res. 105:259-264

7. de Groot, M. J. A., P. Bundock, P. J. J. Hooykaas, and A. G. M. Beijersbergen. 1998. Agrobacterium tumefaciens-mediated transformation of filamentous fungi. Nat. Biotechnol. 16:839-842.

8. El-Sharkawy, S., and Y. J. Abul-Hajj. 1988. Microbial cleavage of zearalenone. Xenobiotica 18:365-371.

9. Eriksen, G. S., and J. Alexander. 1998. Nordic Council of Ministers TemaNord Eriksen, G. S., and J. Alexander. 1998. Nordic Council of Mini

10. Farnworth, E. R., and H. L. Trenholm. 1983. The metabolism of the mycotoxin zearalenone and its effects on the reproductive tracts of young male and female pigs. Can. J. Anim. Sci. 63:967-975.

11. Gaffoor, I., D. W. Brown, R. Plattner, R. H. Proctor, W. Qi, and F. Trail. 2005. Functional analysis of the polyketide synthase genes in the filamentous fungus Gibberella zeae (anamorph Fusarium graminearum). Eukaryot. Cell 4:1926-1933.

12. Gerlach, W., and H. I. Nirenberg. 1982. The genus Fusarium-a pictorial atlas. Mitt. Biol. Bundesanst. Land-Forstwirtsch. Berlin-Dahlem 209:1-406.

13. Ghedira-Chekir, L., K. Maaroufi, A. Zakhama, F. Ellouz, S. Dhouib, E. E. Creppy, and H. Bacha. 1998. Induction of a SOS repair system in lysogenic bacteria by zearalenone and its prevention by vitamin E. Chem. Biol. Interbacteria by zearal. 113:15-25.

14. Green, M. L., M. A. Diekman, J. R. Malayer, A. B. Scheidt, and G. G. Long. 1990. Effect of prepubertal consumption of zearalenone on puberty and subsequent reproduction of gilts. J. Anim. Sci. 68:171-178.

15. Grosse, Y., L. Chekir-Ghedira, A. Huc, S. Obrecht-Pflumio, G. Dirheimer, H. Bacha, and A. Pfohl-Leszkowicz. 1997. Retinol, ascorbic acid and $\alpha$-tocopherol prevent DNA adduct formation in mice treated with the mycotoxins ochratoxin A and zearalenone. Cancer Lett. 114:225-229.

16. Hanahan, J. 1983. Studies on transformation of Escherichia coli with plasmids. J. Mol. Biol. 166:557-580.

17. Higa, A., M. Kimura, K. Mimori, T. Ochiai-Fukuda, T. Tokai, N. TakahashiAndo, T. Nishiuchi, T. Igawa, M. Fujimura, H. Hamamoto, R. Usami, and I. Yamaguchi. 2003. Expression in cereal plants of genes that inactivate I. Yamaguchi. 2003. Expression in cereal plants of genes that in
Fusarium mycotoxins. Biosci. Biotechnol. Biochem. 67:914-918.

18. Higa-Nishiyama, A., N. Takahashi-Ando, T. Shimizu, T. Kudo, I. Yamaguchi, and M. Kimura. 2005. A model transgenic cereal plant with detoxification activity for the estrogenic mycotoxin zearalenone. Transgenic Res. 14:713717.

19. Kakeya, H., N. Takahashi-Ando, M. Kimura, R. Onose, I. Yamaguchi, and H. Osada. 2002. Biotransformation of the mycotoxin, zearalenone, to a non-estrogenic compound by a fungal strain of Clonostachys sp. Biosci. Biotechnol. Biochem. 66:2723-2726.

20. Karlovsky, P. 1994. Inhibition of imidazoleglycerolphosphate dehydratase of Phytophthora parasitica by aminotriazole in situ and after cloning and expresPhytophthora parasitica by aminotriazole in situ and after cloning and expres-
sion of the respective gene (HIS3) in Escherichia coli. J. Phytopathol. 141: sion of the 126.

21. Karlovsky, P. 1999. Biological detoxification of fungal toxins and its use in plant breeding, feed and food production. Natural Toxins 7:1-23.
22. Kim, Y. T., Y. R. Lee, J. Jin, K. H. Han, H. Kim, J. C. Kim, T. Lee, S. H. Yun, and Y. W. Lee. 2005. Two different polyketide synthase genes are required for synthesis of zearalenone in Gibberella zeae. Mol. Microbiol. 58:11021113 .

23. Lazo, G. R., P. A. Stein, and R. A. Ludwig. 1991. A DNA transformationcompetent Arabidopsis genomic library in Agrobacterium. Biotechnology 9:963-967.

24. Long, G. G., and M. A. Diekman. 1986. Characterization of effects of zearalenone in swine during early pregnancy. Am. J. Vet. Res. 47:184-187. 25. Matsuura, Y., and T. Yoshizawa. 1985. Conversion of zearalenone, an estrogenic mycotoxin, by brewing microorganisms. J. Food Hyg. Soc. Jpn. 26:24-28.

26. Mattanovich, D., F. Rüker, A. da Camara, A. Machado, M. Laimer, F. Reguer, H. Steinkellner, G. Himmler, and H. Katinger. 1989. Efficient transformation of Agrobacterium spp. by electroporation. Nucleic Acids Res. 17:6747.

27. Molnar, O., G. Schatzmayr, E. Fuchs, and H. Prillinger. 2004. Trichosporon mycotoxinivorans sp. nov., a new yeast species useful in biological detoxification of various mycotoxins. Syst. Appl. Microbiol. 27:661-671.

28. McMullen, J. R. 1977. Microbiological reduction of zearalenone and related compounds. U.S. patent 4,004,978.

29. Nelson, R. R. 1971. Hormonal involvement in sexual reproduction in the fungi, with special reference to F-2, a fungal estrogen, p. 181-200. In S. Akai and S. Ouchi (ed.), Morphological and biochemical events in plant-parasite interaction. Phytopathological Society of Japan, Tokyo, Japan.

30. Pfohl-Leszkowicz, A., L. Chekir-Ghedira, and H. Bacha. 1995. Genotoxicity of zearalenone, an estrogenic mycotoxin: DNA adduct formation in female mouse tissues. Carcinogenesis 16:2315-2320.

31. Sambrook, J., E. F. Fritsch, and T. Maniatis. 1989. Molecular cloning: a laboratory manual, 2nd ed. Cold Spring Harbor Laboratory Press, Cold Spring Harbor, N.Y.

32. Scott, P. M., S. R. Kanhere, E. F. Daley, and J. M. Farber. 1992. Fermentation of wort containing deoxynivalenol and zearalenone. Mycotoxin Res. 8:58-66.

33. Szuetz, P., A. Mesterhazy, G. Y. Falkay, and T. Bartok. 1997. Early telearche symptoms in children and their reaction to zearalenone contamination in food stuffs. Cereals Res. Commun. 25:429-436.

34. Takahashi-Ando, N., M. Kimura, H. Kakeya, H. Osada, and I. Yamaguchi. 2002. A novel lactonohydrolase responsible for the detoxification of zearalenone: enzyme purification and gene cloning. Biochem. J. 365:1-6.

35. Teperi, E., M. Keskinen, E. Ketoja, and R. Tahvonen. 1998. Screening for fungal antagonists of seed-borne Fusarium culmorum on wheat using in vivo tests. Eur. J. Plant Pathol. 104:243-251.

36. Windels, C. E., C. J. Mirocha, H. K. Abbas, and W. Xie. 1989. Perithecium production in Fusarium graminearum populations and lack of correlation with zearalenone production. Mycology 81:272-277.

37. Woerfel, G., and P. Karlovsky. 1998. Hydrolyse von Zearalenon durch Gliocladium roseum, p. 189-192. In J. Wolff and T. Betsche (ed.), 20th Mycotoxin Workshop. Gesellschaft für Mykotoxinforschung, Detmold, Germany.

38. Wolf, J. C., and C. J. Mirocha. 1973. Regulation of sexual reproduction in Gibberella zeae (Fusarium roseum "graminearum") by F-2 (zearalenone). Can. J. Microbiol. 19:725-734.

39. Wolf, J. C., and C. J. Mirocha. 1977. Control of sexual reproduction in Gibberella zeae (Fusarium roseum "Graminearum"). Appl. Environ. Microbiol. 33:546-551.

40. Wolf, J. C., J. R. Liebermann, and C. J. Mirocha. 1972. Inhibition of F-2 (zearalenone) biosynthesis and perithecium production in Fusarium roseum "Graminearum" Phytopathology 62:937-939.

41. Wu, L., Q. Wang, S. Wang, and F. Zhou. 1992. Biotransformation of zearalenone. Acta Microbiol. Sin. 32:11-16. 


\section{Chapter 3: Phytotoxic effects of zearalenone on growth of Arabidopsis thaliana and protection by heterologous expression of zearalenone lactonase*}

*This manuscript will be submitted for publication in New Phytologist

Jan Utermark and Petr Karlovsky

\section{Abstract}

- Zearalenone, a secondary metabolite produced by several plant-pathogenic fungi of the genus Fusarium, is known to have high estrogenic and anabolic effects on mammals as well as phytotoxic effects.

- In the present study, a sensitive in vitro seedling growth assay was used to evaluate the phytotoxic effect of zearalenone on Arabidopsis thaliana wild type and transformants expressing the zearalenone specific-lactonase gene zes2 from the mycoparasitic fungus Gliocladium roseum which is known to hydrolyse zearalenone.

- While wild type plants after exposure to zearalenone exhibited dwarfism with aberrant morphological changes, transgenic plants were more tolerant to zearalenone showing almost no symptoms.

- These data indicate that zearalenone lactonase protects transgenic Arabidopsis plants from the toxic effects of this mycotoxin.

\section{Introduction}

A complex of closely related species of the genus Fusarium is responsible for destructive and economically very important diseases of cereal crops (Fusarium Head Blight, FHB, of wheat and barley and Fusarium ear rot of maize). In years with climatic conditions that favour the development of these fungi, Fusarium infection can reach epidemic proportions (McMullen et al., 1997). 
Diseases caused by these plant pathogens do not only severely reduce yield, but also result in contamination of grain with mycotoxins, which is a problem of worldwide relevance for the health of farm animals and human consumers. Fusarium species are known to produce several mycotoxins, of which trichothecenes (e.g. deoxynivalenol) and zearalenone are the most important (Wang et al., 1988). The biological activity of zearalenone (2,4-dihydroxy-6-(10-hydroxy-6-oxo-trans-1undecenyl)-benzearalenoneic acid lactone) and its derivatives is dominated by its estrogenic and anabolic effects on mammals. The toxin causes reproductive disorders in farm animals thereby compromising livestock health and productivity. Typical complications associated with zearalenone ingestion are severe morphological and functional disorders of reproductive organs like vulva enlargement, hyperestrogenism, precocious sexual development, pseudopregnancy, loss of embryos, and reduced litter size (Farnworth and Trenholm, 1983; Green et al., 1990; Dacasto et al., 1995; Etienne and Dounnad, 1994). On humans there is some evidence of precocious sexual developments in Puerto Rican children exposed to zearalenone. However, these effects were probably due to the use of a commercial animal growth promoter ( $\alpha$-zearalenol, trade name: Ralgro ${ }^{\circledR}$ ), based on zearalenone metabolites, and not a consequence of a natural exposure (Saenz de Rodriguez et al., 1985). Furthermore, carcinogenic activity (Gao and Yoshizawa, 1997) and genotoxicity (Grosse et al., 1997) of zearalenone have been discussed. Whether zearalenone promotes breast cancer (Ahamed et al., 2001; Schoental, 1985; Tomaszewski et al., 1998) rather than reducing mammary tumorigenesis (Hilakivi-Clarke et al., 1999) is also heavily contested.

However, the precise role of zearalenone in plant development and diseases is still far from clear. For example, in tobacco, zearalenone promote the initiation of the vegetative bud callus tissue (Mirocha et al., 1968) and enhanced $\alpha$-amylase and $\beta$ glucosidase activities of germinating maize seeds (Vianello and Macri, 1982). In winter wheat cell cultures zearalenone exhibited growth regulator characteristics and commonly used synthetic plant growth substances like auxin 2,4-D could be replaced by the mycotoxin (Filek et al., 2004). According to Han and Meng (1991) and Fu and Meng (1993), zearalenone might enhance flowering in the short-day plant Lemna 
perpusilla 6746 and the long-day plant Lemna gibba G3. In day-neutral tobacco (Nicotiana tabacum L. cv. Samsun), zearalenone is one of the important flower stimuli and was related to the flower gradient in shoots (Fu et al., 1995). Application of zearalenone to maize resulted in an increased proton permeability in the root cells and lead to the collapse of the transmembrane electric potential. Filek et al. (2002) also found that zearalenone can affect membrane electric properties and charge in winter wheat cells. Treatment of isolated plant mitochondria with zearalenone caused oxidative phosphorylation and altered ATPase activity in maize roots and pea stems (Vianello and Macri, 1981). Beneath phytohormon-like properties, zearalenone can also be harmful to plants. Thus, the phytotoxic effect of zearalenone appears depend on the plant species (Packa, 1991). Zearalenone concentrations of $10 \mu \mathrm{g} / \mathrm{ml}$ exert an increased mitotic activity on germinating seeds of rye but a decreased one for wheat and field beans. According to Wakuliriski (1989) zearalenone did not affect germination or subsequent root and leaf development of wheat seedlings, even in high concentrations of $50 \mu \mathrm{g} / \mathrm{ml}$ zearalenone. However, root and shoot elongation and fresh mass accumulation of maize embryos were inhibited by zearalenone at $5 \mu \mathrm{g} / \mathrm{ml}$ (McLean, 1996).

We could previously show that zearalenone inhibits the growth of most filamentous fungi except Gliocladium roseum. In the interaction with Fusarium species, the activity of a known zearalenone specific-lactonase from this mycoparasite is an effective strategy for the protection against the fungitoxic effects caused by zearalenone (Utermark and Karlovsky, 2007). The detoxification gene coding for the zearalenone specific-lactonase from $G$. roseum was cloned and characterized by two research groups (Kakeya et al., 2002; Takahashi-Ando et al., 2002; E. H. Crane, J. T. Gilliam, P. Karlovsky, and J. R. Maddox, 3 October 2002, World Trade Organization patent application 02/ 076205; P. Karlovsky, E. H. Crane, J. T. Gilliam, and J. R. Maddox, U.S. patent application 20030073239).

The objective of this work was to prove whether this protection strategy could be adapted by the genetic engineering of plants in order to reduce the detrimental effects of zearalenone. As a first step in applying this strategy under laboratory scale experiments we tested the effects of the heterologous expression of zearalenone 
lactonase on the tolerance of transgenic $A$. thaliana plants to zearalenone impact as to shoot and root development.

\section{Materials and Methods}

\section{Plant growth conditions}

A. thaliana (ecotype Col-0 unless stated) plants were grown until flowering stage in a climate chamber at $24^{\circ} \mathrm{C}$ day $/ 20^{\circ} \mathrm{C}$ night with an air humidity of $65-75 \%$. The photoperiod consisted of 16 hours light and 8 hours darkness with a light intensity of $150 \mu \mathrm{mol} \mathrm{m} \mathrm{m}^{-2} \mathrm{~s}^{-1}$.

\section{Construction of the zes 2 expression vector}

Plasmid pBI121::zes2 contains the coding region of the zearalenone specificlactonase zes2 between the Xbal and Sacl sites of the binary vector $\mathrm{pBI} 121$ (Jefferson et al., 1987). For construction of the vector the two oligonucleotides OL503 (5'-AGA GAGAATCTAGAATGCGCATTCGCAGCACAA-3') and OL504 (5'-TACATAAGAGCT CTCAAAGATACTTCTGCGTA-3') were used for PCR amplification of the zes2 template (GenBank accession no. BD391646) from genomic DNA of G. roseum DSM 62726. The GUS gene in pBI121 was then replaced by the amplified zes2 fragment (795-bp) at Xbal and Sacl sites to generate $\mathrm{pBI} 121:: z e s 2$. This vector was used for plant transformation experiments. The length of the T-DNA from left border (LB) to right border (RB) was $5.05 \mathrm{~kb}$ and cloned inserts of this plasmid were sequenced.

\section{Plant transformation and selection of homozygous transformants}

The construct pBI121::zes2 was introduced into A. tumefaciens strain AGL1 (Lazo et al., 1991). A. thaliana was transformed by floral dipping (Clough and Bent, 1998) and transgenic seeds were surface-sterilized and plated onto Murashige and Skoog (MS) medium (DuChefa Biochemie, Haarlem, Netherlands) containing $50 \mu \mathrm{g} / \mathrm{ml}$ kanamycin. $T_{1}$ seeds were harvested and again sown on kanamycin containing MS medium. Kanamycin-resistant plants were planted, and $T_{2}$ seeds were harvested after 2 months. This self-crossing / selection procedure was repeated up to generation $\mathrm{T}_{4}$ to achieve homozygousity for zes2. Five independent homozygous transformants of $\mathrm{T}_{4}$ plants were used for analysis of zes2 activity. 


\section{Analysis of gene integration in chromosomal DNA of $A$. thaliana}

Total DNA was extracted from plant tissue according to Brandfaß and Karlovsky (2006). PCR was performed to amplify the zes2 fragment (primers 503 and OL504, see above) in the genomic DNA of putatively transformed Arabidopsis transformants to prove the transgene integration into the plant genome.

\section{In vitro Zes2 protein activity assay}

To evaluate the extent of zearalenone degradation by transgenic Arabidopsis plants, crude protein extracts were prepared from the leaves of $\mathrm{T}_{4}$ plants and used for the in vitro detoxification assay. Arabidopsis leaves (about $200 \mathrm{mg}$ FW), ground in liquid nitrogen, were vigorously shaken in extraction buffer $(50 \mathrm{mM}$ Tris- $\mathrm{HCl}, \mathrm{pH} 7.5,10 \mathrm{mM}$ EDTA, $0.1 \%$ Triton $\mathrm{X}-100$ and $0.1 \%$ ß-mercaptoethanol) and the supernatant was recovered. The assay was initiated by adding $100 \mu \mathrm{g}$ crude protein extract to substrate solution $(20 \mu \mathrm{g} / \mathrm{ml}$ of zearalenone in $0.1 \mathrm{M}$ Tris- $\mathrm{HCl}, \mathrm{pH} 9.5)$ to a final volume of $800 \mu \mathrm{l}$ and incubated at $37^{\circ} \mathrm{C}$ for $30 \mathrm{~min}, 4 \mathrm{~h}$ and $20 \mathrm{~h}$, respectively. The enzyme reaction was terminated by adding $10 \mu \mathrm{l}$ of $1 \mathrm{~N} \mathrm{HCl}$. The reaction mixture was extracted two times with $1 \mathrm{ml}$ of ethyl acetate, organic phases merged and the solvent removed in vacuum. The residue was dissolved in $1 \mathrm{ml}$ of $55 \%$ methanol and $45 \%$ water, filtrated and quantified by reverse-phase high-performance liquid chromatography (HPLC) with mass spectrometric detectors.

\section{Zearalenone analysis}

Reverse-phase HPLC with diode array and mass spectrometric detectors was used for zearalenone determination: column - Polaris C18-A, $5 \mu \mathrm{m}, 150 \mathrm{~mm} \times 2 \mathrm{~mm}$ (Varian, Darmstadt, Germany); mobile phase - 55\% methanol, 45\% water, 5\% acetonitrile; flow rate - $0.2 \mathrm{ml} / \mathrm{min}$; column temperature $-40^{\circ} \mathrm{C}$; detection - diode array detector - absorbance at 200-800 nm; mass spectrometry - electrospray in positive mode, scan for mass/charge-ratio 250-500.

\section{Phytotoxic effects}

\section{Agar bioassay}

Square Petri dishes $(10 \times 10 \mathrm{~cm}$ ) were filled with $40 \mathrm{ml}$ MS-agar $(4.3 \mathrm{~g} \mathrm{MS}$ salts, $10 \mathrm{~g}$ sucrose, $0.5 \mathrm{~g}$ MES, $8 \mathrm{~g}$ agar per liter; $\mathrm{pH}$ 5.7) and immediately placed at an angle so 
that the agar formed a slope. Four up to five surface-sterilized seeds of Arabidopsis wild type and accordingly transformants were placed on the agar parallel to the direction of the slope (just below it). Plates were incubated at $4^{\circ} \mathrm{C}$ overnight to break dormancy and placed vertically in a growth chamber. Each Petri dish was scanned after $3 \mathrm{~d}$ to quantify the root length of the germinated seedlings.

\section{Leaf assay}

Healthy leaves (approximately $0.5 \mathrm{~cm}$ long and $0.5 \mathrm{~cm}$ wide) were cut from rosettes of 3 week old transgenic or wild type plants and placed in a 96 well microtitter plate. Subsequently, the leaves were floated on sterile distilled water. Thus, each well contained $100 \mu \mathrm{l}$ distilled water amended with zearalenone and its derivatives $\alpha$ and $\beta$ zearalenol, $\alpha$ and $\beta$ zearalanol and zearalanone (Sigma-Aldrich, Steinheim, Germany) by adding appropriate amounts of stock solutions in methanol. The concentration of methanol was adjusted to $1 \%$. Zearalenone and its derivatives were tested three times in a dilution series of $0,1.0,2.5,5.0,10$ and $20 \mu \mathrm{g} / \mathrm{ml}$. The uncovered 96 well plates were placed in glass petri dishes to maintain humidity and leaves were photographed daily.

\section{Assessment of cell growth after zearalenone treatment}

For the classical histological studies, whole roots or free-hand made sections of roots of seven day old seedlings where placed directly on glass slides in drops of water, covered with a cover glass, and observed under a light microscope (Leitz DMRB, Leica, Mannheim, Germany).

\section{Results}

Molecular characterization of zes2-expression in transgenic Arabidopsis plants The zearalenone lactonase coding gene zes 2 was incorporated into the plant expression vector pBI121 under the control of a constitutive and powerful cauliflower mosaic virus (CaMV) $35 \mathrm{~S}$ promoter to assure strong expression (Fig. 1) and transferred into A. thaliana by means of Agrobacterium tumefaciens- mediated transformation.

Several kanamycin-resistant Arabidopsis $\mathrm{T}_{0}$-transformants were recovered, grown to maturity and their seeds collected for further analysis. These transformants were selfcrossed to obtain $\mathrm{T}_{1}$-seeds. Selection of $\mathrm{T}_{1}$-progenies revealed that $60 \%$ of the seeds 
from each transformant failed to produce green cotyledons. $40 \%$ continued to grow and remained green. This self-crossing / selection procedure was repeated up to generation $T_{4}$ to achieve homozygousity for zes2. Before investigating the zearalenone degrading activity, five transformants of $A$. thaliana carrying the gene coding for zearalenone lactonase were analysed by PCR. All transformants (referred as $\mathrm{H}-1$, $\mathrm{H}-2, \mathrm{H}-3, \mathrm{H}-4$ and $\mathrm{H}-5$ ) were positive for zes2 (data not shown) and were used for in vitro zearalenone detoxification.

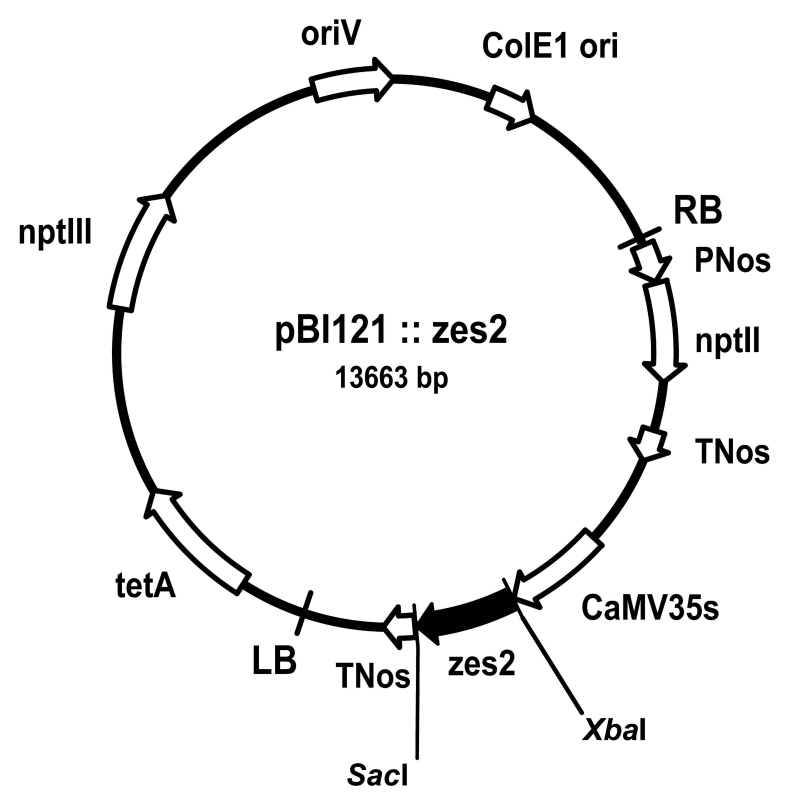

Figure 1. Physical map of pB|121::zes2.

pBI121::zes2 was constructed with the zearalenone lactonase gene placed under the control of the constitutive promoter for the 35S RNA from Cauliflower Mosaic Virus (CaMV35s) and followed by a Nopaline synthase terminator (TNos). The plasmid also contains the neomycin phosphotransferasell gene (nptll) conferring resistance to kanamycin in plants and the corresponding kanamycin resistance gene in bacteria (nptIII).

\section{Zearalenone lactonase expression analysis in different plant tissues}

To evaluate the zearalenone degradation activity of the transgenic Arabidopsis plants, crude protein extracts were prepared from the leaves of $T_{4}$ plants and used in an in vitro detoxification assay. No mycotoxin degradation, compared to a blank 
control (data not shown), was observed for the protein extract prepared from the wild type (Fig. 2-A). In contrast, the amount of zearalenone decreased significantly in the reaction mixture obtained from $A$. thaliana transformants $\mathrm{H}-1$ and $\mathrm{H}-2$. Thus two transformants rapidly detoxified all the zearalenone after $4 \mathrm{~h}$ exposure. These results indicate a strong zes 2 expression in transgenic $A$. thaliana $\mathrm{H}-1$ and $\mathrm{H}-2$. A significant amount of zearalenone remained in the $\mathrm{H}-3, \mathrm{H}-4$ and $\mathrm{H}-5$ supernatant after $4 \mathrm{~h}$ of degradation.

A

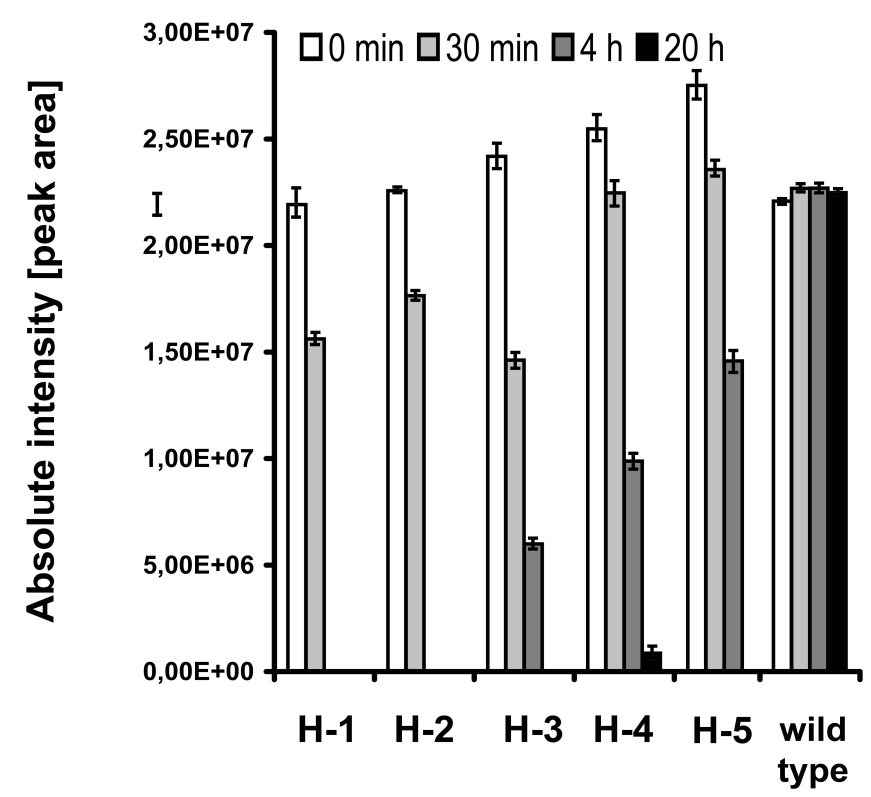

B

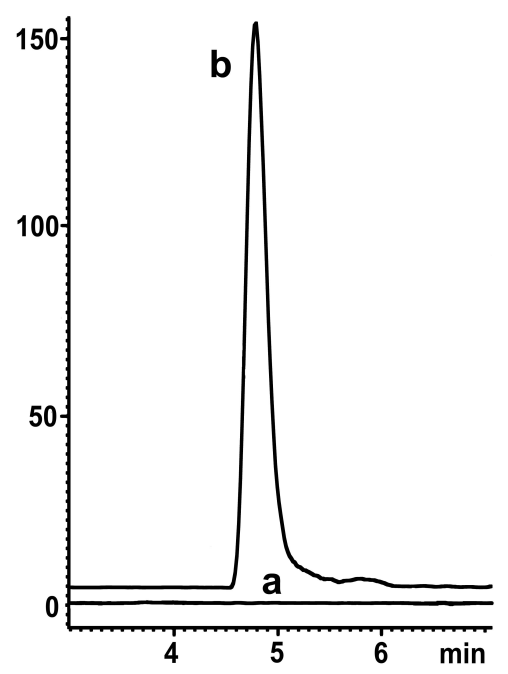

Figure 2. Comparison of the detoxification of zearalenone by different Arabidopsis transformants.

(A) Degradation of $20 \mu \mathrm{g}$ zearalenone/ml by crude protein extracts from $\mathrm{T}_{4}$ leaves of five independent zearalenone lactonase expressing Arabidopsis transformants and non transformed wild type. Analysis of the enzymatic reaction of the transformants was examined at $0 \mathrm{~min}$ and after $30 \mathrm{~min}, 4 \mathrm{~h}$ and $20 \mathrm{~h}$ incubation at $24^{\circ} \mathrm{C}$. The error bars represent standard deviations $(n=4)$.

(B) Zearalenone degradation by $A$. thaliana seeds of wild type (chromatogram $b$ ) and of $\mathrm{T}_{4}$ plants of transformant $\mathrm{H}-1$ (chromatogram a). Seeds were soaked in zearalenone solution $(5 \mu \mathrm{g} / \mathrm{ml})$ for 3 days at $24^{\circ} \mathrm{C}$. The amount of zearalenone was detected by HPLC-MS. 
Additionally, Arabidopsis seeds of wild type as well as transformants were incubated with zearalenone to evaluate the activity of zearalenone lactonase in mature seeds. After different periods of incubation, the remaining amount of zearalenone was quantified by HPLC analysis. Concentration of zearalenone in the wild type supernatant was not reduced compared to the control (data not shown), indicating that the mycotoxin in the solution was not absorbed or degraded by the seeds. In contrast, transformed $A$. thaliana seeds rapidly detoxified zearalenone. Thus, after 3 days of incubation, the toxin was completely removed (Fig. 2-B). These in vitro detoxification analyses using different plant tissues clearly show that zearalenone lactonase is produced in an active form in transgenic $A$. thaliana transformants.

\section{Zearalenone inhibits morphological development in A. thaliana}

The effects of zearalenone on seed germination, development of roots, hypocotyl, cotyledons and florescence of transformed as well as wild type Arabidopsis plants were tested. To develop a suitable test system for measuring phytotoxicity, seedlings were sown and grown in the presence of various zearalenone concentrations on solid medium. In both non-transformed and transformed Arabidopsis seeds zearalenone did not inhibit germination in concentrations of up to $20 \mu \mathrm{g} / \mathrm{ml}$ (data not shown). However, the morphological development of wild type seedlings was significantly affected by zearalenone. The main phytotoxic effect was a lack of root hair formation and dwarfism (Fig. 3-A). Root elongation was retarded by zearalenone exceeding $1 \mu \mathrm{g} / \mathrm{ml}$ (Fig. 3-B). Further effects on wild type plants, observed after $12 \mathrm{~d}$, included a shortened hypocotyl, a clear delay in development of the cotyledons and a reduced leaf area. Additionally, the wild type did not developed floral buds after 20 days on medium containing zearalenone at $5 \mu \mathrm{g} / \mathrm{ml}$ (Fig. 4).

Furthermore, after 13 days cultivation of wild type plants with zearalenone at $5 \mu \mathrm{g} / \mathrm{ml}$, the cells in the tap root were smaller and more tightly arranged compared to cultivation without zearalenone (Fig. 5). The toxin also altered the tissue organization of the Arabidopsis primary root apex (Fig. 5). The lateral and columella root cap showed a change in cell division patterns. While central cells and initial cells show a typical arrangement in the root grown without zearalenone, however, after exposure to zearalenone, cell arrangement is disorganized and central cells and surrounding initials 
are difficult to identify. The most affected root tissue is the columella root cap, in which cell layers reflecting the synchronous cell division of columella initials have disappeared.

A

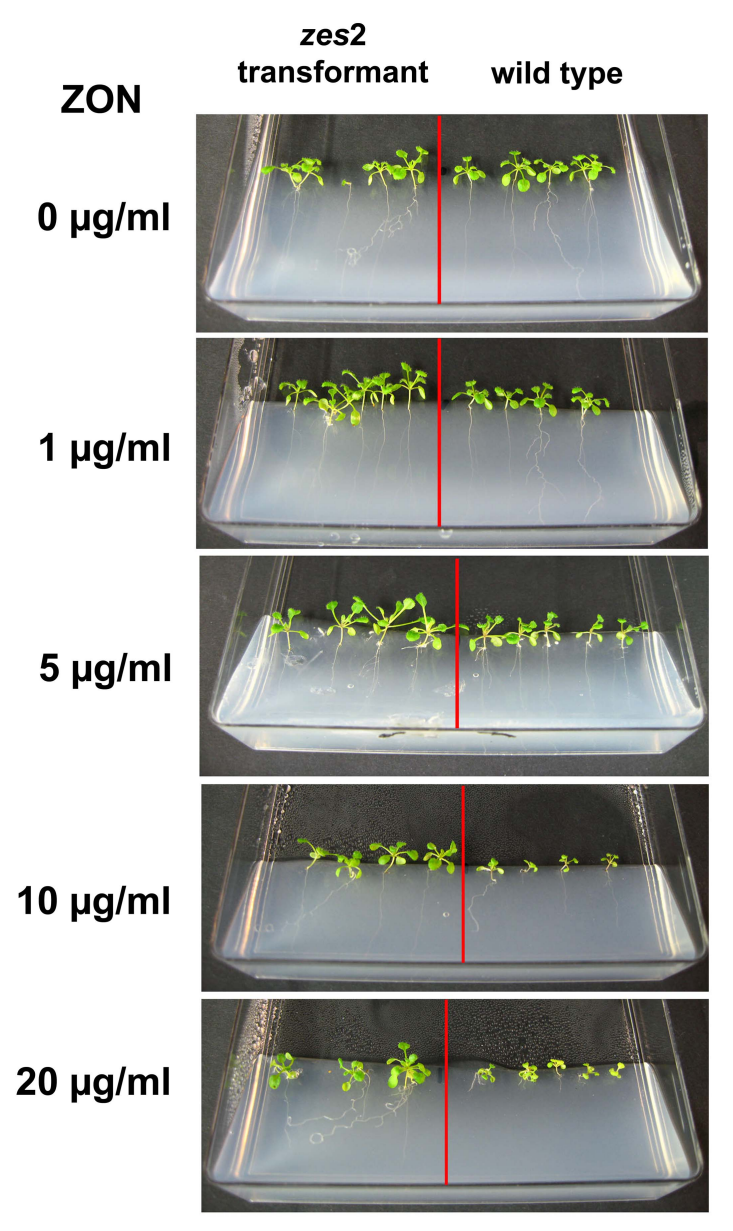

B

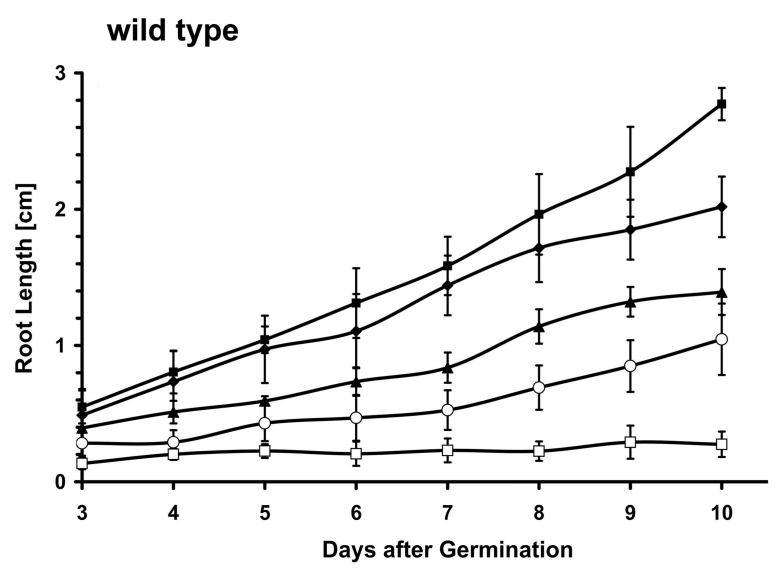

zes2 transformant

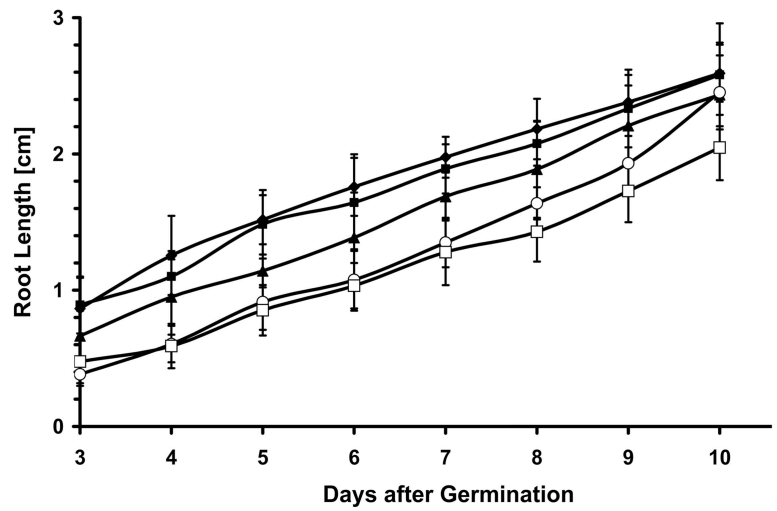

Figure 3. Phytotoxic effects of zearalenone on $A$. thaliana.

(A) Photographs show representatives of 12-d-old seedlings of Arabidopsis wild type plants and zes2 transformants grown on MS medium containing zearalenone (ZON) at $1,5,10$ and $20 \mu \mathrm{g} / \mathrm{ml}$. Zearalenone was added as a methanol stock solution to agar medium cooled to $60^{\circ} \mathrm{C}$. The final concentration of methanol was set to $1 \%$.

(B) Phytotoxic effects of zearalenone at $0 \mu \mathrm{g} / \mathrm{ml}(\mathbf{\square}), 1 \mu \mathrm{g} / \mathrm{ml}(\diamond), 5 \mu \mathrm{g} / \mathrm{ml}(\boldsymbol{\Delta}), 10 \mu \mathrm{g} /$ $\mathrm{ml}(\circ)$ and $20 \mu \mathrm{g} / \mathrm{ml}(\square)$ on the root elongation of zes2 transformants and wild type A thaliana plantlets.

The graphs represent the primary root length of the 10-d-old seedlings grown on MS 
agar medium with or without zearalenone. Each Petri dish was scanned $3 \mathrm{~d}$ after germination and results are presented as average values \pm from three experiments.

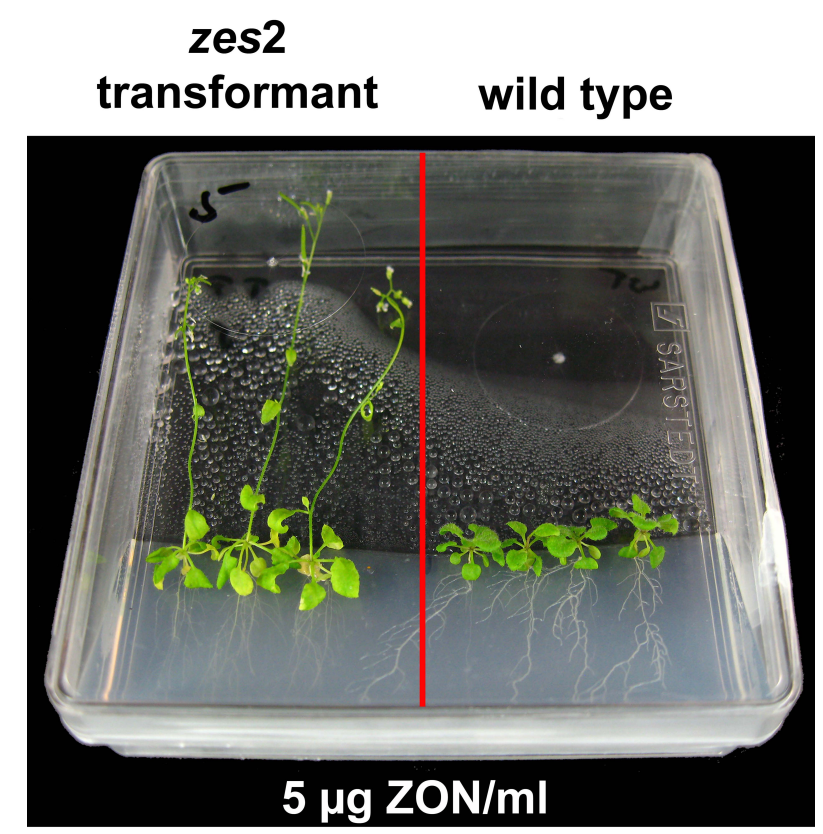

Figure 4. Effect on bud differentiation of zes2 transformants and wild type

\section{A. thaliana plantlets after exposure to $5 \mu \mathrm{g}$ zearalenone/ml for 15 days.}

To examine the effects of zearalenone on the phenotypic defects of the zearalenone lactonase expressing transformants of $\mathrm{A}$. thaliana, we grew the transgenic plants under the same conditions such as wild type plants. Normal formation of floral buds was observed at $20 \mu \mathrm{g} / \mathrm{ml}$ zearalenone (Fig. 4). Root hair and cotyledon development of zes 2 transformants was unaffected by zearalenone at $5 \mu \mathrm{g} / \mathrm{ml}$. The seedlings had green, expanded cotyledons and a normal developed phenotype (Fig. 3-A). Zearalenone at $1 \mu \mathrm{g} / \mathrm{ml}$ did not inhibit the root elongation on agar media when compared with the controls without zearalenone. However, tap root length was reduced by zearalenone at $5 \mu \mathrm{g} / \mathrm{ml}$ and more (Fig. 3-B). Roots of zes2 transformants exhibited a coiling effect induced by zearalenone exceeding $10 \mu \mathrm{g} / \mathrm{ml}$. In addition, abnormal root gravitropism in response to zearalenone was observed at $20 \mu \mathrm{g} / \mathrm{ml}$ with the roots growing horizontally (Fig. 3-A). Zearalenone treated roots of transgenic Arabidopsis plants showed no abnormal morphology in cell size and cell arrangement. The root 
apical meristem was indistinguishable from that of plants grown without zearalenone (Fig.5).
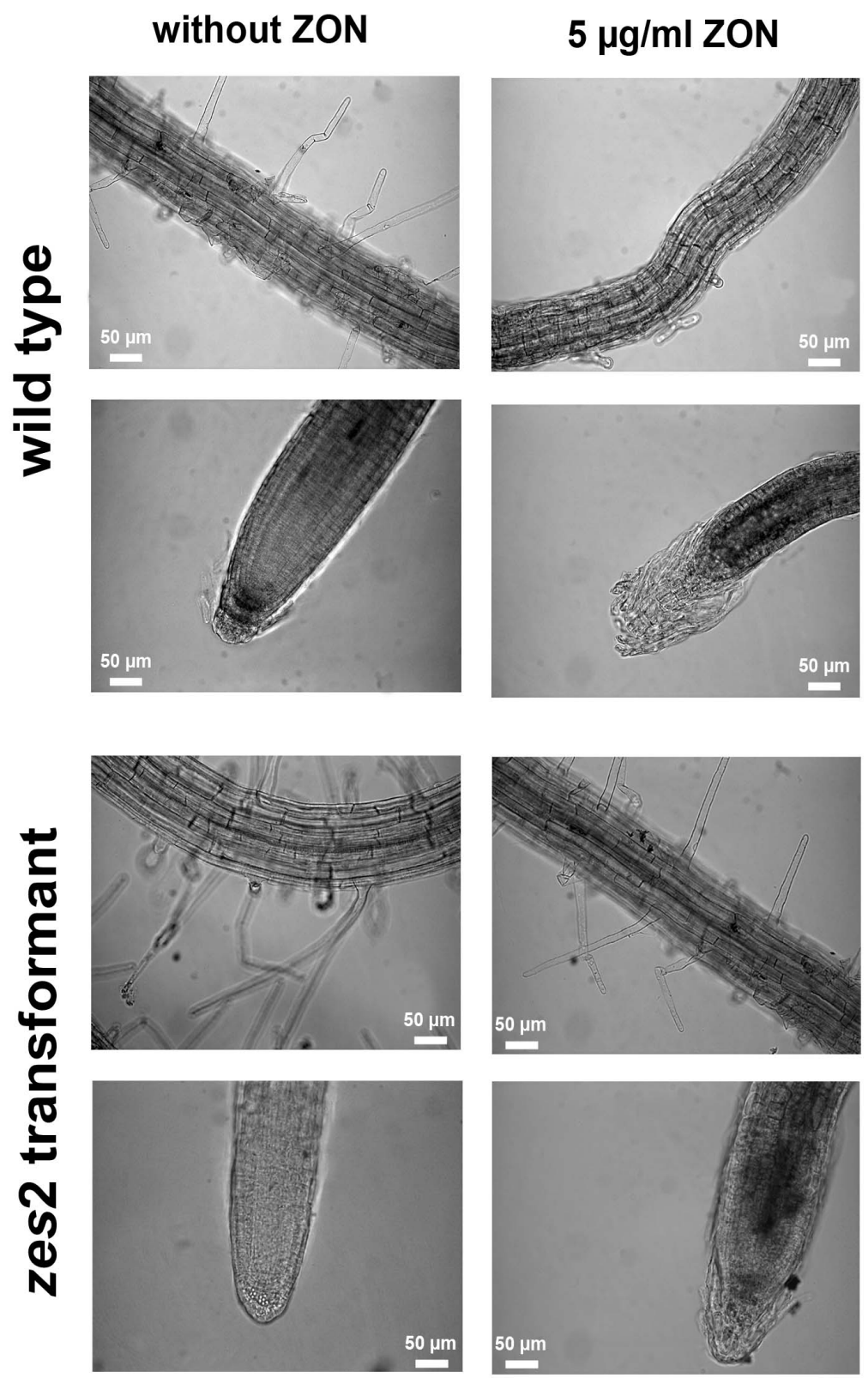

Figure 5. Phytotoxic effects of zearalenone on root hair development and cell arrangement of apical tissues of primary roots in wild type and transgenic Arabidopsis plants.

Non-transformed and zes2 expressing 12-day-old seedlings incubated in the absence (left) and presence (right) of $5 \mu \mathrm{g} / \mathrm{ml}$ zearalenone. 


\section{Tolerance of Arabidopsis leaves to zearalenone and derivatives}

Pathogen-derived molecules are often associated with bleaching in plant leaves (Jackson and Taylor, 1996; Stone et al., 2000). To investigate the zearalenone related bleaching in Arabidopsis plants of wild type and zes2 transformants, detached leaves were incubated with water containing $1 \mu \mathrm{g} / \mathrm{ml}$ or $20 \mu \mathrm{g} / \mathrm{ml}$ zearalenone. Furthermore, in order to check whether there were some differences in bleaching response between $\alpha$ - and $\beta$-zearalenol, $\alpha$ - and $\beta$-zearalanol and zearalanone, these derivatives were also tested in the same manner.

Bleaching was developed on the wild type leaves after exposure of $24 \mathrm{~h} 48 \mathrm{~h}$ and $60 \mathrm{~h}$ to zearalenone at $1 \mu \mathrm{g} / \mathrm{ml}$ or $20 \mu \mathrm{g} / \mathrm{ml}$. Leaf bleaching symptoms were dose and time dependent. A slight bleaching effect was detectable at $1 \mu \mathrm{g} / \mathrm{ml}$ zearalenone after $24 \mathrm{~h}$. Such lesions spread out more rapidly in leaves injected with zearalenone at 20 $\mu \mathrm{g} / \mathrm{ml}$. Additionally, exposure to $20 \mu \mathrm{g} / \mathrm{ml}$ zearalenone resulted in total bleaching of the leaves after $48 \mathrm{~h}$ exposure (Fig. 6-A).

In contrast, no bleaching symptoms of zearalenone lactonase expressing Arabidopsis plants were observed with zearalenone at $1 \mu \mathrm{g} / \mathrm{ml}$. A slight bleaching was detectable at $20 \mu \mathrm{g} / \mathrm{ml}$ zearalenone in transgenic leaves at $60 \mathrm{~h}$ (Fig. 6-A). 

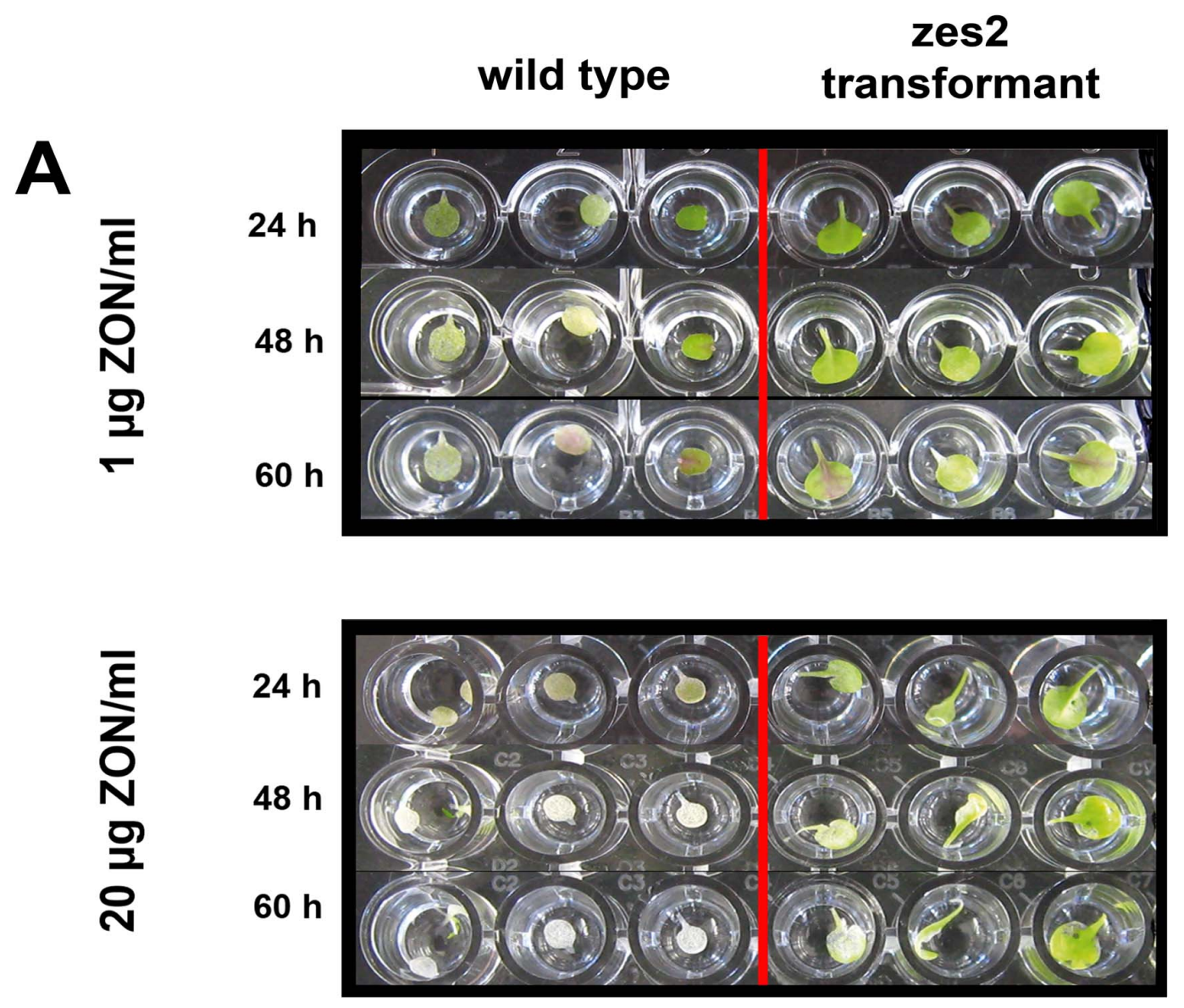

B

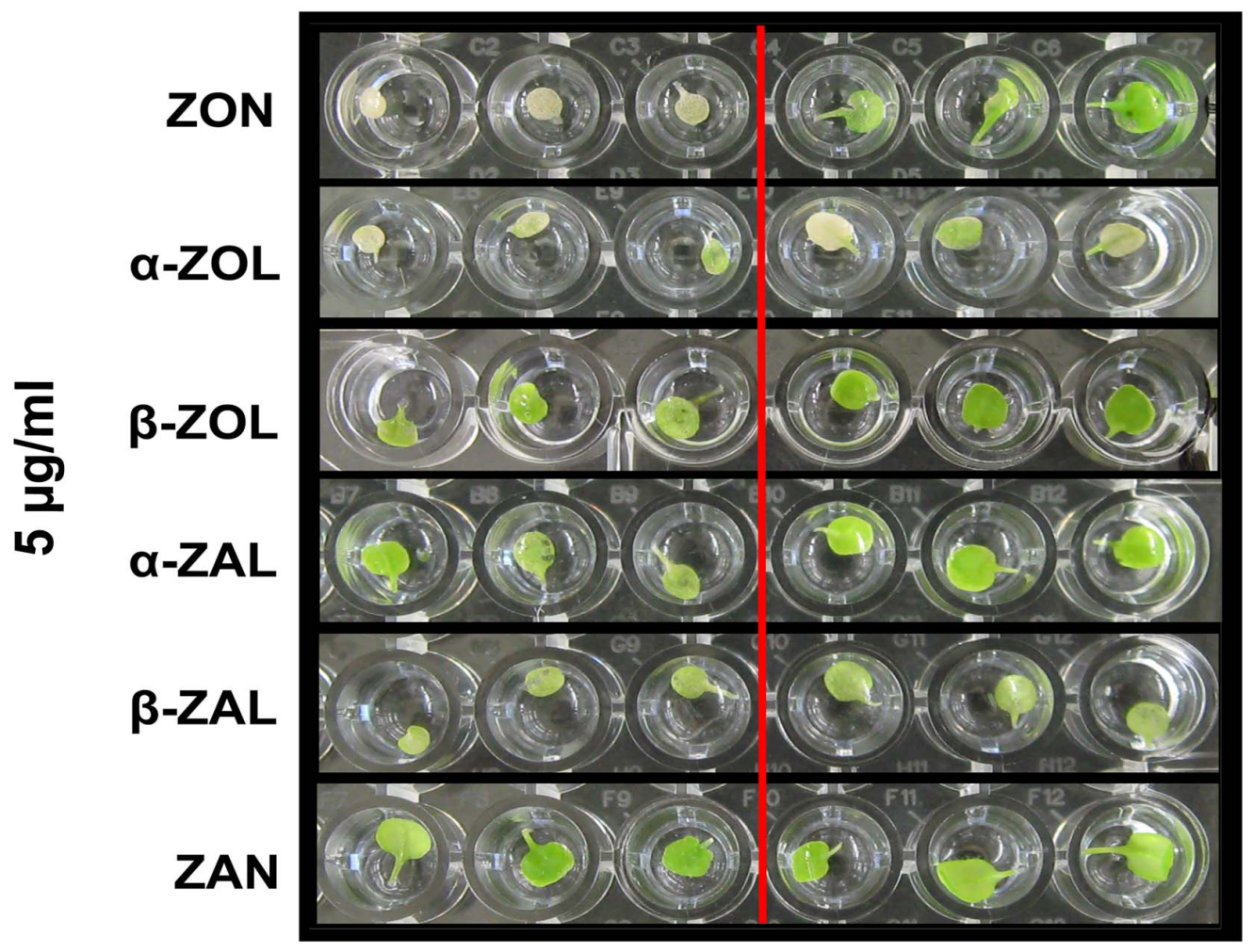


Figure 6. Bleaching symptoms in A. thaliana wild type and transformed leaves caused by zearalenone and its analogous.

Leaves of 21-day-old Arabidopsis wild type or zearalenone lactonase expressing transformants were incubated at 24-h-light photoperiod.

(A) Bleaching experiment using $1 \mu \mathrm{g} / \mathrm{ml}$ or $20 \mu \mathrm{g} / \mathrm{ml}$ zearalenone (ZON). The effects were recorded after $24 \mathrm{~h}, 48 \mathrm{~h}$ and $60 \mathrm{~h}$ incubation.

(B) Effects of $5 \mu \mathrm{g} / \mathrm{ml}$ zearalenone and its derivatives $\alpha$ - and $\beta$-zearalenol ( $\alpha$ - and $\beta$ ZOL), $\alpha$ - and $\beta$-zearalanol ( $\alpha$ - and $\beta$-ZAL) and zearalanone (ZAN) on bleaching response after $48 \mathrm{~h}$ exposure.

In the second set of experiments, the bleaching formation in response to five derivatives of zearalenone was investigated (Fig. 6-B). Bleaching of wild type leaves was observed for a zearalenol at $5 \mu \mathrm{g} / \mathrm{ml}$. The phytotoxic effects of a zearalenol on Arabidopsis leaves were stronger compared to those of zearalenone resulting in complete photosynthesis inhibition after $48 \mathrm{~h}$. Interestingly, leaves of zes2 transformants treated with $\alpha$ zearalenol were also relatively pale green. $\beta$ zearalenol, $\alpha$ and $\beta$ zearalanol and zearalanone did not exhibit any toxicity on wild type as well as transgenic leaves of Arabidopsis plants (Fig. 6-B).

\section{Discussion}

In this paper, the phenotypic effects of zearalenone and five of its derivatives on different tissues of $A$. thaliana wild type plants and transformants expressing a zearalenone specific-lactonase were analysed.

We could demonstrate that zearalenone had a strong impact on the development of wild type plants under laboratory conditions. Thus, we could show that zearalenone inhibited root and shoot growth of Arabidopsis plantlets. Generally, root development appeared to react more sensitive to the toxin than shoot development. Zearalenone treatment affected the tissue organization of the primary root apex. Hence, zearalenone significantly altered cell proliferation. The fact that the toxin decreased the cell size suggests that reduced root length and dwarfism of the plants is caused by the inhibition of cell extension. 
We constructed transgenic $A$. thaliana transformants that were capable to detoxify zearalenone by the heterologous expression of the zearalenone specific-lactonase gene zes2. Primarily, we found that the expression of the zes2 gene significantly increased the tolerance of transgenic Arabidopsis plants to zearalenone. Zearalenone detoxification activity was detected in all examined organs of the plant body, including transgenic seeds. These results indicate an active protection of transgenic A. thaliana against toxic effects of the mycotoxin.

For quantitative analysis of phytotoxicity and structure activity relationships, zearalenone and five of its derivatives were used in a leaf assay. The derivatives lead to the formation of different phytotoxic phenotypes. Interestingly, $\alpha$ - zearalenol was many fold more active than its parent molecule zearalenone and showed the strongest phytotoxic potencial. Leaves were bleached, suggesting damage by photooxidative effects or a deleterious effect on chloroplast function.

Our finding that zearalenone at a concentration of $5 \mu \mathrm{g} / \mathrm{ml}$ inhibited the formation of floral buds is in line with previous studies. Thus, Fu et al. (2000) reported that exposure to $3 \mu \mathrm{g} / \mathrm{ml}$ of zearalenone completely blocked bud development in Nicotiana tabacum.

A. thaliana plants have been extensively used to measure the effect of fungal toxins on growth and development on tissue as well as on cell level (Stone et al., 2000; Kuroyanagi et al., 2005). But so far, the role of mycotoxins in pathogenesis has not been clarified unequivocally. The biological function of zearalenone in plant-pathogen interactions and the relevance of the phytotoxic potential as well as the mode of action remain subjects for further studies. Microarray experiments were conducted to identify genes differentially expressed after zearalenone treatment of $A$. thaliana (NASCArrays), focussing on signalling pathways by which the plant responses towards zearalenone are triggered. First results indicate a possible role of zearalenone as a suppressor of some plant defence responses. In other investigations, non zearalenone-producing mutants of $F$. graminearum did not alter virulence phenotypes (Gaffoor et al., 2005; Kim et al., 2005). These contradictory results demonstrate the importance of studying the role of this mycotoxin in plant-pathogen interactions.

Whether transgenic detoxification of zearalenone in vivo can also diminish pathogeni- 
city of mycotoxin-producing Fusarium spp. remains to be tested.

The parallels between the F.graminearum-wheat and the F. graminearumArabidopsis pathosystems, and investigations using zearalenone lactonase expressing mutants of Arabidopsis should help to solve this question. Additionally, microarray experiments might support pinpointly the investigation of the mode of action of this mycotoxin. Regardless of their role in pathogenesis, the presence of mycotoxins in agricultural commodities presents a health concern for both animals and humans. Transgenic plants exhibiting zearalenone detoxifying activity are one approach for the efficient decontamination of zearalenone within plant tissues. Hence, this strategy could improve the nutritional quality of plant-based foods and feeds. The fact that the transgenic Arabidopsis seeds showed substantial zearalenone-degrading activity during seed maturation as assessed by the in vitro enzyme assay makes this approach promising. However, this mycotoxin decontamination strategy needs to be evaluated by intensive in vivo studies, including largescale investigation experiments with several different animal systems. Additionally, potentially negative impacts of mycotoxin-degrading transgenic plants, such as effects on nutritional properties and the risk from arising allergens also need to be assessed in the future.

\section{References}

Ahamed S, Foster JS, Bukovsky A, Wimalasena J. 2001. Signal transduction through the Ras/Erk pathway is essential for the mycoestrogen zearalenoneinduced cell-cycle progression in MCF-7 cells. Mol. Carcinog. 30:88-98.

Brandfass C, Karlovsky P. 2006. Simultaneous detection of Fusarium culmorum and F. graminearum in plant material by duplex PCR with melting curve analysis. BMC Microbiology 6:4.

Clough SJ, Bent AF. 1998. Floral dip: a simplified method for Agrobacterium mediated transformation of Arabidopsis thaliana. Plant J. 16:735-743.

Dacasto M, Rolando P, Nachtmann C, Ceppia L, Nebbia C. 1995. Zearalenone mycotoxicosis in piglets suckling sows fed contaminated grain. Vet. Hum. Toxicol. 37:359-361. 
Etienne M, Dourmad JY. 1994. Effects of zearalenone or glucosinolates in the diet on reproduction in sows: a review. Livest. Prod. Sci. 40:99-113.

Farnworth ER Trenholm HL. 1983. The metabolism of the mycotoxin zearalenone and its effects on the reproductive tracts of young male and female pigs. Can. J. Anim. Sci. 63:967-975.

Filek M, Biesaga-Kościelniak J, Marcińska I, Machácková I, Krekule J. 2004. The influence of growth regulators on membrane permeability in cultures of winter wheat cells. Z. Naturforsch. [C] 59:673-678.

Filek M, Zembala M, Szechynska-Hebda M. 2002. The influence of phytohormones on zeta potential and electrokinetic charges of winter wheat cells. $Z$. Naturforsch. [C] 57:696-704.

Fu YF, Meng FJ. 1993. The effects of zearalenone the growth and development of Lemma Gibba G3. Acta Phytophysiologiae Sinica 19:395-398.

Fu YF, Han YZ, Zhao DG, Meng FJ. 2000. Zearalenone and flower bud formation in thin-cell layers of Nicotiana tabacum L. Plant Growth Regul. 30: 271-274.

Fu YF, Li HY, Meng FJ.1995. The possible role of zearalenone in the floral gradient in Nicotiana tabacum L. J. Plant Physiol. 147:197-202.

Gaffoor I, Brown DW, Plattner R, Proctor RH, Qi W, Trail F. 2005. Functional analysis of the polyketide synthase genes in the filamentous fungus Gibberella zeae (anamorph Fusarium graminearum). Eukaryot. Cell 4:1926-1933.

Gao HP, Yoshizawa T. 1997. Further study on Fusarium mycotoxins in corn and wheat from a high-risk area for human esophageal cancer in China. Mycotoxins 45:51-55.

Green ML, Diekman M.A, Malayer JR, Scheidt AB, Long GG. 1990. Effect of prepubertal consumption of zearalenone on puberty and subsequent reproduction of gilts. J. Anim. Sci. 68:171-178.

Grosse Y, Chekir-Ghedira L, Huc A, Obrecht-Pflumio S, Dirheimer G, Bacha H, Pfohl-Leszkowicz A. 1997. Retinol, ascorbic acid and a-tocopherol prevent DNA adduct formation in mice treated with the mycotoxins ochratoxin $A$ and zearalenone. Cancer Lett. 114:225-229. 
Han YZ, Meng FJ. 1991. Studies on zearalenone influencing the growth and development of Lemna perpusilla. Chinese Sciences Bulletin 36:1037-1040.

Hilakivi-Clarke L, Onojafe I. Raygada M, Cho E, Skaar T, Russo I, Clarke R. 1999. Prepubertal exposure to zearalenone or genistein reduces mammary tumorigenesis. Br. J. Cancer 80:1682-1688.

Jefferson RA, Kavanagh TA, Bevan MW. 1987. GUS fusions, beta- glucuronidase as a sensitive and versatile gene fusion marker in higher plants. EMBO J. 6:3901-3907.

Kakeya H, Takahashi-Ando N, Kimura M, Onose R, Yamaguchi I, Osada H. 2002. Biotransformation of the mycotoxin, zearalenone, to a non-estrogenic compound by a fungal strain of Clonostachys sp. Biosci. Biotechnol. Biochem. 66:2723-2726.

Kim YT, Lee YR, Jin J, Han KH, Kim H, Kim JC, Lee T, Yun SH, Lee YW. 2005. Two different polyketide synthase genes are required for synthesis of zearalenone in Gibberella zeae. Mol. Microbiol. 58:1102-1113.

Kuroyanagi M, Yamada K, Hatsugai N, Kondo M, Nishimura M, Hara-Nishimura I. 2005. Vacuolar processing enzyme is essential for mycotoxin-induced cell death in Arabidopsis thaliana. J. Biol. Chem. 280:32914-32920.

Lazo GR. Stein PA, Ludwig RA. 1991. A DNA transformation competent Arabidopsis genomic library in Agrobacterium. Biotechnol. 9:963-967.

McLean M. 1996. The phytotoxicity of selected mycotoxins on mature, germinating Zea mays embryos. Mycopathologia 132:173-183.

McMullen MP. Jones R, Gallenberg D. 1997. Scab of wheat and barley: A reemerging disease of devastating impact. Plant Dis. 81:1340-1348.

Mirocha CJ. Christensen CM, Nelson GH. 1968. Physiologic activity of some fungal estrogen produced by Fusarium. Cancer Research 28: 2319-2322.

NASCArrays. Experiment Reference Number: NASCARRAYS-71. Online resource:http://affymetrix.arabidopsis.info/narrays/experimentpage.pl?experimentid=71.

Packa D. 1991. Cytogenetic changes in plant cells as influenced by mycotoxins. 
Mycotox. Res. 7:150-155.

Saenz de Rodriguez CA. Bougovanni AM, Conde de Borrego L. 1985. An Epidemic of precocious development in Puerto Rican children. J. Pediatr. 107, 393-396.

Schoental R. 1985. Trichothecenes, zearalenone and other carcinogenic metabolites of Fusarium and related microfungi. Adv. Cancer Res. 45:217-290.

Stone JM. Heard JE, Asai T, Ausubel FM. 2000. Simulation of fungal-mediated cell death by fumonisin B1 and selection of fumonisin B1-resistant (fbr) Arabidopsis mutants. Plant Cell. 12:1811-1822.

Takahashi-Ando N, Kimura M, Kakeya H, Osada H, Yamaguchi I. 2002. A novel lactonohydrolase responsible for the detoxification of zearalenone: enzyme purification and gene cloning. Biochem. J. 365:1-6.

Tomaszewski J, Miturski R, Semczuk A, Koarski J, Jakowicki J. 1998. Tissue zearalenone concentration in normal hyperplasic and neoplastic human endometrium. Gynakologe 69:363-366.

Utermark J, Karlovsky P. 2007. Role of zearalenone lactonase in protection of Gliocladium roseum from fungitoxic effects of the mycotoxin zearalenone. Appl. Environ. Microbiol. 73, 637-642.

Vianello A, Macri F. 1981. Effect of zearalenone (F-2) on pea stem, maize root and rat liver mitochondria. Planta 153:443-446.

Vianello A, Macri F. 1982. Zearalenone enhances $\alpha$-amylase and $\beta$-glucosidase activity of germinating maize seeds. Phytopath. Medit. 21:86-88.

Wakuliriski W. 1989. Phytotoxicity of Fusarium metabolites in relation to pathogenicity. In: Chelkowski J (ed), Fusarium Mycotoxins, Taxonomy and Pathogenicity. Amsterdam: Elsevier Press :257-268.

Wang YZ, Miller JD. 1988. Effect of Fusarium graminearum metabolites on wheat tissue in relation to Fusarium head blight resistance. J. Phytopathol. $122: 118-125$. 


\title{
Chapter 4: Genetic transformation of filamentous fungi by Agrobacterium tumefaciens
}

Published in Nature Protocols (DOI: 10.1038/nprot.2008.83.)

Jan Utermark and Petr Karlovsky

\begin{abstract}
Agrobacterium tumefaciens-mediated transformation of filamentous fungi consists of (i) induction of $A$. tumefaciens culture harbouring a binary vector, (ii) co-incubation of bacteria with fungal spores on a solid support, and (iii) selection of transformants. During the induction, vir genes on the helper component of the binary vector are activated, conditioning $A$. tumefaciens for transformation. During co-cultivation, TDNA part of the binary vector system is transferred into fungal nucleus and inserted into the genome. Transformants are selected on a medium with appropriate antibiotic. In order to maximize the number of transformants, the ratio of $A$. tumefaciens cells to fungal spores and the duration of the co-cultivation need be optimized. The procedure takes two to three weeks for fast-growing fungi.
\end{abstract}

\section{Introduction}

Kingdom Fungi consists of about two million species ${ }^{1}$, which include pathogens and symbionts of plants and animals and major biomass decomposers essential for all ecosystems. From the human perspective, fungal fruit bodies are consumed directly and many traditional food products are manufactured by fungal fermentation. Industrially produced fungal cultures serve as the source of enzymes, antibiotics, vitamins, amino acids and other substances ${ }^{2,3}$.

The growing number of sequences of fungal genes and entire fungal genomes, together with transcriptomics and proteomics data accumulating on model species, have generated numerous of hypotheses about the biological function of fungal genes. Many of these hypotheses exist as sequence annotations and are based on 
indirect evidence such as sequence comparisons and data on the regulation of gene expression. Verifying the accuracy of this annotation often is the major limiting step in the analysis of fungal genomes. These hypotheses normally are tested by gene inactivation, which can be achieved either by gene disruption via homologous recombination or by RNAi-mediated gene silencing. A crucial prerequisite for both methods is an efficient genetic transformation protocol.

There are four techniques suitable for the genetic transformation of filamentous fungi

- treatment of protoplasts with polyethylene glycol,

- electroporation,

- biolistic methods

- Agrobacterium tumefaciens.

Before de Groot et al.'s introduction of $A$. tumefaciens into fungal transformation ${ }^{4}$, the most common method for the genetic transformation of filamentous fungi was treatment of a mixture of fungal protoplasts or spheroplasts and DNA with calcium salt and polyethylene glycol. The difficulty of protoplast preparation and regeneration, high batch-to-batch variation in the quality of enzyme cocktails used to digest fungal cell wall, and the low yields of transformants for some species were all important drawbacks. Electroporation and biolistic techniques were used rarely with relatively low yields ${ }^{5}$ and unstable transformants ${ }^{6}$ being common complaints.

Since 1998, A. tumefaciens-mediated transformation of fungi has become a viable substitute for protoplast/polyethylene glycol method ${ }^{7}$. A. tumefaciens is a soil-borne plant pathogenic bacterium that genetically manipulates its hosts by transferring a fragment of DNA (T-DNA) from its plasmid (Ti plasmid) into the plant genome ${ }^{8}$. T-DNA contains genes encoding enzymes of biosynthetic pathways for phytohormones and opines. Expression of these genes leads to the formation of tumors which serve the pathogen as an ecological niche and supplies it with nutrients. By replacing these genes with a cassette containing a gene to be transferred into the plant genome and a selectable marker, the $A$. tumefaciens-mediated transformation process can, and has been, used extensively for the past 20 years to genetically engineer plants. Protocols for $A$. tumefaciens-mediated transformation of dicotyledons such as Arabidopsis thaliana ${ }^{9}$ and soybean ${ }^{10}$ and monocotyledons such as maize ${ }^{11}$ and rice ${ }^{12}$ 
are well established. Since the discovery by de Groot et al. ${ }^{4}$ that chemical treatment of A.tumefaciens also enables this bacterium to genetically transform fungal mycelium, this technique has become available for the manipulation of fungal genomes. Similarly to the plant transformation process, a binary vector system consisting of a small plasmid with T-DNA and a second, large plasmid carrying the genes necessary for the process (vir genes) usually is used. The technique is suitable for both large-scale random insertional mutagenesis and targeted gene replacement. Although the majority of fungal species transformed using $A$. tumefaciens so far were Ascomycetes (58 species), the method has also been successfully applied to Basidiomycetes (15 species), Zygomycetes (4 species) and even fungus-like protists Oomycetes ( 3 species). A direct comparison of the protoplast method with $A$. tumefaciens-mediated transformation is not possible because the efficiencies are calculated in different ways: the number of transformants per $\mu \mathrm{g}$ DNA is used in the former and the number of transformants per plate or experiment in the latter method. In our hands, establishing $A$. tumefaciens-mediated transformation for a new species is faster and easier as compared to the protoplast method.

Fungal transformation mediated by A. tumefaciens consists of three steps: Induction of a bacterial culture harboring appropriate plasmids, co-incubation of the culture with fresh fungal spores on a solid support, and selection of transformants on a medium with a selection agents (figure 1). We optimized the method extensively and have used it routinely for the transformation of five species during the last six years. 


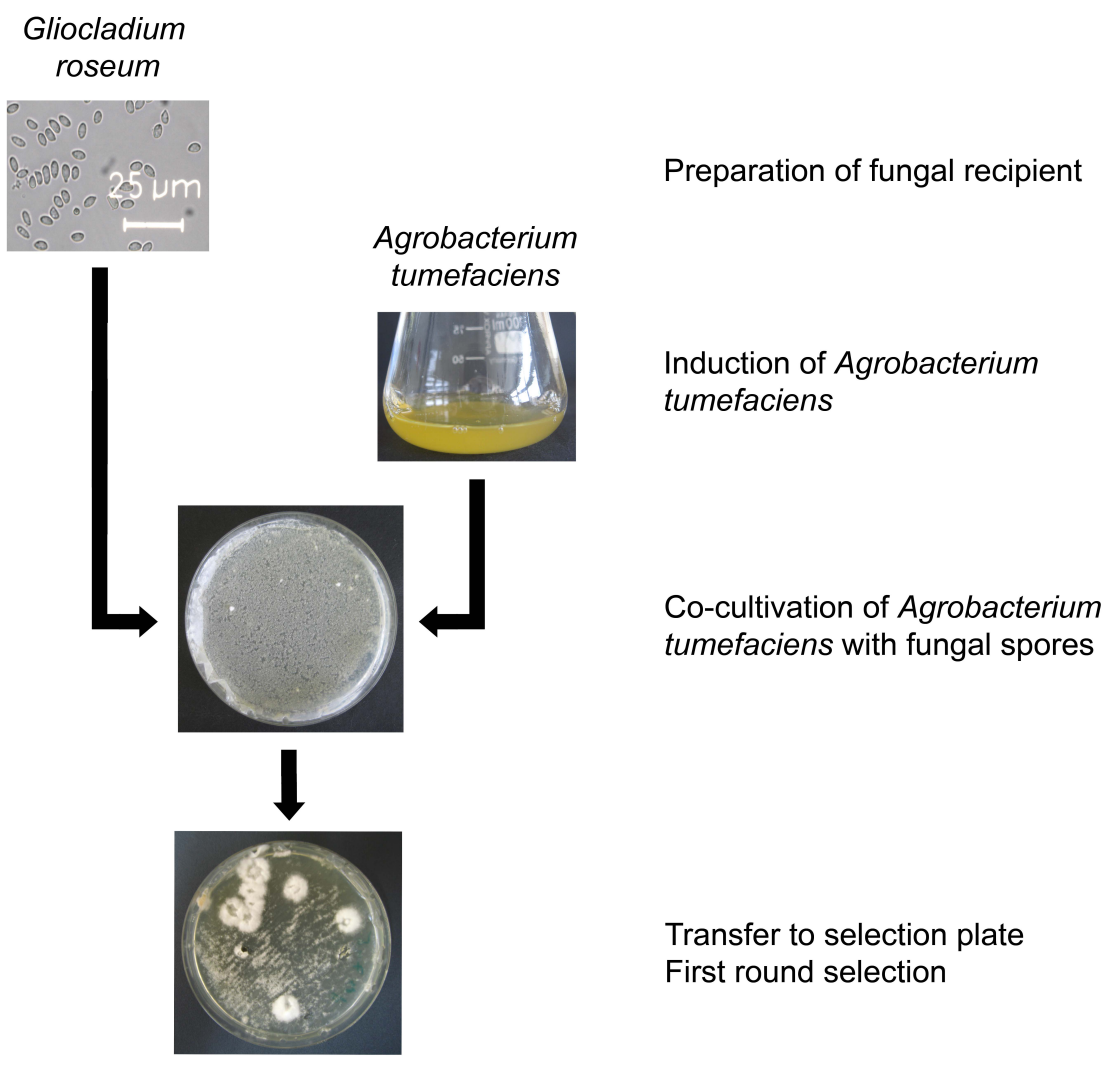

Figure 1. Flow chart of Agrobacterium tumefaciens-mediated transformation of Gliocladium roseum.

\section{Materials}

\section{A. tumefaciens}

Agrobacterium tumefaciens strain AGL1 was provided by Dr. Susanne Frick, Leibniz Institute of Plant Biochemistry (Halle/Saale, Germany) and used as the T-DNA donor. The strain was stored in a 90:10 water:glycerol suspension at $-70^{\circ} \mathrm{C}$.

\section{Recipient fungal strains}

Gliocladium roseum DSM62726

Fusarium verticillioides DSM 62264 (deposited as Fusarium moniliforme)

Leptosphaeria maculans T12aD34 (provided by A. von Tiedemann, Goettingen University, Goettingen, Germany) 
Verticillium longisporum VL $43^{13}$

Trichoderma harzianum T5.8 (provided by A. von Tiedemann, Goettingen University, Goettingen, Germany)

\section{Reagents}

LB broth, low salts (Duchefa, Prod. No. L1703.0500; see reagent setup)

Potato extract glucose broth (Roth, Prod. No. CP74.1; see reagent setup)

Czapek Dox broth (Duchefa, Prod. No. C1714.0500; see reagent setup)

3',5'-Dimethoxy-4'-hydroxyacetophenone (Acetosyringone, Aldrich, Prod. No.

D134406).

Hygromycin B (Duchefa, Prod. No. H0192.0005)

CAUTION: Very toxic by inhalation and in contact with skin. Use personal protective equipment.

Kanamycin sulfate monohydrate (Duchefa, Prod. No. K0126.0025)

Carbenicillin disodium salt (Sigma-Aldrich, Prod. No. C1389)

Rifampicin (Duchefa, Prod. No. R0146.0025)

Cefotaxime (Duchefa, Prod. No. C0111.0025)

Potassium dihydrogen phosphate $\left(\mathrm{KH}_{2} \mathrm{PO}_{4}\right.$, Merck, Prod. No. 4873)

Di-Potassium hydrogen phosphate $\left(\mathrm{K}_{2} \mathrm{HPO}_{4}\right.$, Merck, Prod. No. 1.05101.5000)

Magnesium sulphate 7 hydrate $\left(\mathrm{MgSO}_{4} \cdot 7 \mathrm{H}_{2} \mathrm{O}\right.$, Roth, Prod. No. P02711)

Sodium chloride ( $\mathrm{NaCl}$, Roth, Prod. No. 3957.2)

Calcium chloride 2 hydrate $\left(\mathrm{CaCl}_{2} \cdot 2 \mathrm{H}_{2} \mathrm{O}\right.$, Merck, Prod. No. 2382)

Iron(II) sulfate heptahydrate $\left(\mathrm{FeSO}_{4} \cdot 7 \mathrm{H}_{2} \mathrm{O}\right.$, Fluka, Prod. No. 44980)

Zinc sulfate heptahydrate $\left(\mathrm{ZnSO}_{4} \cdot 7 \mathrm{H}_{2} \mathrm{O}\right.$, Fluka, Prod. No. 96501)

Copper(II) sulfate pentahydrate $\left(\mathrm{CuSO}_{4} \cdot 5 \mathrm{H}_{2} \mathrm{O}\right.$, Fluka, Prod. No. 61245)

Boric acid $\left(\mathrm{H}_{3} \mathrm{BO}_{3}\right.$, Fluka, Prod. No. 15660)

Manganese(II) sulfate hydrate $\left(\mathrm{MnSO}_{4} \cdot \cdot \mathrm{H}_{2} \mathrm{O}\right.$, Aldrich, Prod. No. 229784)

Sodium molybdate dihydrate $\left(\mathrm{Na}_{2} \mathrm{MoO}_{4} \cdot 2 \mathrm{H}_{2} \mathrm{O}\right.$, Fluka, Prod. No. 71756)

Ammonium nitrate $\left(\mathrm{NH}_{4} \mathrm{NO}_{3}\right.$, Roth, Prod. No. K299.1)

Glycerol (Roth, Prod. No. 7530.1)

2-(N-Morpholino)-ethane sulphonic acid (MES, Roth, Prod. No. 4256.3)

Glucose monohydrate (Roth, Prod. No. 6780.1) 
L-asparagine (Sigma-Aldrich, Prod. No. A0884)

Iron(III) chloride hexahydrate $\left(\mathrm{FeCl}_{3} \cdot 6 \mathrm{H}_{2} \mathrm{O}\right.$, Fluka, Prod. No. 44944)

Agar-Agar (Roth, Prod. No. 5210.2)

\section{Equipment}

Electroporator Gene Pulser II (Bio Rad, Prod. No. 165-2112)

Electroporation cuvettes, $0.1 \mathrm{~cm}$ gap (Bio Rad, Prod. No. 165-2083)

Petri dishes: $92 \times 16 \mathrm{~mm}$ (Sarstedt, Prod. No. 82.147)

Incubator programmable to different temperatures $\left(23^{\circ} \mathrm{C}-28^{\circ} \mathrm{C}\right)$

Horizontal orbital shaker (New Brunswick Scientific, Prod. No. M1282-0050)

Cellophane sheets (Max Bringmann $\mathrm{GmbH}$, Wendelstein, Prod. No. 303)

CRITICAL: See reagent setup and figure 2.

Sterile $15 \mathrm{ml}$ plastic tubes with screw cap ("Falcon" tubes, Sarstedt, Prod. No.

62.554.502)

$0.2 \mu \mathrm{m}$ sterile filter (Sartorius, Prod. No. 11106-30)

Drigalski spatula (Roth, Prod. No. T724.1)

Thoma hemacytometer (Roth, Prod. No. T732.1)

\section{Reagent setup}

$200 \mathrm{mM}$ acetosyringone: Dissolve $390 \mathrm{mg}$ acetosyringone in $10 \mathrm{ml}$ of dimethyl sulfoxide. Filter-sterilize $(0.2 \mu \mathrm{m})$ and store at $-20^{\circ} \mathrm{C}$.

$200 \mathrm{mM}$ cefotaxime: Dissolve $96 \mathrm{mg}$ cefotaxime in $10 \mathrm{ml}$ of distilled water. Filtersterilize $(0.2 \mu \mathrm{m})$ and store at $-20^{\circ} \mathrm{C}$.

$50 \mathrm{mg} \mathrm{ml}^{-1}$ kanamycin: Dissolve $2 \mathrm{~g}$ kanamycin monosulfate in $30 \mathrm{ml}$ of distilled water, bring to a final volume of $40 \mathrm{ml}$. Filter-sterilize $(0.2 \mu \mathrm{m})$ and store at $-20^{\circ} \mathrm{C}$.

$100 \mathrm{mg} \mathrm{ml}^{-1}$ hygromycin B: Add $9 \mathrm{ml}$ of distilled water to $1 \mathrm{ml}$ hygromycin B $(1 \mathrm{~g}$ $\left.\mathrm{ml}^{-1}\right)$. Filter-sterilize $(0.2 \mu \mathrm{m})$ and store at $-20^{\circ} \mathrm{C}$.

$1.25 \mathrm{M}$ potassium phosphate buffer: Dissolve $17 \mathrm{~g} \mathrm{KH}_{2} \mathrm{PO}_{4}$ in $90 \mathrm{ml}$ of distilled water and make up the volume to $100 \mathrm{ml}$. Dissolve $22 \mathrm{~g} \mathrm{~K}_{2} \mathrm{HPO}_{4}$ in $90 \mathrm{ml}$ of distilled water and make up the volume to $100 \mathrm{ml}$. Add $\mathrm{K}_{2} \mathrm{HPO}_{4}$ solution dropwise to $\mathrm{KH}_{2} \mathrm{PO}_{4}$ solution until $\mathrm{pH}$ reaches the value of 4.8 . Sterilize by autoclaving.

MN buffer: Dissolve $30 \mathrm{~g} \mathrm{MgSO}_{4} \cdot 7 \mathrm{H}_{2} \mathrm{O}$ and $15 \mathrm{~g} \mathrm{NaCl}$ in $900 \mathrm{ml}$ of distilled water 
and make up the volume to $1000 \mathrm{ml}$. Filter-sterilize $(0.2 \mu \mathrm{m})$ and store at room temperature.

IM-salts: Dissolve $100 \mathrm{mg}$ of each $\mathrm{H}_{3} \mathrm{BO}_{3}, \mathrm{ZnSO}_{4} \cdot 7 \mathrm{H}_{2} \mathrm{O}, \mathrm{CuSO}_{4} \cdot 5 \mathrm{H}_{2} \mathrm{O}, \mathrm{MnSO}_{4}$. $\mathrm{H}_{2} \mathrm{O}$, and $\mathrm{Na}_{2} \mathrm{MoO}_{4} \cdot 2 \mathrm{H}_{2} \mathrm{O}$ in $900 \mathrm{ml}$ of distilled water and make up the volume to $1000 \mathrm{ml}$. Filter-sterilize $(0.2 \mu \mathrm{m})$ and store at room temperature.

$10 \mathrm{mg} \mathrm{ml}^{-1} \mathrm{CaCl}_{2} \cdot 2 \mathrm{H}_{2} \mathrm{O}$ : Dissolve $1 \mathrm{~g}$ of $\mathrm{CaCl}_{2} \cdot 2 \mathrm{H}_{2} \mathrm{O}$ in $90 \mathrm{ml}$ of distilled water and make up to $100 \mathrm{ml}$. Store at $-20^{\circ} \mathrm{C}$.

$250 \mathrm{mg} \mathrm{ml}{ }^{-1} \mathrm{CaCl}_{2} \cdot 2 \mathrm{H}_{2} \mathrm{O}$ : Dissolve $5 \mathrm{~g}$ of $\mathrm{CaCl}_{2} \cdot 2 \mathrm{H}_{2} \mathrm{O}$ in $15 \mathrm{ml}$ of distilled water and make up to $20 \mathrm{ml}$. Store at $-20^{\circ} \mathrm{C}$.

$1 \mathrm{mg} \mathrm{ml}^{-1} \mathrm{FeSO}_{4} \cdot 7 \mathrm{H}_{2} \mathrm{O}$ : Dissolve $100 \mathrm{mg} \mathrm{FeSO}_{4} \cdot 7 \mathrm{H}_{2} \mathrm{O}$ in $90 \mathrm{ml}$ distilled water and make up to $100 \mathrm{ml}$. Store at $-20^{\circ} \mathrm{C}$.

$100 \mathrm{mg} \mathrm{ml}^{-1} \mathrm{FeCl}_{3} \cdot 6 \mathrm{H}_{2} \mathrm{O}$ : Dissolve $1 \mathrm{~g}$ of $\mathrm{FeCl}_{3} \cdot 6 \mathrm{H}_{2} \mathrm{O}$ in $10 \mathrm{ml}$ of distilled water. Store at $-20^{\circ} \mathrm{C}$.

$10 \mathrm{mg} \mathrm{ml}^{-1}$ thiamine: Dissolve $100 \mathrm{mg}$ of thiamine in $10 \mathrm{ml}$ of distilled water, sterilize by filtration and store at $-20^{\circ} \mathrm{C}$.

$200 \mathrm{mg} \mathrm{ml}^{-1} \mathrm{NH}_{4} \mathrm{NO}_{3}$ : Dissolve $20 \mathrm{~g} \mathrm{NH}_{4} \mathrm{NO}_{3}$ in $70 \mathrm{ml}$ of distilled water and make up to $100 \mathrm{ml}$. Filter-sterilize $(0.2 \mu \mathrm{m})$ and store at room temperature.

$50 \%$ glycerol: Add $50 \mathrm{ml}$ glycerol to $50 \mathrm{ml}$ of distilled water. Store at $4^{\circ} \mathrm{C}$.

1 M MES: Dissolve $20 \mathrm{~g}$ MES in $90 \mathrm{ml}$ of distilled water and stirr at $50^{\circ} \mathrm{C}$ until MES is completely dissolved. Adjust $\mathrm{pH}$ to 5.5 with $5 \mathrm{M} \mathrm{NaOH}$ and make up the volume to $100 \mathrm{ml}$. Store at $4^{\circ} \mathrm{C}$.

$200 \mathrm{mg} \mathrm{ml}^{-1}$ glucose: Dissolve $20 \mathrm{~g}$ glucose monohydrate in $90 \mathrm{ml}$ of distilled water and stir at $50^{\circ} \mathrm{C}$ until glucose is completely dissolved. Make up to $100 \mathrm{ml}$ and use immediately or store at $-20^{\circ} \mathrm{C}$.

LB medium: Dissolve $20 \mathrm{~g}$ "LB broth" powder in $900 \mathrm{ml}$ of distilled water and adjust $\mathrm{pH}$ to 7.2 with $1 \mathrm{M} \mathrm{NaOH}$. Make up to $1000 \mathrm{ml}$, autoclave at $121^{\circ} \mathrm{C}$ for $15 \mathrm{~min}$. Cool to room temperature and add antibiotics (table 1).

For agar plates, add $15 \mathrm{~g}$ agar-agar before autoclaving, cool to $55^{\circ} \mathrm{C}$, add antibiotics, mix well and dispense $20 \mathrm{ml}$ per Petri dish.

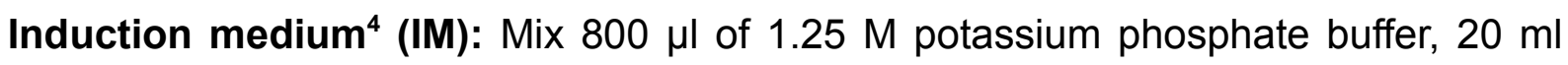
MN buffer, $1 \mathrm{ml}$ of $10 \mathrm{mg} \mathrm{ml}^{-1} \mathrm{CaCl}_{2}, 1 \mathrm{ml}$ of $1 \mathrm{mg} \mathrm{ml}^{-1} \mathrm{FeSO}_{4}, 5 \mathrm{ml}$ IM-salts, $2 \mathrm{ml}$ of 
$200 \mathrm{mg} \mathrm{ml}^{-1} \mathrm{NH}_{4} \mathrm{NO}_{3}, 10 \mathrm{ml}$ of $50 \%$ glycerol, $40 \mathrm{ml}$ of $1 \mathrm{M} \mathrm{MES}$ and $1 \mathrm{ml}$ (liquid medium) or $5 \mathrm{ml}$ (solid medium) of $200 \mathrm{mg} \mathrm{ml}^{-1}$ glucose and make up the volume to $1000 \mathrm{ml}$. For solid medium (co-cultivation) add $15 \mathrm{~g}$ agar-agar. Autoclave at $121^{\circ} \mathrm{C}$ for $15 \mathrm{~min}$. Cool to $55^{\circ} \mathrm{C}$, add $1 \mathrm{ml}$ of $200 \mathrm{mM}$ acetosyringone. Mix vigorously. Solid medium: dispense $20 \mathrm{ml}$ per Petri dish. Store the agar plates and liquid medium at room temperature.

? Troubleshooting.

GM7 medium ${ }^{14}$ for the selection of transformants: Dissolve $3 \mathrm{~g}$ L-asparagine, $1 \mathrm{~g}$ $\mathrm{KH}_{2} \mathrm{PO}_{4}, 0.5 \mathrm{~g} \mathrm{MgSO}_{4} \cdot 7 \mathrm{H}_{2} \mathrm{O}$, and $20 \mathrm{~g}$ glucose in $900 \mathrm{ml}$ of distilled water. Add 200 $\mu \mathrm{l}$ of $250 \mathrm{mg} \mathrm{ml}^{-1} \mathrm{CaCl}_{2}, 100 \mu \mathrm{l}$ of $100 \mathrm{mg} \mathrm{ml}^{-1} \mathrm{FeCl}_{3}$ and $100 \mu \mathrm{l}$ of $10 \mathrm{mg} \mathrm{ml}^{-1}$ thiamine. Adjust the $\mathrm{pH}$ to 5.6 with $1 \mathrm{M} \mathrm{NaOH}$ and make up the volume to $1000 \mathrm{ml}$. Add $15 \mathrm{~g}$ agar-agar and autoclave at $121^{\circ} \mathrm{C}$ for $15 \mathrm{~min}$. Cool to $55^{\circ} \mathrm{C}$, add hygromycin $B$ from a stock solution of $100 \mathrm{mg} \mathrm{ml}^{-1}$ to reach the required concentration (table 1) and cefotaxime to $200 \mu \mathrm{M}$. Mix vigorously. Pour the medium into sterile plastic Petri plates in a sterile hood.

Czapek Dox medium for the selection of transformants: Dissolve $33.4 \mathrm{~g}$ Czapek Dox powder in $900 \mathrm{ml}$ of distilled water and bring the volume to $1000 \mathrm{ml}$. Add $15 \mathrm{~g}$ agar-agar and autoclave at $121^{\circ} \mathrm{C}$ for $15 \mathrm{~min}$. Cool the medium to $55^{\circ} \mathrm{C}$, add hygromycin $B$ from a stock solution of $100 \mathrm{mg} \mathrm{ml}^{-1}$ to reach the required concentration (table 1) and cefotaxime to $200 \mu \mathrm{M}$. Mix vigorously. Pour the medium into sterile plastic Petri plates in a sterile hood.

Potato extract glucose medium for the selection of transformants: Dissolve 26.5 $\mathrm{g}$ potato extract glucose broth in $900 \mathrm{ml}$ of distilled water and bring the volume to $1000 \mathrm{ml}$. Add $15 \mathrm{~g}$ agar-agar and autoclave at $121^{\circ} \mathrm{C}$ for $15 \mathrm{~min}$. Cool the medium to $55^{\circ} \mathrm{C}$ and add hygromycin $\mathrm{B}$ to the required concentration and cefotaxime to $200 \mu \mathrm{M}$. Mix vigorously. Pour the medium into sterile plastic Petri plates in a sterile hood. 


\section{BOX1: Preparation of $A$. tumefaciens for electroporation}

\section{=> Timing 3 days}

6. Add a single colony of $A$. tumefaciens AGL1 to $20 \mathrm{ml}$ LB medium in a $100 \mathrm{ml}$ Erlenmeyer flask, grow overnight on a rotary shaker at $28^{\circ} \mathrm{C}$ and $150 \mathrm{rpm}$.

CRITICAL: A. tumefaciens cultures should always be grown from a single colony picked from a freshly streaked plate.

7. Inoculate 1 liter LB medium in a 3 I Erlenmeyer flask with $5-10 \mathrm{ml}$ of fresh overnight culture. Shake well at $28^{\circ} \mathrm{C}$ in a rotary shaker at $200 \mathrm{rpm}$. Monitor the growth of the strain until $\mathrm{OD}_{600}$ reaches a value 0.5 to 0.9 . Chill the flask on ice for $15 \mathrm{~min}$.

CRITICAL: If cells grow over $\mathrm{OD}_{600}$ of 0.9 , dilute with fresh $\mathrm{LB}$ broth to an optical density of approx. 0.2 and regrow to desired optical density.

8. Pellet the cells in a sterile centrifuge tube at $4000 \times \mathrm{g}$ for $10 \mathrm{~min}$ at $4^{\circ} \mathrm{C}$.

CRITICAL: Do not centrifuge at a higher g-value than needed to pellet the cells. More centrifugal force applied for a longer time reduces the survival rate after electroporation.

9. Wash pellet twice in $100 \mathrm{ml}$ of cold distilled water and centrifuge at $4000 \times \mathrm{g}$ for 10 min at $4^{\circ} \mathrm{C}$; remove and discard supernatant.

10. Resuspend cell pellet in $20 \mathrm{ml}$ of cold $10 \%$ glycerol. Centrifuge at $4000 \times \mathrm{g}$ for 10 min at $4^{\circ} \mathrm{C}$; remove and discard supernatant.

11. Resuspend the cells in a final volume of $2-3 \mathrm{ml}$ of cold $10 \%$ glycerol.

12. To freeze competent cells, aliquot into $1.5 \mathrm{ml}$ microcentrifuge tubes (45 $\mu \mathrm{l}$ tube $\left.{ }^{-1}\right)$ and place tubes in liquid nitrogen until frozen. Store at $-70^{\circ} \mathrm{C}$ for up to 2 years.

\section{BOX2: Transformation of Agrobacterium tumefaciens by electoporation}

\section{$=>$ Timing 4 hours}

1. Place LB medium in a $28^{\circ} \mathrm{C}$ water bath. Place selective plates at $28^{\circ} \mathrm{C}$ for 1 hour.

2. Place electroporation cuvettes and microcentrifuge tubes on ice.

3. Thaw electrocompetent cells of $A$. tumefaciens on ice (about $10 \mathrm{~min}$ ) and mix cells by flicking the tube gently. Transfer $40 \mu \mathrm{l}$ of the cell suspension to a cooled microcentrifuge tube. Add $1 \mu$ l of plasmid solution in water containing $10-100$ pg plasmid DNA and mix gently. 
4. Carefully transfer the cell/DNA mixture into a chilled cuvette without introducing bubbles. Make sure that the suspension deposits along the bottom of the cuvette. Electroporate by using the following conditions: Voltage $1.8 \mathrm{kV}$, shunt resistor 200 $\Omega$, and capacitor $25 \mu \mathrm{F}$. The typical time constant resulting from this setting is 4 milliseconds.

5. Immediately after delivering the pulse, add $800 \mu$ of LB medium pre-heated to $28^{\circ} \mathrm{C}$ to the cuvette, mix by inverting the cuvette twice and then transfer the contents to a $1.5 \mathrm{ml}$ microcentrifuge tube.

6. Incubate without shaking at $28^{\circ} \mathrm{C}$ for 3 hours.

7. Spread $100 \mu \mathrm{l}$ of cell suspension onto LB agar medium containing the appropriate antibiotics.

8. Incubate at $28^{\circ} \mathrm{C}$ for approximately $48 \mathrm{~h}$ until colonies appear.

\section{BOX 3: Preparation of membranes for co-cultivation}

Cellophane membranes can be purchased pre-cut into cicrles fitting Petri dishes or cut from household cellophane foil for preserves (see equipment) into circles $9.5 \mathrm{~cm}$ diameter. A stack of cellophane membranes interlaced with filter paper strips is placed into a glass Petri dish of $11 \mathrm{~cm}$ diameter filled with distilled water and autoclaved for $15 \mathrm{~min}$ at $121^{\circ} \mathrm{C}$ (figure 2). Cellophane membranes work as well as do the nylon membranes, Hybond $\mathrm{N}$ and Hybond $\mathrm{N}+$, used by others (Michielse et al., 2005). 


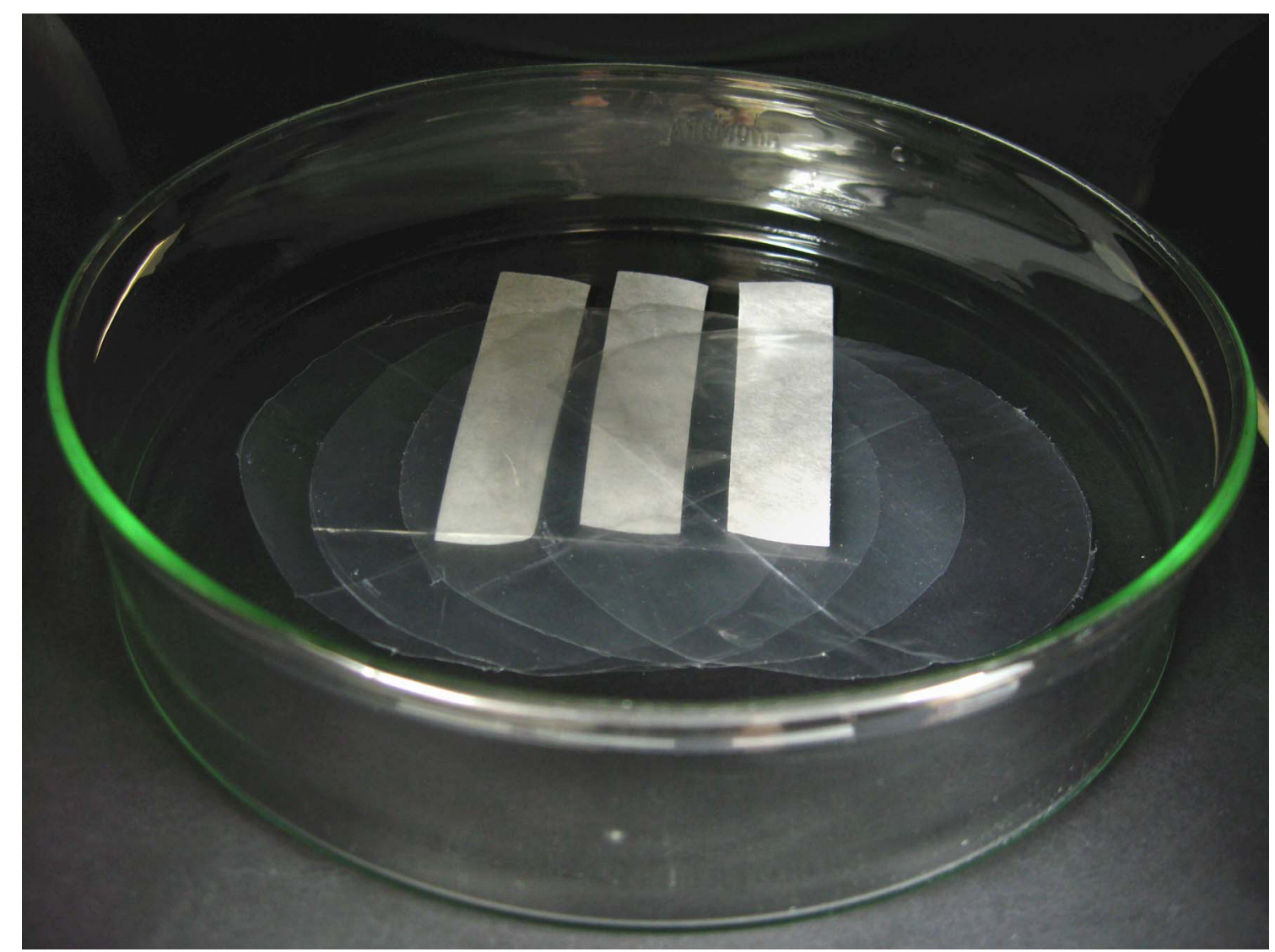

Figure 2. Autoclaved cellophane sheets.

\section{BOX 4: Determination of fungal spore density}

The spore density is calculated by counting spores in a Thoma hemacytometer with a depth of $0.1 \mathrm{~mm}$. A single large square subdivided into 16 smaller squares, which are divided into 16 mini squares each $\left(0.0025 \mathrm{~mm}^{2}\right)$.

1. Moisten the external supports with distilled water and push the cover glass gently onto the counting chamber from the front. The formation of interference lines (Newton rings) between the external support and the cover glass shows that the cover glass is correctly positioned.

CRITICAL: The cover glass is fragile and is special for this chamber.

2. Place a drop of a diluted spore suspension into the counting chamber covered by cover glass. The gap between the cover glass and the chamber base fills up due to capillary action. 
3. Place the counting chamber under a light microscope, select an appropriate magnification and count spores in 4 small squares (figure 3 ). Spores crossing the border of a square are counted on two sides only for each square.

4. The spore concentration is calculated as:

Spores $\mathrm{ml}^{-1}=$ total spore count in 4 small squares $\times 2500 \times$ dilution factor.

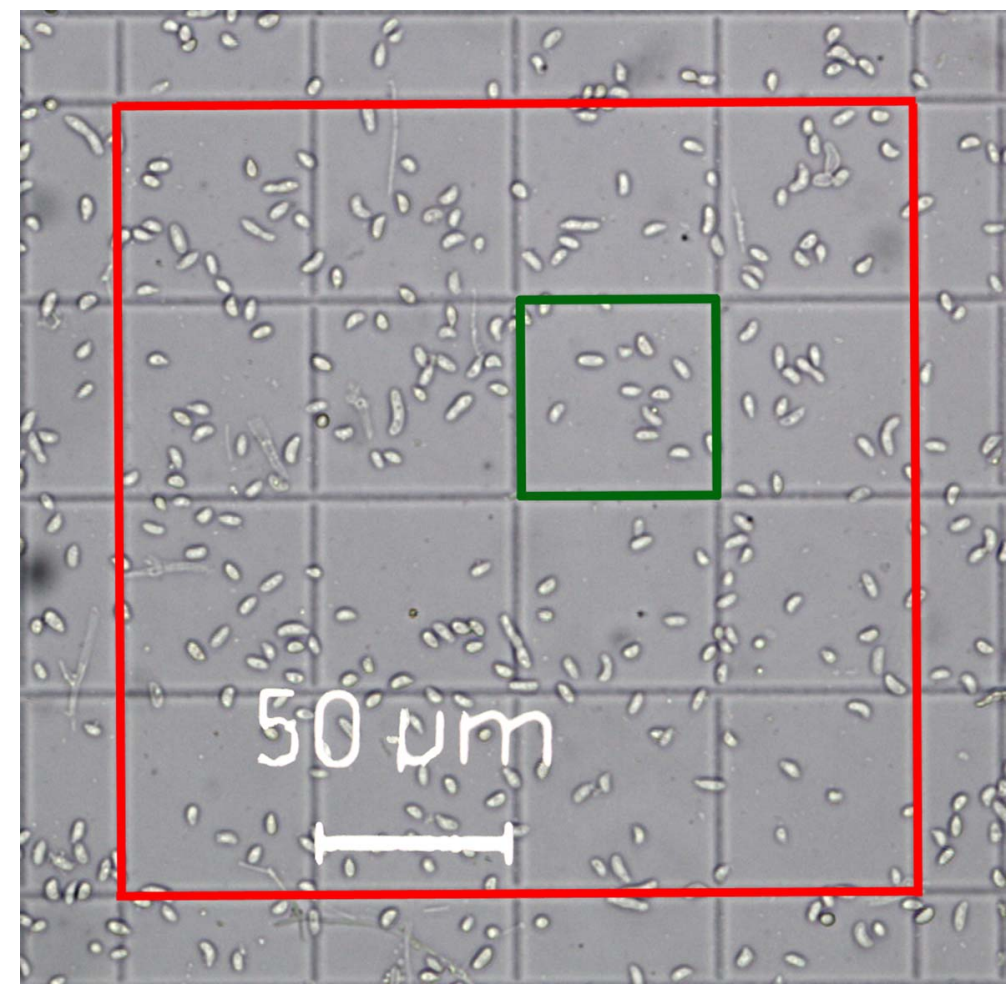

Figure 3. Thoma hemacytometer with spores of Gliocladium roseum. A small square (red) is divided into 16 mini squares $0.0025 \mathrm{~mm} 2$ each (green). For details see BOX 3 .

\section{BOX 5:Determination of the concentration of selection agent}

Fungal spores are plated on an appropriate agar medium $\left(10^{6}\right.$ spores per $9 \mathrm{~cm}$ plate) containing a dilution series of hygromycin from 50 to $300 \mu \mathrm{g} / \mathrm{ml}$. The lowest concentration at which no growth occur is selected for transformation. The most widely used antibiotic for the selection of fungal transformants is hygromycin B (table 1). 
Table 1. Fungal species successfully transformed with $A$. tumefaciens AGL1

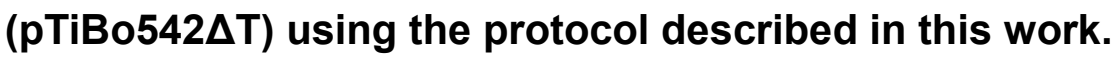

\begin{tabular}{|c|c|c|c|c|}
\hline $\begin{array}{l}\text { Binary } \\
\text { vector }\end{array}$ & $\begin{array}{l}\text { Resistance } \\
\text { cassette }\end{array}$ & $\begin{array}{l}\text { Recipient } \\
\text { species }\end{array}$ & $\begin{array}{l}\text { Selection } \\
\text { medium }\end{array}$ & Reference \\
\hline pZG05 & $\begin{array}{l}\text { gpdA-hph- } \\
\text { trpC }\end{array}$ & $\begin{array}{l}\text { Gliocladium } \\
\text { roseum }^{15}\end{array}$ & $\begin{array}{l}\text { GM7 medium } \\
\text { containing } \\
\text { hygromycin } \\
\left(250 \mu \mathrm{g} \mathrm{m}^{-1}\right)\end{array}$ & 15 \\
\hline pPK2 & $\begin{array}{l}\text { gpdA-hph- } \\
\text { trpC }\end{array}$ & $\begin{array}{l}\text { Leptosphaeria } \\
\text { maculans }\end{array}$ & $\begin{array}{l}\text { Czapek Dox } \\
\text { medium } 50 \mu \mathrm{g} \\
\mathrm{ml}^{-1}\end{array}$ & $\begin{array}{l}\text { JU, B Koopmann, PK. } \\
\text { Mitt. Biol. Bundes- } \\
\text { anst. Land- Forst-wirt- } \\
\text { schaft } 396,576-577 \\
(2004)\end{array}$ \\
\hline $\begin{array}{l}\text { pZG07- } \\
\text { GFP }\end{array}$ & oliC-hph-tubA & $\begin{array}{l}\text { Gliocladium } \\
\text { roseum }^{14}\end{array}$ & $\begin{array}{l}\text { GM7 medium } \\
250 \mu \mathrm{gl}^{-1}\end{array}$ & 16 \\
\hline pPK2 & $\begin{array}{l}\text { gpdA-hph- } \\
\operatorname{trpC}\end{array}$ & $\begin{array}{l}\text { Verticillium } \\
\text { longisporum }^{4}\end{array}$ & $\begin{array}{l}\text { Czapek Dox } \\
\text { medium } \\
50 \mu \mathrm{g} \mathrm{ml}^{-1}\end{array}$ & 17 \\
\hline pPK2 & $\begin{array}{l}\text { gpdA-hph- } \\
\operatorname{trpC}\end{array}$ & $\begin{array}{l}\text { Fusarium verti- } \\
\text { cillioides } \\
\text { (this work) }\end{array}$ & $\begin{array}{l}\text { PDA medium } \\
200 \mathrm{\mu g} \mathrm{ml}^{-1}\end{array}$ & this work \\
\hline pZG06 & $\begin{array}{l}\text { gpdA-hph- } \\
\operatorname{trpC}\end{array}$ & $\begin{array}{l}\text { Trichoderma } \\
\text { harzianum } \\
\text { (this work) }\end{array}$ & $\begin{array}{l}\text { PDA medium } \\
200 \mathrm{\mu g} \mathrm{ml}^{-1}\end{array}$ & this work \\
\hline
\end{tabular}

\section{Procedure}

\section{Preparation of fungal recipient}

\section{$=>$ Timing 20 days}

Preparation of fresh fungal spores is described for Gliocladium roseum (Clonostachys rosea) as an example. The optimal medium, incubation temperature and time varies with species. For most fungi investigated in the laboratory, culture conditions inducing sporulation are known. Factors enhancing spore production in most species are irradiation with near-UV light, incubation on media with a low nutrient content, e.g. straw extract, and the use of vigorously agitated liquid cultures instead of solid cultures. 
1. Inoculate $G$. roseum onto PDA agar and incubate for 20 days at $24^{\circ} \mathrm{C}$.

2. Wash spores from one Petri dish with $3 \mathrm{ml}$ of sterile tap water. Use a Drigalski spatula to release the spores gently from mycelium.

3. Collect spore suspension and determine spore concentration as described in BOX3.

4. Adjust spore density to $10^{7}$ spores $\mathrm{ml}^{-1}$ with sterile tap water.

CRITICAL: Store spore suspensions for transformation experiments at $4^{\circ} \mathrm{C}$ for no more than 50 hours.

\section{Preparation A. tumefacies AGL1 as a donor}

\section{=> Timing 48 hours}

5. Inoculate $10 \mathrm{ml}$ of LB medium in a $100 \mathrm{ml}$ Erlenmeyer flask containing appropriate antibiotics with a single colony of $A$. tumefacies carrying a transformation vector (table 1). Grow the strain at $28^{\circ} \mathrm{C}$ on a rotary shaker at $200 \mathrm{rpm}$ until the $\mathrm{OD}_{600}$ reaches 0.5 to 0.9 . For selection of $A$. tumefaciens carrying Ti-plasmid pTiBo542 $\Delta$ T and any binary vector from the list shown in Table 1, supplement the growth medium with kanamycin, rifampicin, and carbenicillin at 50,50 , and $25 \mu \mathrm{g}$ $\mathrm{ml}^{-1}$, respectively.

CRITICAL: A. tumefaciens cultures for transformation experiments should always be grown from a single colony picked from a freshly streaked selective plate. Subculturing directly from glycerol stocks, agar stabs or old liquid cultures may lead to unsatisfactory results.

\section{Pre-induction of T-DNA mobilization in Agrobacterium tumefaciens \\ $=>$ Timing 12 hours}

6. Centrifuge $5 \mathrm{ml}$ of the culture in a sterile $15 \mathrm{ml}$ centrifuge tube at $4000 \times \mathrm{g}$ for 5 min at room temperature.

7. Decant the supernatant as soon as the rotor stops. Add $1 \mathrm{ml} \mathrm{IM}$ to the cell pellet; pipet up and down or vortex gently until cells are uniformly resuspended.

8. Transfer the mixture to a $2 \mathrm{ml}$ microcentrifuge tube and centrifuge at $4000 \mathrm{xg}$ for $5 \mathrm{~min}$ at room temperature. Wash the cells a second time by resuspending in $500 \mu \mathrm{I} \mathrm{IM}$ using the same technique. Centrifuge the cell suspension at $4000 \times \mathrm{g}$ 
for $5 \mathrm{~min}$ at room temperature.

9. Resuspend the bacterial pellet in $150 \mu \mathrm{I}$ of IM.

10. Dilute bacterial cells to $\mathrm{OD}_{600}=0.15$ with IM supplemented with $200 \mu \mathrm{M}$ acetosyringone. Grow cells for 8-12 hours with vigorous aeration in a $100 \mathrm{ml}$ Erlenmeyer flask at $28^{\circ} \mathrm{C}$ until the cells reach $\mathrm{OD}_{600}=0.3$.

Critical step: Do not grow cells at temperatures $>28^{\circ} \mathrm{C}$. If the culture develops visible clumps, do not use it.

\section{Co-cultivation of Agrobacterium tumefaciens and fungal recipient}

\section{$\Rightarrow$ Timing 60 hours}

11. Prepare $200 \mu \mathrm{l}$ of a $1: 1 \mathrm{mixture}$ of the fungal spore suspension $\left(10^{7} \mathrm{ml}^{-1}\right)$ and the induced $A$. tumefaciens culture from step 10 and spread onto the surface of a cellophane sheet placed on an IM agar plate supplemented with $200 \mu \mathrm{M}$ acetosyringone.

CRITICAL: For uniform distribution use a sterile Drigalski spatula or a glass "hockey" stick.

12. Incubate the plates for 60 hours at $23^{\circ} \mathrm{C}$. (Optimal time and temperature may differ by species.) Transformation of all species listed in table 1 was successful under these conditions.

CRITICAL: A dense layer of mycelium must be formed at the end of the co-cultivation period (figure 4).

? Troubleshooting 

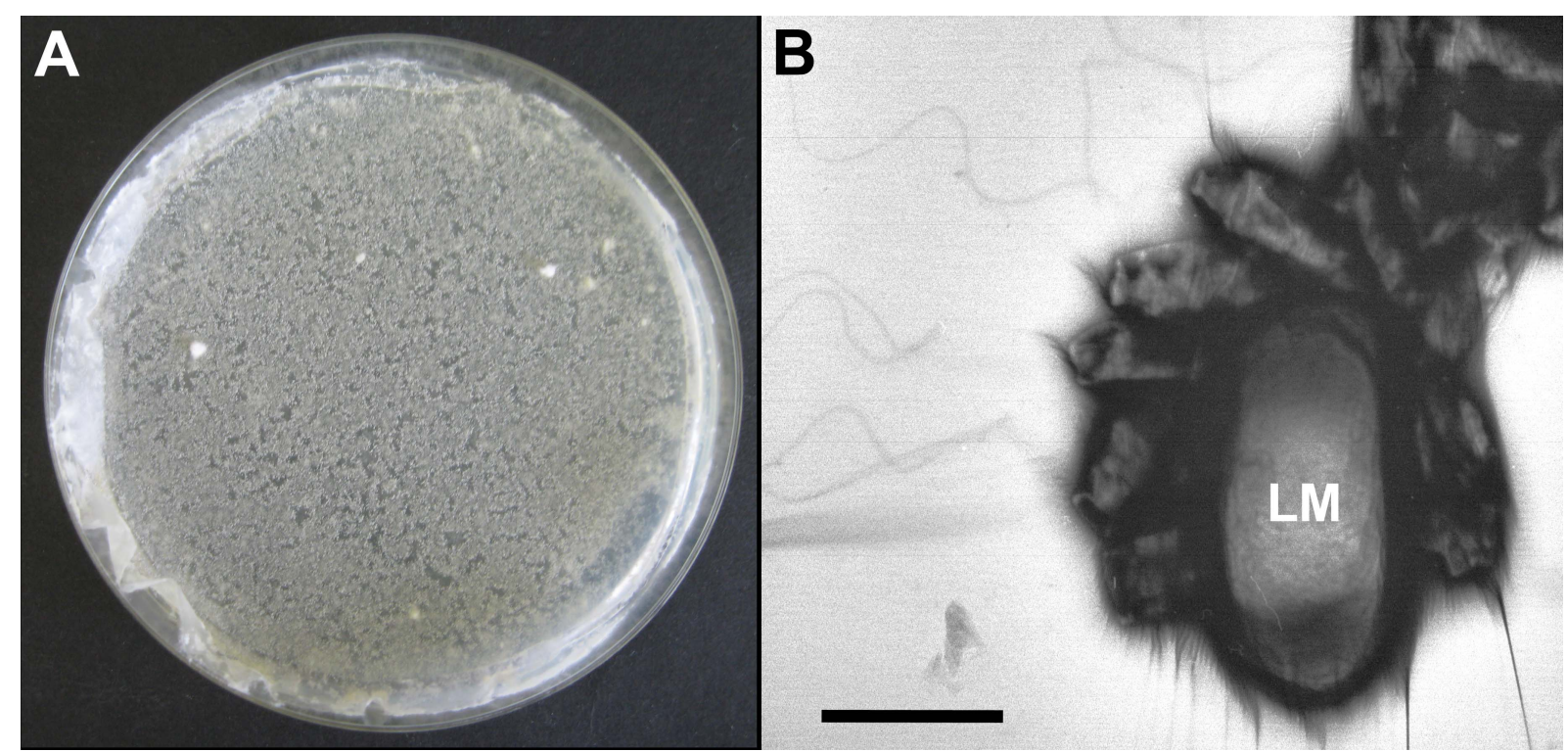

Figure 4. Co-cultivation of $\boldsymbol{A}$. tumefaciens with fungal spores.

A) A. tumefaciens with Gliocladium roseum with on a cellophane membrane after 60 hours of co-cultivation.

B) Leptosphaeria maculans spore (LM) with A. tumefaciens cells attached after $12 \mathrm{~h}$ of co-cultivation, surrounded by detached flagellae. Samples were stained with $2 \%$ uranyl acetate $(\mathrm{w} / \mathrm{v})$ and visualized by transmission electron microscopy. Scale bar: $2.5 \mu \mathrm{m}$.

\section{Selection of transformants}

\section{=> Timing: up to 7 days}

13. After co-cultivation, use sterile forceps to transfer the cellophane membranes onto selection plates containing $200 \mu \mathrm{M}$ cefotaxime and hygromycin B (or other antibiotic depending on the selection marker used).

14. After 7-10 days (may differ depending on the species), colonies of transformants should be readily visible on the background of decaying mycelium (figure 5). Transfer the colonies onto fresh selection plates containing the same antibiotics.

? Troubleshooting

For troubleshooting guidance, see Table 2. 


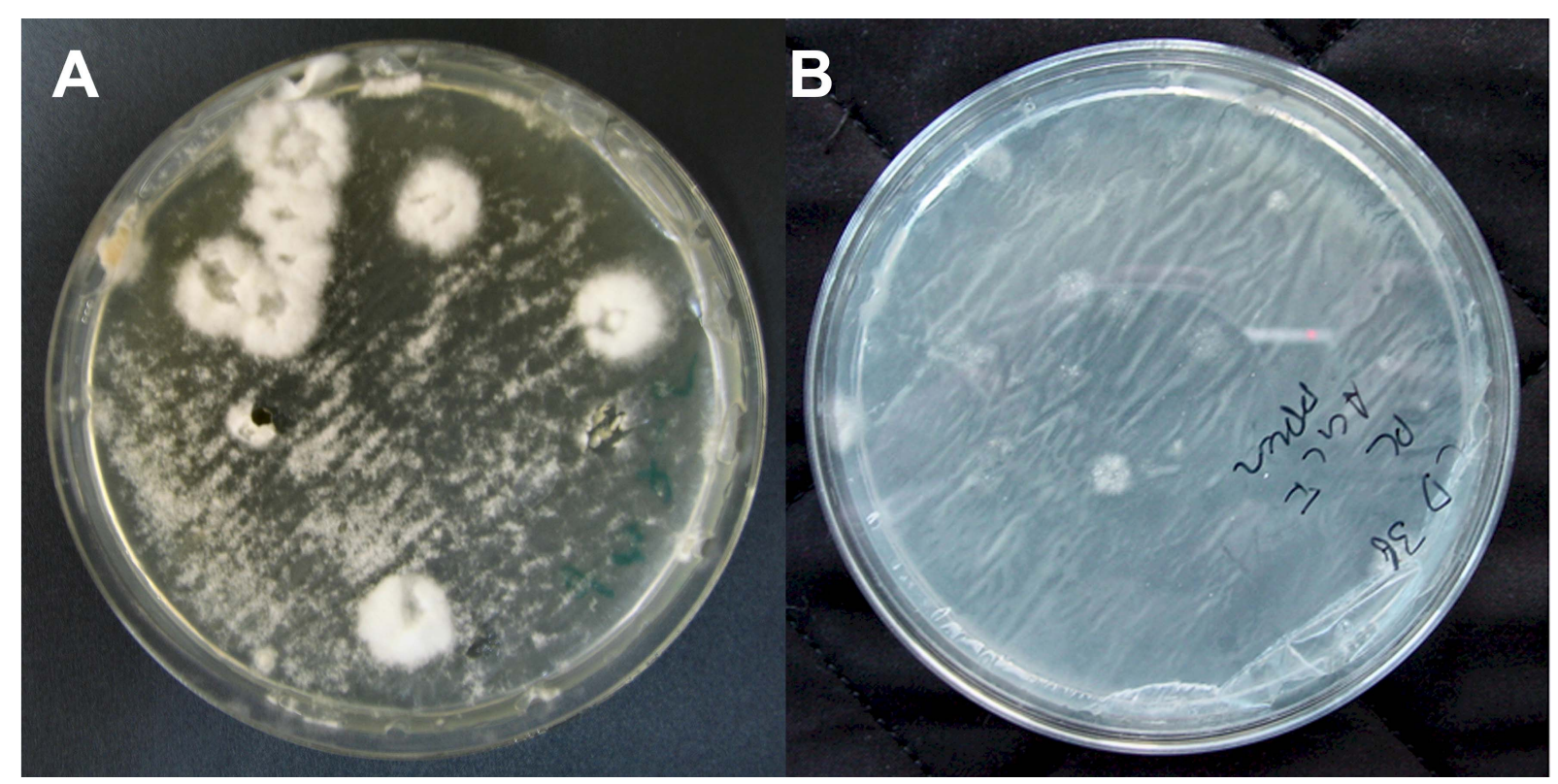

Figure 5. Selection of transformats.

(A) Gliocladium roseum after 10 days of incubation on a cellophane membrane on GM7 medium containing $250 \mu \mathrm{g} \mathrm{ml}-1$ hygromycin B and $200 \mu \mathrm{M}$ cefotaxime.

(B) Leptosphaeria maculans after 7 days of incubation on a cellophane membrane on Czapek-Dox medium supplemented with $50 \mu \mathrm{g} \mathrm{ml}^{-1}$ hygromycin B and $200 \mu \mathrm{M}$ cefotaxime.

\section{Anticipated results}

The procedure routinely generates 8 - 15 hygomycin resistant colonies per $10^{6}$ fungal spores per plate for both $G$. roseum and $L$. maculans. It can be used to generate hundreds of independent transformation events in one experiment and is suitable for saturation mutagenesis.

Adaptation of the protocol to different fungal species is easy. A crucial parameter to determine for each fungal isolate separately is the concentration of the selection agents. No further optimization is needed when a limited number of transformants have to be generated (e.g., transformation of overexpression or silencing constructs). For genome-wide mutagenesis, the efficiency of the transformation should be maximized. The most important parameters to optimize are the ratio between A. tumefaciens cells and fungal spores and the duration of the co-cultivation. 
Table 2. Troubleshooting table.

\begin{tabular}{|c|c|c|c|}
\hline Step & Problem & Reason & Solution \\
\hline $\begin{array}{l}\text { Induction } \\
\text { medium }\end{array}$ & $\begin{array}{l}\text { IM medium does } \\
\text { not solidify }\end{array}$ & $\mathrm{pH}$ is too low & $\begin{array}{l}\text { Check } \mathrm{pH} \text { values of phosphate } \\
\text { buffer and MES solution used to } \\
\text { make IM. Increase agar concen- } \\
\text { tration to } 20 \mathrm{~g} \mathrm{liter}^{-1} \text { if the problem } \\
\text { persists. }\end{array}$ \\
\hline 5 & $\begin{array}{l}\text { Agglutination of } A \text {. } \\
\text { tumefaciens cells } \\
\text { in liquid culture }\end{array}$ & Unknown & $\begin{array}{l}\text { Start a new culture. If the } \\
\text { problem persists, inoculate a new } \\
\text { plate of the glycerol stock. }\end{array}$ \\
\hline 12 & $\begin{array}{l}\text { No dense mycelial } \\
\text { mat on IM after } \\
\text { co-cultivation }\end{array}$ & $\begin{array}{l}\text { Impaired fungal } \\
\text { spore viability }\end{array}$ & Prepare fresh spore suspension \\
\hline
\end{tabular}

\section{References}

1) Mueller, G. M. \& Schmit, J. P. Fungal biodiversity: what do we know? What can we predict? Biodivers. Conserv. 16, 1-5 (2007).

2) Demain, A.L. Microbial biotechnology. Trends Biotech. 18, 26-31 (2000).

3) Askenazi, M. et al. Integrating transcriptional and metabolite profiles to direct the engineering of lovastatin-producing fungal strains. Nat. Biotech. 21, 150-156 (2003).

4) de Groot, M.J., Bundock, A.P., Hooykaas, P.J.J. \& Beijersbergen, A.G.M. Agrobacterium tumefaciens-mediated transformation of filamentous fungi. Nat. Biotechnol. 16, 839-842 (1998).

5) Meyer, V., Müller, D., Strowig, T. \& Stahl, U. Comparison of different transformation methods for Aspergillus giganteus. Curr. Genet. 43, 371-377 (2003).

6) Helber, N., \& Requena, N. Expression of the fluorescence markers DsRed and GFP fused to a nuclear localization signal in the arbuscular mycorrhizal fungus Glomus intraradices. New Phytol. 177, 537-548 (2007). 
7) Michielse, C.B, Hooykaas, P.J., van den Hondel, C.A. \& Ram, A.F. Agrobacteriummediated transformation as a tool for functional genomics in fungi. Curr. Genet. 48, 1-17 (2005).

8) Gelvin, S.B. Agrobacterium-mediated plant transformation: The biology behind the "gene-jockeying" tool. Microbiol. Mol. Biol. Rev. 67,16-37 (2003).

9) Zhang, X., Henriques, R., Lin, S.S., Niu, Q.W., \& Chua, N.H. Agrobacterium-mediated transformation of Arabidopsis thaliana using the floral dip method. Nat. Protoc. 1, 641-646 (2006).

10)Kereszt, A. et al. Agrobacterium rhizogenes-mediated transformation of soybean to study root biology. Nat. Protoc. 2, 948-952 (2007).

11) Ishida, Y., Hiei, Y. \& Komari, T. Agrobacterium-mediated transformation of maize. Nat. Protoc. 2, 1614-1621 (2007).

12)Nishimura, A., Aichi, I. \& Matsuoka, M. A protocol for Agrobacterium-mediated transformation in rice. Nat. Protoc. 1, 2796-2802 (2006).

13)Zeise, K. \& von Tiedemann, A. Morphological and physiological differentiation among vegetative compatibility groups of Verticillium dahliae in relation to $V$. longisporum. J. Phytopathol. 149, 469-475 (2001).

14)Karlovsky, P. Inhibition of imidazoleglycerolphosphate dehydratase of Phytophthora parasitica by aminotriazole in situ and after cloning and expression of the respective gene (HIS3) in Escherichia coli. J. Phytopathol. 141, 121-126 (1994).

15)Utermark, J. \& Karlovsky, P. Role of zearalenone lactonase in protection of Gliocladium roseum from fungitoxic effects of the mycotoxin zearalenone. Appl. Environ. Microbiol.73, 637-642 (2007).

16)Utermark, J. \& Karlovsky, P. Quantification of green fluorescent protein fluorescence using real-time PCR thermal cycler. BioTechniques 41, 50-54 (2006).

17)Eynck, C., Koopmann, B., Grunewaldt-Stoecker, G., Karlovsky, P. \& von Tiedemann, A. Differential interactions of Verticillium longisporum and $V$. dahliae with Brassica napus detected with molecular and histological techniques. Eur. J. Plant Pathol. 118, 259-272 (2007). 


\title{
Chapter 5: Biosensor for zearalenone
}

\section{Biosensor for mycotoxin zearalenone based on mycotoxin-sensing mycoparasite Gliocladium roseum}

*This manuscript will be submitted for publication in Nature Biotechnology

\author{
Jan Utermark and Petr Karlovsky
}

Mycotoxin zearalenone is a resorcylic lactone derivative produced by plant pathogenic Fusarium species. Specific knowledge of concentrations which actually occur in the infected tissue would facilitate the understanding of the phytotoxic effects caused by zearalenone. However, the currently used techniques for mycotoxin determination, either chromatography or ELISA, are unsuitable for in situ real time monitoring of mycotoxin biodistribution on plant-based tissues. We harness the zearalenone-sensing ability of the mycoparasitic fungus Gliocladium roseum to develop a novel kind of biosensor for zearalenone. Genetically engineered fusions of the zearalenonesensing promoter-element and reporter genes encoding Green Fluorescent Protein (GFP) and Gaussia princeps lucifease were constructed. G. roseum strains harbouring the fusion constructs act as specific and highly sensible system in a bioassay which exhibit fluorescence (GFP) or emit light (luciferase) upon exposure to zearalenone. We used the strains for real-time macroscopic imaging of zearalenone biodistribution on Fusarium infected maize tissue. Based on these imaging properties, the place of origin of native zearalenone synthesis in target tissue was discovered.

Mycotoxin zearalenone is a resorcylic lactone derivative produced by plant pathogenic Fusarium species in maize and small-grain cereals. Because of strong 
estrogenic effects exerted by zearalenone on mammals, exposure to zearalenone via contaminated food and feed poses a health risk to humans and farm animals (Zinedine et al., 2007). The metabolite is therefore regarded as a mycotoxin. Contamination of feedstuff with zearalenone during the growing season causes heavy losses in animal production (Dacasto et al., 1995; Vanyi et al., 1994). Hence, regulatory limits for zearalenone in food and feed commodities have been established in most countries (FAO, 2004). The legal requirements and the growing awareness of the risk of mycotoxin contamination in grain-processing industry have increased the demand for fast, cost-effective methods for zearalenone detection and quantification suitable for a high number of samples.

A standard instrumental method for zearalenone determination is high-performance liquid chromatography (HPLC) with spectrophotometric or mass spectrometric detection after cleanup of samples by solid-phase extraction or on an immunoaffinity column. Alternatively, enzyme-linked immunoassay is used when the demands on precision and reliability are relaxed. Neither method is suitable for in-situ detection of zearalenone. Furthermore, the costs of both techniques are prohibitive for large-scale analysis such as screening of microbial cultures for zearalenone degradation. In the last decade, bioassays for zearalenone have been developed with the goal of providing a low cost, high throughput alternative to established methods. All bioassays available so far rely on the high affinity of mammalian estrogen receptors for zearalenone. Cloned human androgen receptors, alpha- and beta-estrogen receptors were used in yeast-based bioassays with green fluorescent protein and luciferase reporters (Beck et al., 2005; Bovee et al., 2006; Mitterbauer et al., 2003; Leskinen et al., 2005). Because mammalian estrogen receptors primarily respond to steroidal estrogens, zearalenone bioassays based on these receptors cannot be used for the analysis of samples containing steroids, for example to check beef imports for contamination with the zearalenone-derived growth promotant zearanol (trade name Ralgro $^{\odot}$ ) which is banned in the European Union. Furthermore, mammalian estrogen receptors also respond to a number of phytoestrogens (e.g. coumestrol, daidzein, formononetin, biochanin A and genistein; Beck et al., 2005) which limits the application of estrogen receptor-based biosensors on samples of plant origin. Furthermore, 
xenoestrogens binding to estrogen receptors (e.g. 4-nonylphenol and dichlorodiphenyldichloroethylene (DDE); Luo et al., 2005; Chedrese and Feyles, 2001) are widespread environmental pollutants.

Mycoparasite Gliocladium roseum produces a lactonase which hydrolyses zearalenone (Sharkawy \& Abu-Hajj, 1987) and protects the fungus from the fungitoxic effect of the mycotoxin (Utermark and Karlovsky, 2007). The gene zes2 encoding zearalenone lactonase has been cloned (Crane et al., 2002, patent application 02/ 076205; P. Karlovsky et al, U.S. patent application 20030073239; Takahashi-Ando et al., 2002; Kakeya et al., 2002) and expressed in different crops to reduce the level of zearalenone in infected grain (Igawa et al., 2007; Higa et al., 2003). The inducibility of zes2 in $G$. roseum by zearalenone and the undetectably low basal activity of the enzyme in the absence of an inducer (Woerfel, G. \& P.K. Hydrolyse von Zearalenon durch Gliocladium roseum, p. 189-192. In J. Wolff and T. Betsche (ed.), 20 $0^{\text {th }}$ Mycotoxin Workshop. Gesellschaft für Mykotoxinforschung, Detmold, Germany (1998)) inspired us to exploit the zearalenone-sensing ability of G. roseum as a basis for a novel kind of biosensors for mycotoxins. 

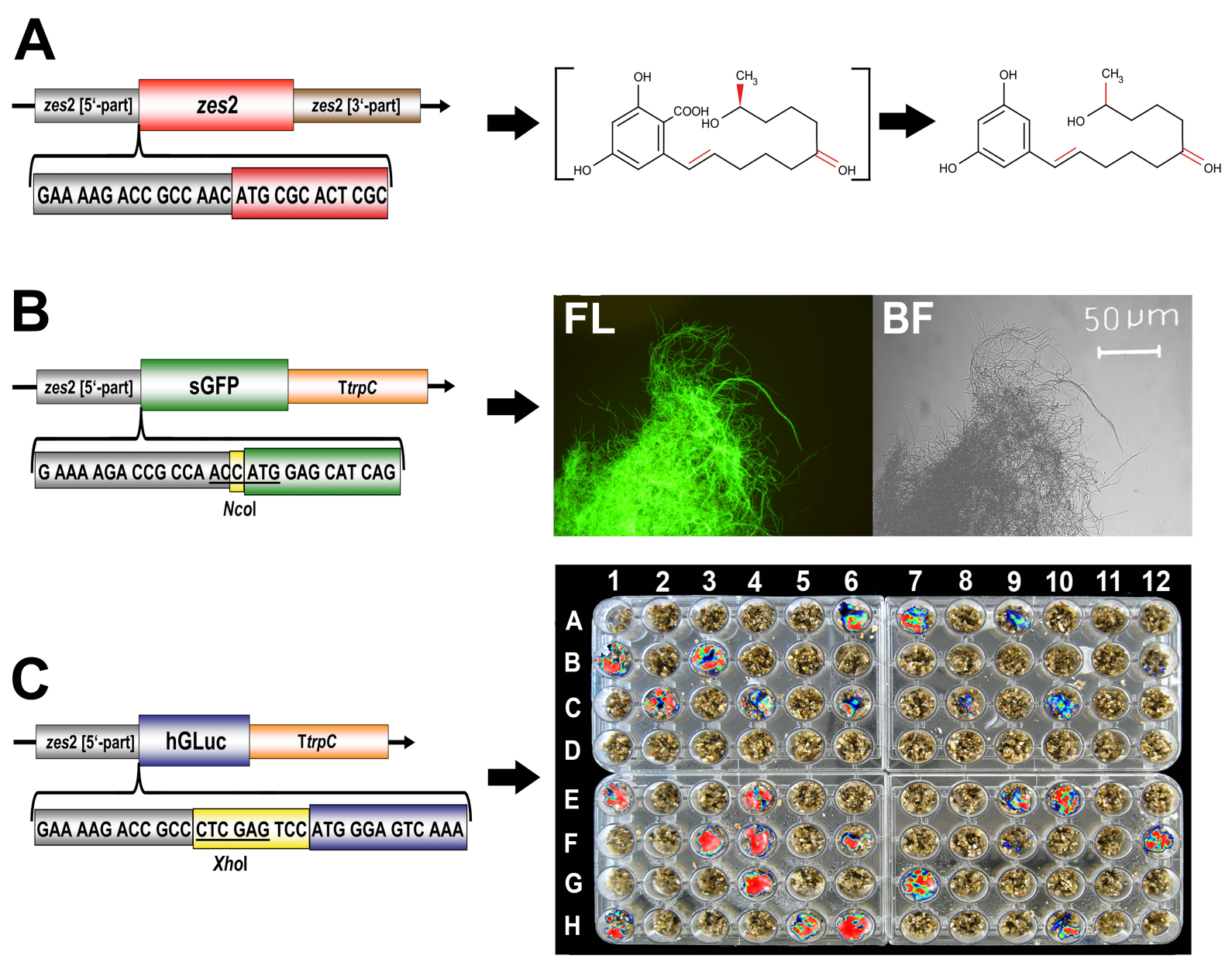

Figure 1. Effect of zearalenone-sensing ability of G. roseum.

(A) Left: Native locus of zes2 in G. roseum wild type. The coding region of zes2 (highlighted in red) is flanked by zes2-upstream region (highlighted in grey) and zes2 downstream region (highlighted in brown).

Right: Pathway of the detoxification of zearalenone. Structures of the cleavage product (1-(3,5-dihydroxyphenyl)-10'-hydroxy-1'-undecen-6'-one is indicated. A putative unstable intermediate is shown in square brackets.

(B) Left: Orientation of the GFP-zes2 fusion locus in G. roseum. The zes2-GFP locus consists of the GFP gene fused to the zes2 upstream region. The surroundings of the GFP start codon were modified by insertion of one nucleotide in order to create an Ncol site (highlighted in yellow) to place GFP coding region (highlighted in green) under the control of the zes2 upstream region (highlighted in grey) and followed by a termination region from trpC gene (TtrpC, highlighted in orange).

Right: Epifluorescence micrographs (BL, bright field; FL, fluorescence) of zear- 
alenone induced GFP expression of G. roseum. $10^{6}$ spores of the zes2-GFP fusion strain grown in $15 \mathrm{ml} \mathrm{GM7-medium} \mathrm{containing} 1 \mu \mathrm{g}$ zearalenone/ml for 3 days at $24^{\circ} \mathrm{C}$.

(C) Left:Orientation of the hGLuc-zes2 fusion locus in G. roseum. The zes2 upstream region (highlighted in grey) was modified by the insertion of ten nucleotides (highlighted in yellow) in order to create an Xhol site connecting hGLuc coding region (highlighted in purple) and zes2 upstream region (highlighted in grey). Gene fusion was terminated by the $3^{\prime}$ sequence of the $A$. nidulans trpC gene (TtrpC, highlighted in orange).

Right: Bioluminescence response of zearalenone-sensing G. roseum. Different Fusarium species (supplementary Fig. 1) were cultivated on Hidy-Medium at $24^{\circ}$ in order to produce zearalenone. After 28 days $10^{6}$ spores of the zes2-hGLuc fusion strain were added to each well. Imaging was done after 2 days incubation following treatment with $50 \mu \mathrm{l}$ of $50 \mu \mathrm{M}$ coelenterazine per well.

Translational fusion of zes2 with green fluorescent protein (GFP) was used for the first biosensor. The gene replacement cassette consisted of $0.5 \mathrm{~kb}$ of the upstream area of zes2 fused to the coding sequence of GFP at the start codon, hygromycin B resistance gene and about $1 \mathrm{~kb}$ of coding sequence and downstream regions of zes2. Kozak consensus sequence for eukaryotes (Kozak, 1984) was used to engineer the surroundings of the start codon in order to improve the efficiency of translation. Gene replacement was conducted by Agrocacterium tumefaciens-mediated genetic transformation of G. roseum. Eleven hygromycin B-resistant colonies were selected and checked by PCR for the presence of the coding sequence for GFP. Southern blot analyses of Hindlll digested genomic DNA (data not shown) showed that all 11 transformants contained true gene replacements by a double recombination in the zes2 locus. We hypothesized that inactivation of zes2 by gene replacement would generate a more sensitive bioassay strain as compared to an ectopic insertion.

One strain with zes2-GFP fusion (TF-20) was selected for further analysis. Fungal hyphae emitted green fluorescence in the presence of zearalenone while no fluores- 
cence was detectable in the absence of zearalenone (Fig. 1-B). The response of the strain to zearalenone was investigated by measuring the fluorescence of GFP after incubation of germinating spores of the strain with zearalenone at concentrations of $0.05 \mu \mathrm{g} / \mathrm{ml}$ to $2.0 \mu \mathrm{g} / \mathrm{ml}$ (Fig. 2-A). The fluorescence increased with zearalenone concentration in a dose dependent manner, the minimal inducing concentration being $100 \mathrm{pg} / \mathrm{ml}$. The optimal incubation time for a high sensitivity detection were $42 \mathrm{~h}$, but zearalenone at a concentration of $2 \mu \mathrm{g} / \mathrm{ml}$ induced strong fluorescence already after 24 h (Fig2-B).
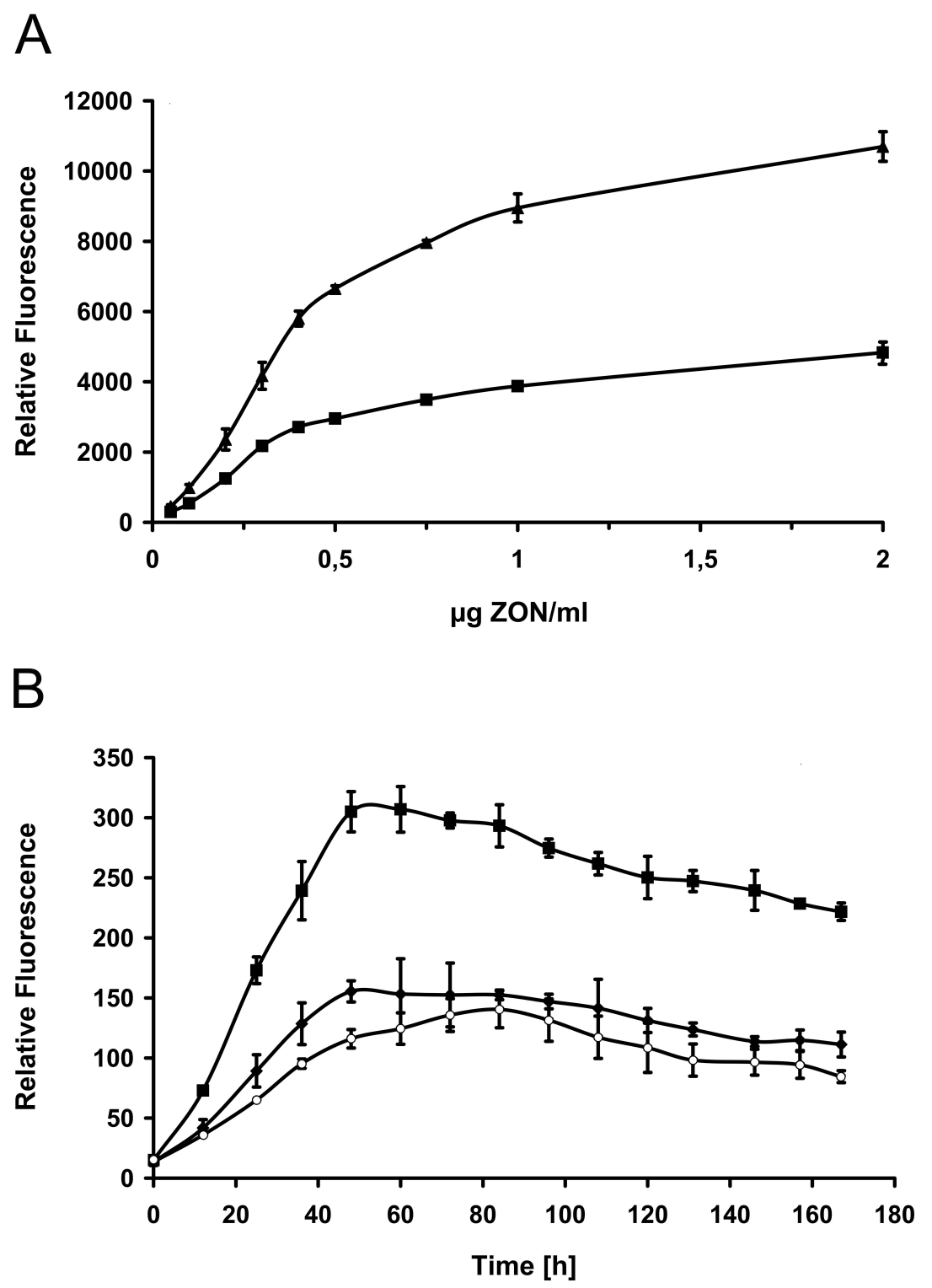

Figure 2. Sensitivity of G. roseum zes2-GFP fusion strains to zearalenone. 
$10^{6}$ spores of the GFP fusion strain were cultivated at $24^{\circ} \mathrm{C}$ in $100 \mu \mathrm{GM} 7$-medium and zearalenone was added to the culture after 3 days.

(A) Fluorescence response of the fusion strains was measured after $24 \mathrm{~h} \mathrm{( \Xi )}$ and 48 $\mathrm{h}(\boldsymbol{\Delta})$ treatment with increasing zearalenone concentrations.

(B) Fluorescence emission of the fusion strain after exposure to zearalenone at 0.5 $\mu \mathrm{g} / \mathrm{ml}(\circ), 1 \mu \mathrm{g} / \mathrm{ml}(\diamond)$ and $2 \mu \mathrm{g} / \mathrm{ml}(\mathbf{\square})$. The response was measured every $12 \mathrm{~h}$ up to $172 \mathrm{~h}$.

Results are presented as average values \pm from five experiments.

The specificity of the response of strain TF-20 was assessed by incubation with zearalenone derivatives, a steroidal estrogen and selected isoflaonoids (Fig. 3-A). The ranking of these substances by their zes2-GFP inducing activity was: a-zearalanol > zearalanone $>$ zearalenone $>\alpha$-zearalenol $>\beta$-zearalanol. No flurorescence after exposure to $\beta$-zearalenol was observed, confirming previously reported lack of inducing activity of beta-zearalenone regarding zearalenone lactonase activity (Crane et al., 2002, patent application 02/ 076205; P. Karlovsky et al, U.S. patent application 20030073239; Woerfel, G. \& P.K. Hydrolyse von Zearalenon durch Gliocladium roseum, p. 189-192. In J. Wolff and T. Betsche (ed.), 20 ${ }^{\text {th }}$ Mycotoxin Workshop. Gesellschaft für Mykotoxinforschung, Detmold, Germany (1998)). As both zearalenone and $\alpha$-zearalenone induce zes 2 but $\beta$-zearalenol does not, the resorcylic lactone-sensing system of $G$. roseum strictly distinguishes among configurations at carbon atom No. 6'. This is startling because C6' is part of a flexible macrocyclic ring. While $\alpha$ - and $\beta$-zearalenols, as well as other known naturally occurring derivatives of zearalenone, can assume a large number of conformations, we speculate that a putative receptor which triggers zes2 expression immobilizes resorcylic lactones in its surface before a zes2-controlling signal is generated.

The discrimination against certain stereochemistry at carbon 6' by zes2 induction is puzzling. Although $\beta$-zearalenone is less fungitoxic than zearalenone and $\alpha$-zearalenol (Utermark and Karlovsky, 2007), it appears unlikely that the selection pressure caused by metabolic costs of zes2 expression can account for the discrimination against beta-zearalenone. The hypothesis appears even less plausible considering 
that $\beta$-zearalenone occurs in nature together with zearalenone, from which it is generated by reduction (Palyusik et al., 1980; Steele et al., 1976). The lack of understanding of the mechanism and biological meaning of the stereospecificity of the regulation of zes2, however, does not hamper the exploitation of the system in a bioassay.

The capability of the GFP strains to recognize other chemicals was assessed by testing the effect of four fungal metabolites (radicicol, fumonisin $\mathrm{BI}$, fusaric acid and gliotoxin) as well as two substances with estrogenic activity (genistein and $\beta$ - estradiol) on induced reporter gene activation. Fig. 3-B shows that both compound classes do not interfere with the zes2 promoter. All tested chemicals were unable to induce GFP response in the transgenic strain demonstrating the specificity of the bioassay and the successful construction of a transcriptional fusion of the zes2 promoter region to a reporter gene encoding GFP in G. roseum. 
A

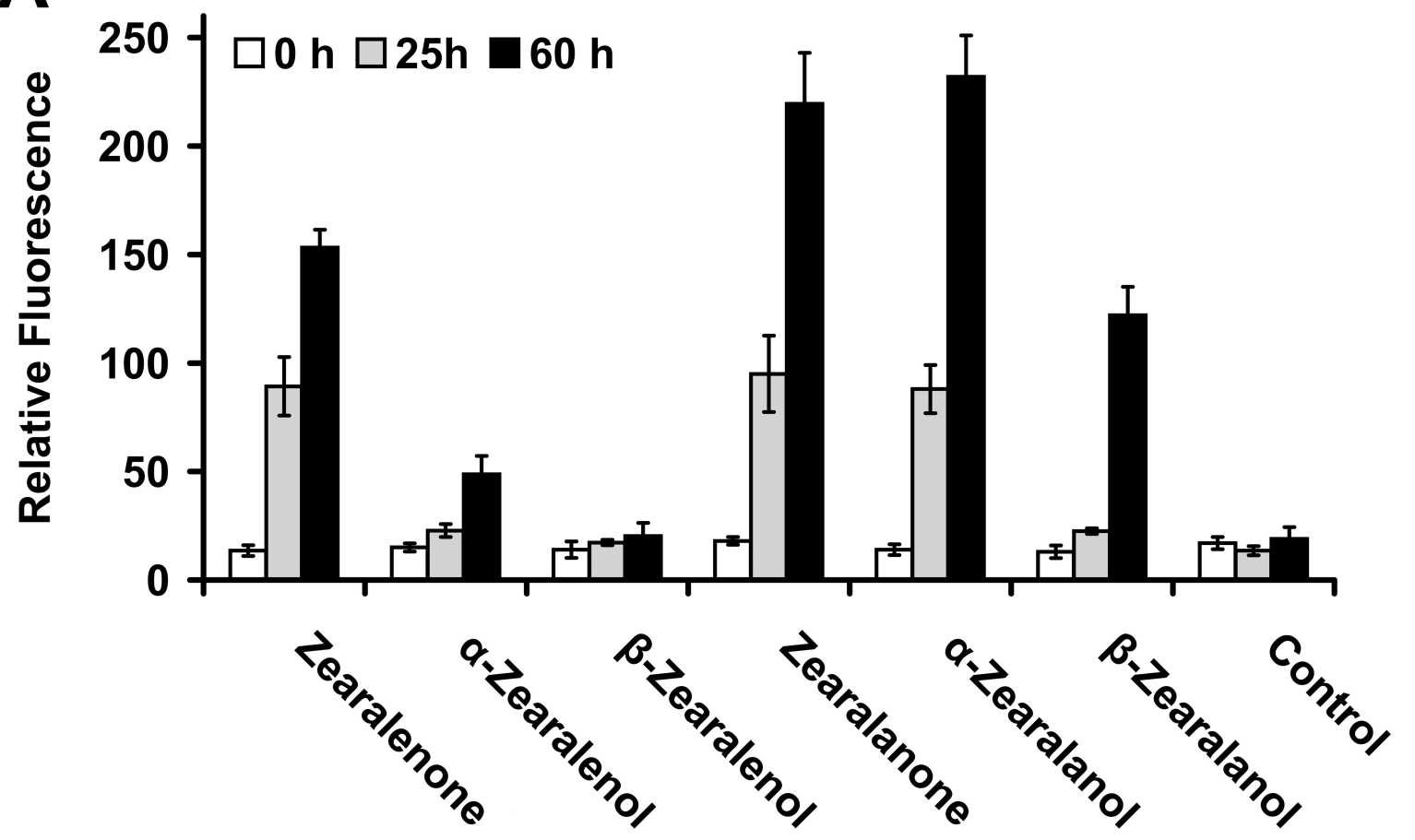<smiles>C[C@H](CCCC(=O)CCC/C=C/c1cc(O)cc(O)c1C(=O)O[Na])OC(=O)[O-]</smiles><smiles>C[C@H](CCCCC(=O)O)OC(=O)c1c(O)cc(O)cc1CCCCCC(=O)O</smiles><smiles>C[C@H](CCC[C@@H](O)CCC/C=C/c1cc(O)cc(O)c1C(=O)O[Na])OC(=O)[O-]</smiles><smiles>C[C@H](CCCC[C@H](O)CCCCc1cc(O)cc(O)c1C(=O)O)OC(=O)O</smiles><smiles>C[C@@H](CCCC[C@H](O)CCC/C=C/c1cc(O)cc(O)c1C(=O)O)O[C@@H](C)CCCC(C)(C)C</smiles><smiles>C[C@@H](CCCC[C@H](O)CCCCc1cc(O)cc(O)c1C(=O)O[C@H](C)C(=O)O)OC(=O)O</smiles> 
B

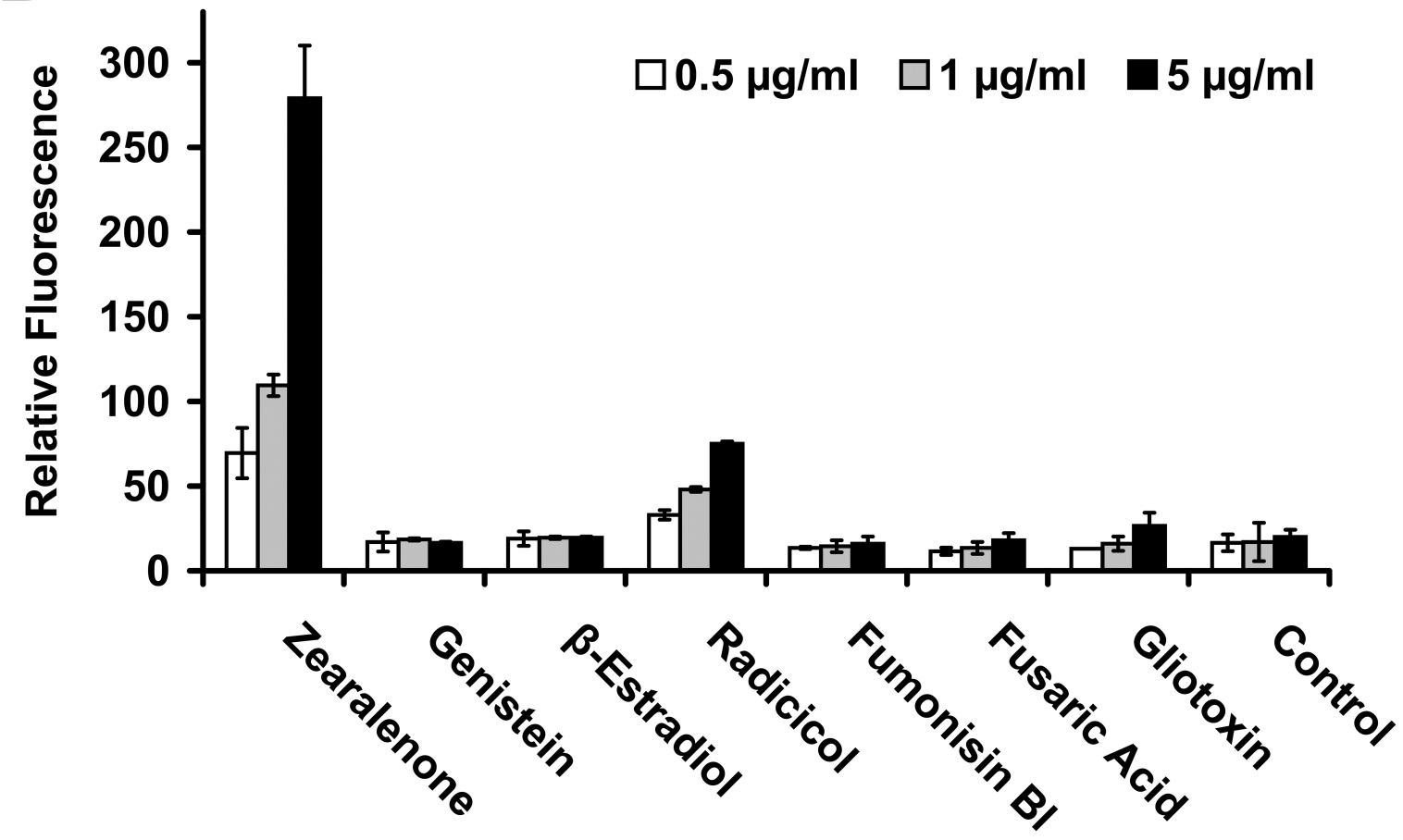

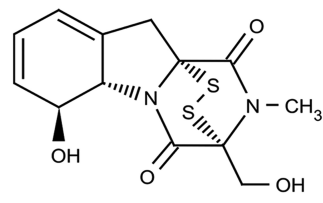

Gliotoxin<smiles>CCCCc1ccc(C(=O)O)nc1</smiles>

Fusaric Acid<smiles>O=c1c(-c2ccc(O)cc2)coc2cc(O)cc(O)c12</smiles>

Genistein

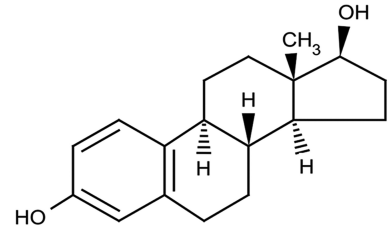

$\beta$-Estradiol<smiles>CC1CC2OC(=O)c3c(O)cc(O)cc3CC(=O)/C=C\C=C/[C@@H](O1)O2</smiles>

Radicicol<smiles>CCCC[C@H](C)[C@H](OC(=O)C[C@H](CC(=O)O)C(=O)O)[C@@H](C[C@@H](C)C[C@@H](O)CCCC[C@H](O)C[C@H](O)[C@H](C)N)OC(=O)C[C@@H](CC(=O)O)C(=O)O</smiles> 


\section{Figure 3. Specificity of the zes2 regulation in G. roseum.}

$10^{6}$ spores of G. roseum with GFP fusion at zes2 locus were cultivated in $100 \mu \mathrm{l}$ GM7-medium at $24^{\circ} \mathrm{C}$. After 3 days, the analytes were added to the culture.

(A) Effects of $1 \mu \mathrm{g} / \mathrm{ml}$ zearalenone and its derivatives $\alpha$ and $\beta$ zearalenol, $\alpha$ and $\beta$ zearalanol and zearalanone on fluorescence response after $25 \mathrm{~h}$ and $60 \mathrm{~h}$ exposure.

(B) Effect of increasing concentrations of the fungal metabolites radicicol, fumonisin $\mathrm{BI}$, fusaric acid and gliotoxin and the estrogenic substances genistein and $\beta$ - estradiol on fluorescence signals. The effects were recorded after $30 \mathrm{~h}$ incubation.

Columns represent averages of 5 measurements with error bars of \pm standard deviation.

Bioluminescent imaging which is based on the endogenous production of light by the expression of the enzyme luciferase (LUC) was used to design a second zearalenone-sensing biosensor. The power of bioluminescent tagging of microorganisms was demonstrated by varrious nondestructive, in situ investigations (Chen and Griffiths, 1996; Baker et al., 1992; Contag et al., 1997). In order to sense zearalenone in Fusarium infected plant tissue the start codon of the humanized version of the Gaussia princeps luciferase gene (hGLuc) was connected to the cloned upstream area of zes2 $(0.5 \mathrm{~kb})$. Its surroundings were also engineered by menas of Kozak consensus sequence for eukaryotes (Kozak, 1984). The gene replacement cassette also contains the hygromycin $B$ resistance gene and about $1 \mathrm{~kb}$ of coding sequence and downstream regions of zes2. Targeted gene replacement in G. roseum was mediated by $A$. tumefaciens transformation. Five hygromycin B-resistant colonies were subcultured and screening for luciferase coding sequence by PCR amplification and Southern blot analyses of Hindlll digested genomic DNA. All five transformants evidenced that the zes2-hGLuc mutated allele was introduced into the G. roseum chromosome by homologous recombination. One strain was selected and designated TF-2 for further investigations.

Hidy-medium, a synthetic semi solid support, artificially inoculated with Fusarium spp. was used to test the response of the strain TF-2 to zearalenone. The assay was simplified by scaling it down to a 12-well format and zearalenone producing and non- 
producing Fusarium spp. (supplementary Fig. 1) were cultivated. After 28 days, spores of the zearalenone-sensing strain TF-2 were plated into each well and bioluminescence response was measured after 3 days by applying a $50 \mu \mathrm{M}$ coelentrazine substrate dose. Figure 1-C shows that only zearalenone producing Fusarium strains were able to induce LUC response in the transgenic strain. These results demonstrated the feasibility of the bioassay to sense zearalenone under environmental conditions without a loss of activity due to matrix effects.

Since, the LUC biosensor grown on artificial media was easily able to identify zearalenone, we performed an experiment to determine distribution of zearalenone in complex environments like plant tissues. The biodistribution of zearalenone in plant tissue was investigated by using a maize cob naturally infected with Fusarium graminearum. The maize cob was cleaved lengthwise in two halves and sterilized in a chloric gas atmosphere for $24 \mathrm{~h}$. After efficient degassing, spores of the zearalenone-sensing transformant TF-2 were plated on the maize surface (Fig. 4). Three days after inoculation, G. roseum strain TF-2 expressing the hGLuc could be readily visualized macroscopically on maize cob surface tissue (Fig. 4). Emitted photons were detected immediately after addition of $50 \mu \mathrm{M}$ coelenterazine over the entire inoculated tissue surface. After a 2 min integration of the signal, it became apparent that there were different signal intensities in different areas of the tissue surface. The differences appeared to be associated with different zearalenone concentrations, which suggested its differential distribution on the tissue surface.

To verify the results of the sensor, the maize ear was rasterised into cuboids and extracts of each cuboid were prepared and analysed for zearalenone by conventional reversed-phase HPLC-MS. The response of strain TF-2 occurring on maize tissue cuboids was compared to the zearalenone concentrations obtained by HPLC-MS. The results showed that zearalenone induced a bioluminescent response in the transgenic strain of a minimal concentration of $50 \mathrm{mg} / \mathrm{kg}$ maize tissue. Figure 4 shows that the zearalenone content was concentrated in the rachis of the maize cob which was clearly visualized by the LUC response in the transgenic strain and confirmed by HPLC-analysis.

To conclude, a novel fungal biosensor has been developed which signals zear- 
alenone colorimetrically. Our findings demonstrate that real-time macroscopic imaging of zearalenone biodistribution on plant tissue surfaces is possible when the specific and highly sensible zearalenone-sensing ability of $G$. roseum is used to generate a translational fusion of zes2 with hGLuc. Methodologically, some experimental simplifications can be introduced for the practical use of this genetic system which offers innovative opportunities. The isolation of the zearalenone receptor elements in G. roseum and its heterologous expression in planta would pioneer the development of a new, improved and highly specific biosensor for zearalenone.

Since mycotoxin research advanced in the last decade due to the progress in instrumental analytical chemistry and immunochemistry, a plethora of data on the content of numerous mycotoxins in plants have been provided. Homogenization of the plant tissue is the first step of each mycotoxin determination protocol. Due to the mixture of mycotoxin contaminated and uncontaminated tissue we know very little about their biodistribution in the infected tissue. The interpretation of phytotoxicity data obtained by the treatment of whole plants, plant organs and cell cultures with defined concentrations of mycotoxins, however, requires the knowledge of concentrations which actually occur in the infected tissue and which might be orders of magnitude higher than the average concentrations determined in plant homogenates and extracts. To close this gap, local concentration of mycotoxins in plant tissue need to be determined. The use of biosenors provides a promising strategy to monitor the process of zearalenone production and biodistribution in situ. 


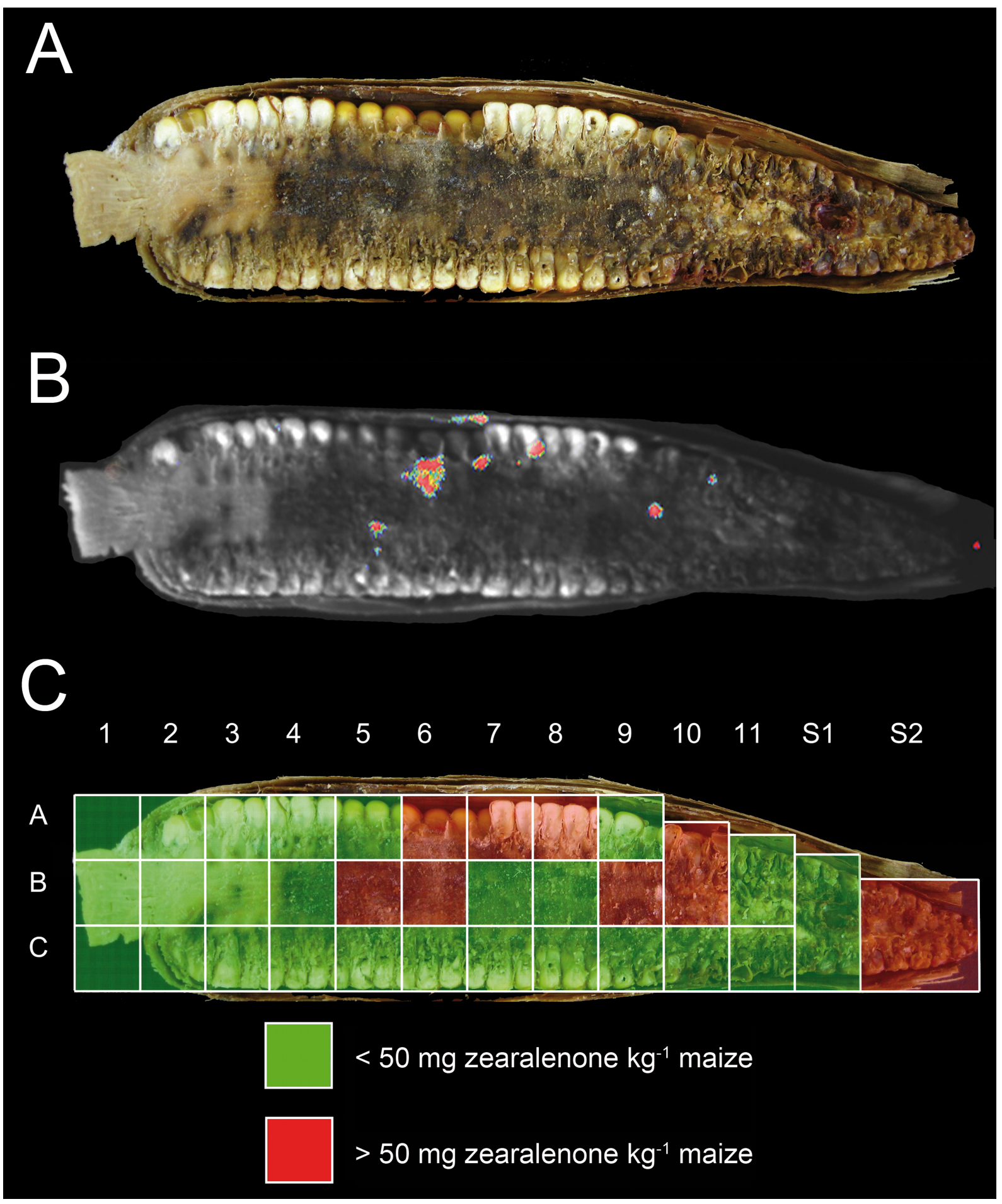

Figure 4. In situ detection of zearalenone distribution in maize ear infected with Fusarium graminearum.

(A) A maize cob naturally infected with Fusarium graminearum was selected in a field in Einbeck (Germany) in 2007 and cut in halves longitudinally. 
(B) $5 \times 10^{7}$ spores of G. roseum with zes2-hGLuc were plated on the maize tissue surface and incubated in a humid chamber for 3 days at $24^{\circ} \mathrm{C}$. Bioluminescence was immediately monitored after spraying the sample with $50 \mu \mathrm{M}$ coelenterazine using a CCD camera.

(C) The maize ear was deep-frozen at $-70^{\circ} \mathrm{C}$, cuboids of $15 \times 15 \times 3 \mathrm{~mm}$ were dissected with a scalpel and zearalenone concentration was determined by HPLCMS. Areas containing more than $50 \mathrm{mg}$ zearalenone $/ \mathrm{kg}$ are marked red.

\section{Methods}

\section{Microbial strains and culture}

G. roseum DSM 62726 was used as the genetically engineered mycotoxin sensor. Mycelium from the fungus was cultured on GM7-medium (Karlovsky, 1994). Conidiospores were prepared from Petri dish cultures upon fungal cultivation for $20 \mathrm{~d}$ at $24{ }^{\circ} \mathrm{C}$ (Utermark and Karlovsky, 2008). Fusarium spp. were in-house strains of the culture collection of Mycotoxin and Molecular Phytopathology unit, Goettingen University (listed in supplementary Fig. 1). For zearalenone production these strains were plated onto modified Hidy medium (Richardson et al., 1984) in a 12 well tissue culture plate at $24^{\circ} \mathrm{C}$ for 28 days.

\section{Construction of in situ display vectors for zearalenone}

The in situ display vectors were constructed on the backbone of pZG05 (Utermark and Karlovsky, 2007). For the construction of pZG07-sGFP, the 541 bp upstreamregulatory sequence of zes2 (GenBank accession no. AB076037) were amplified with primers OL505 (5'-AAGACAGAGCTCAACCAACCAGCCAGAAGTTAGA-3') and OL513 (5'-TACATAACCATGGTTGGCGGTCTTTTCGTGGGAG-3'), containing recognition sequences for $\mathrm{SaCl}$ and $\mathrm{Ncol}$, respectively. Amplification was performed by PCR with 35 cycles of $96^{\circ} \mathrm{C}$ for $30 \mathrm{~s}, 61^{\circ} \mathrm{C}$ for $30 \mathrm{~s}$, and $72^{\circ} \mathrm{C}$ for $50 \mathrm{~s}$ with a final extension at $72^{\circ} \mathrm{C}$ for $5 \mathrm{~min}$.

The fusion between zes2 upstream sequence and GFP was generated by cloning the zes2-upstream PCR fragment into the plasmid pBS::gpd::SGFP (Eynck et al., 2007) treated with Sacl and Ncol to replace the gpdA-promoter. This plasmid contains the 
derivative SGFP, which has a serine to threonine substitution at position 65 (S65T, Heim et al., 1995) in order to increase brightness.

The hygromycin B resistance cassette containing the hygromycin phosphotransferase gene from Escherichia coli ( $h p h)$ under the control of oliC promoter from Aspergillus nidulans and tubA terminator from Botrytis cinerea was isolated as a 2.6 $\mathrm{kb}$ Xbal-Hindlll fragment from the plasmid pLOB1 (GenBank accession No. AJ439603) and cloned into the corresponding Xbal/Hindlll sites of pUC57 (GenBank accession No. Y14837). The resulting vector was designated pUC57::hph.

The zes2-upstream-GFP fusion construct was removed from pBS::zes2 upstreamGFP with Sacl and Eco32l as a $1.6 \mathrm{~kb}$ fragment and connected to the hygromycin B resistance cassette in Sacl and blunted Xbal digested pUC57::hph to produce pUC57::zes2-upstream::GFP::hph. The $4.2 \mathrm{~kb}$ Sacl/Hindlll fragment of these plasmid was cloned between the corresponding Sacl and Acc65l (blunt-ended)-sites of the binary vector $\mathrm{pZG05}$ to yield $\mathrm{pZG07-GFP.}$

The strategy to generate the in situ zearalenone monitoring vector pZG07-LUC based on the humanized version of luciferase (hGLuc, 185 aa, $19.9 \mathrm{kDa}$ ) from the marine copepod Gaussia princeps.

The plasmid pK19 (Pridmore, 1987) which contains the hygromycin B resistance cassette consists of 3 modules (hygromycin phosphotransferase gene from E. coli, under the control of both the gpdA promoter and the trpC terminator from A. nidulans) was treated with Sacl and BamHI to replace the hygromycin B gene and the gpdA promoter. A $540 \mathrm{bp}$ fragment corresponding to zes2-upstream region was amplified form genomic DNA of G. roseum (Acc. No. AB076037) by PCR with primers OL505 (5'-AAGACAGAGCTCAACCAACCAGCCAGAAGTTAGA-3') and OL522 (5'TACATAACTCGAGGCGGTCTTTTCGTGGGA-3'), that possessed a Sacl/Xhol site, respectively. Simultaneously, the 560 bp coding sequence of the hGLuc gene was amplified from the plasmid pGLuc-Basic (Tannous et al., 2005) using primers OL520 (5'-TACATACTCGAGACCATGgGAGTCAAAGTTCTGTTTGC-3') and OL521 (5'AAGAGAAGGATCCGTGTTAGTCACCACCGGCCCCCTTGAT-3') containing recognition sequences for $\mathrm{Xhol}$ and $\mathrm{BamHI}$, respectively.

Gene hGLuc was joined in a tri-fragment ligation with the Sacl/Xhol-digested PCR 
product of the amplified zes2-upstream sequence and Sacl/BamHI-digested backbone of pK19 including trpC terminator to create the hGLuc expression cassette. This cassette was removed from the plasmid pK19 by digesting with Sacl and Xbal. The resulting $1.8 \mathrm{~kb}$ fragment was inserted into the corresponding Sacl/Xbal sites of pUC57::hph.

The hGLuc expression and hygromycin B resistance cassette was isolated from pUC57 by digestion with Sacl and Hindlll. This $4.5 \mathrm{~kb}$ fragment was cloned into the remaining backbone binary vector pZG05 digested with Sacl and Acc65I (bluntended) to generate the final construct pZG07-LUC.

\section{Generation of a transgenic G. roseum strain for real-time monitoring of zes2 gene expression}

The fusion constructs pZG07-sGFP and pZG07-LUC were introduced into the Agrobacterium tumefaciens strain AGL1 by electroporation (Mattanovich, 1989). Recipient strain G. roseum was transformed by $A$. tumefaciens as described previously (Utermark and Karlovsky, 2008). The putative hygromycin-resistant transformants were picked, subcultured onto GM7- medium containing $250 \mu \mathrm{g} / \mathrm{ml}$ hygromycin $\mathrm{B}$ and $200 \mu \mathrm{M}$ cefotaxim to prevent the growth of $A$. tumefaciens. The colonies were subcultured on hygromycin B-containing medium at least eight times.

\section{Analysis targeted replacement of zes2 in chromosomal DNA of G. roseum}

PCR was used to amplify the particular reporter gene fragments GFP or hGLuc in the genomic DNAs of putatively transformed strains to prove the integration into the fungal genome. Southern hybridization was used to evaluate zes2 locus in the genome of $G$. roseum as previously described (Utermark and Karlovsky, 2007). Total DNA was extracted from mycelium according to Brandfaß and Karlovsky (2006). The probe, a digoxigenin-labeled 820 bp zes2-fragment was prepared by using dUTP conjugated with digoxigenin (Roche Diagnostics $\mathrm{GmbH}$, Penzberg, Germany) and the primers OL500 (5'-TACATACATATGCGCATTCGCAGCACAA-3') and OL501 (5'AAGAGAAAGATCTTCAAAGATACTTCTGCGTA-3'). Nucleic acids were transferred to a Hybond $\mathrm{N}^{+}$nylon membrane (Amersham Biosciences Europe $\mathrm{GmbH}$, Freiburg, Germany) using a VacuGene XL (Pharmacia, Freiburg, Germany) blotting apparatus. 
Hybridizations were carried out using the DIG Easy Hyb (Roche Diagnostics GmbH, Penzberg, Germany) hybridization solution at $50^{\circ} \mathrm{C}$. Standard hybridization and washing techniques recommended by the manufacturer were used.

\section{Fluorescence measurement of zearalenone lactonase synthesis}

One hundred microliter aliquots of $G$. roseum TF-20 conidiospores $\left(1 \times 10^{7} / \mathrm{ml}\right)$ in GM7-medium were germinated in a 96 well PCR plate (Sarstedt $\mathrm{GmbH}$, Nümbrecht, Germany). After 3 days of cultivation at $24^{\circ} \mathrm{C}$, the $\mathrm{GM} 7$-medium was replaced by fresh GM7-medium amended with zearalenone, $\alpha$-and $\beta$-zearalenol, $\alpha$-and $\beta$-zearalanol, zearalanone, radicicol, fumonisin $\mathrm{BI}$, fusaric acid, gliotoxin, genistein and $\beta$ estradiol by adding appropriate amounts of stock solutions in $5 \%(\mathrm{v} / \mathrm{v})$ methanol. Exposure was performed for up to 172 hours in various concentrations. Fluorescence response was assayed directly in a real-time thermal cycler (Utermark and Karlovsky, 2006).

\section{In situ monitoring responses of zearalenone}

A naturally infected maize cob was cleaved into halves longitudinally and sterilized in a chlorgas atmosphere for $24 \mathrm{~h}$. After efficient degassing, the G. roseum transformant with zes2-hGLuc fusion (TF-2) was plated on the surface of the maize tissue in a concentration of $5 \times 10^{7}$ spores/ml suspended in $5 \mathrm{ml} \mathrm{GM7-medium.} \mathrm{After} \mathrm{incubation}$ for 4 days at $24^{\circ} \mathrm{C}, 50 \mu \mathrm{M}$ coelenterazine (Sigma-Aldrich, Steinheim, Germany) in 3 $\mathrm{ml}$ assay-buffer (Dyer et al., 2000) were sprayed on the surface of the maize tissue. Photon counts were acquired for 2 min using the CCD camera system (Hamamatsu Photonics, Herrsching, Germany). Conventional white-light surface images were obtained immediately before each photon counting session to provide a true-to-life outline of the cob. Following data acquisition, postprocessing and visualization were performed using WASABI software (Hamamatsu). Images were displayed as a pseudo-colour photon count image, superimposed on a gray-scale, white-light image, allowing assessment of both bioluminescence areas and its biological source. Regions of interest were defined using an automatic intensity contour procedure to identify bioluminescent signals with intensities significantly greater than background. 


\section{Extraction of zearalenone and mass spectrometry}

Maize tissue was frozen at $-70^{\circ} \mathrm{C}$. After $5 \mathrm{~h}$, near-surface tissue was dissected into cuboids of $15 \times 15 \times 3 \mathrm{~mm}$ with a scalpel. Each cuboid-tissue was milled, homogenized, extracted in $2 \mathrm{ml}$ of acetonitrile:water $(84: 16(\mathrm{v} / \mathrm{v}))$ and shaken vigorously overnight in a wrist-action shaker. The supernatant was evaporated to dryness in a speed vacuum chamber. Samples were dissolved in a mixture of $55 \%$ methanol-45\% water-5\% acetonitrile and defatted with $500 \mu \mathrm{l}$ of hexane. After phase separation, the lower phase was sterile filtered into HPLC vials. Reverse-phase high-performance liquid chromatography (HPLC) with mass spectrometric detectors was used to identify zearalenone as described previously (Utermark and Karlovsky, 2007).

\section{Supplementary information}

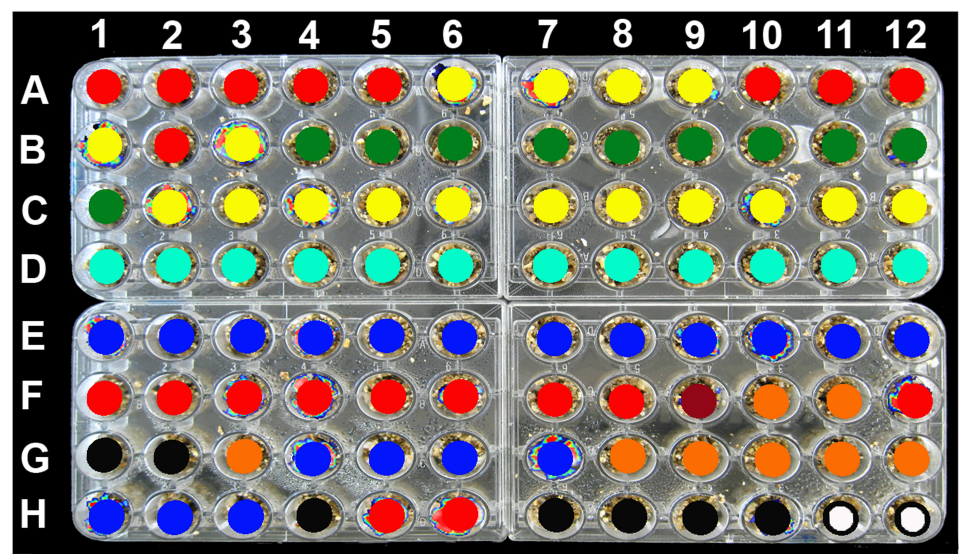

\begin{tabular}{l|l} 
F. culmorum & F. nygamai \\
F. equiseti & F. oxysporum \\
F. graminearum & F. proliferatum \\
F. moniliforme & F. subglutinans
\end{tabular}

Control without Fusarium spp.

Supplementary figure 1: Fusarium spp. were cultivated on Hidy-Medium in order to produce zearalenone (Fig. 1). Each colour-coded well presents one house-hold isolate of the indicated species. 


\section{References}

1. Baker, J.M., Griffiths, M.W. \& Collins-Thompson, D.L. Bacterial bioluminescence: applications in food microbiology. J. Food Prot. 55, 62-70 (1992).

2. Beck, V., Pfitscher, A. \& Jungbauer, A. GFP-reporter for a high-throughput assay to monitor estrogenic compounds. J. Biochem. Biophys. Methods 64, 19-37 (2005).

3. Bovee, T.F., Helsdingen, R.J., Rietjens, I.M., Keijer, J. \& Hoogenboom, R.L. Rapid yeast estrogen bioassays stably expressing human estrogen receptors $\alpha$ and $\beta$, and green fluorescent protein: a comparison of different compounds with both receptor types. J. Steroid Biochem. Mol. Biol. 91, 99-109 (2004).

4. Caceres, G. et al. Imaging of luciferase and GFP-transfected human tumours in nude mice. Luminescence 18, 218-223 (2003).

5. Chedrese, P.J. and Feyles, F. The diverse mechanism of action of dichlorodiphenyldichloroethylene (DDE) and methoxychlor in ovarian cells in vitro. Reprod. Toxicol. 15, 693-698 (2001).

6. Chen, J. \& Griffiths, M.W. Luminescent Salmonella strains as real time reporters of growth and recovery from sublethal injury in food. Int. J. Food Microbiol. 31, 27-43 (1996).

7. Contag, C.H. et al. Visualizing gene expression in living mammals using a bioluminescent reporter. Photochem. Photobiol. 66, 523-531 (1997).

8. Dacasto, M., Rolando, P., Nachtmann, C., Ceppa, L. \& Nebbia, C. Zearalenone mycotoxicosis in piglets suckling sows fed contaminated grain. Vet. Hum. Toxicol. 37, 359-361 (1995).

9. Dyer, B.W., Ferrer, F.A., Klinedinst, D.K. \& Rodriguez, R. A noncommercial dual luciferase enzyme assay system for reporter gene analysis. Anal. Biochem. 282, 158-161 (2000).

10.FAO. Worldwide regulations for mycotoxins in food and feed in 2003. FAO Food and Nutrition paper No. 81. Food and Agriculture Organization of the United Nations, Rome, Italy (2004).

11. Heim, R., Cubitt A.B. \& Tsien, R.Y. Improved green fluorescence. Nature 373, 663 (1995). 
12. Higa, A. et al. Expression in cereal plants of genes that inactivate Fusarium mycotoxins. Biosci. Biotechnol. Biochem. 67, 914-918 (2003).

13. Igawa, T. et al. Reduced contamination by the Fusarium mycotoxin zearalenone in maize kernels through genetic modification with a detoxification gene. Appl. Environ. Microbiol. 73,1622-1629 (2007).

14. Kakeya, H. et al. Biotransformation of the mycotoxin, zearalenone, to a non-estrogenic compound by a fungal strain of Clonostachys spp. Biosci. Biotechnol. Biochem. 66, 2723-2726 (2002).

15. Kozak, M. Point mutations close to the AUG initiator codon affect the efficiency of translation of rat preproinsulin in vivo. Nature 308, 241-246 (1984).

16. Leskinen, P., Michelini, E., Picard, D., Karp, M. \& Virta, M. Bioluminescent yeast assays for detecting estrogenic and androgenic activity in different matrices. Chemosphere 61, 259-266 (2005).

17.Luo, Q. et al. Distinct effects of 4-nonylphenol and estrogen-17 beta on expression of estrogen receptor alpha gene in smolting sockeye salmon. Comp. Biochem. Physiol. C Toxicol. Pharmacol. 140, 123-130 (2005).

18. Mitterbauer, R. et al. A sensitive and inexpensive yeast bioassay for the mycotoxin zearalenone and other compounds with estrogenic activity. Appl. Environ. Microbiol. 69, 805-811 (2003).

19.Palyusik, M., Hagler, W.M., Horváth, L. \& Mirocha, CJ. Biotransformation of zearalenone to zearalenol by Candida tropicalis. Acta Vet. Acad. Sci. Hung. 28, 159-166 (1980).

20.Pridmore. R.D. New and versatile cloning vectors with kanamycin-resistance marker. Gene 56, 309-312 (1987).

21. Richardson, K.E., Hagler, W,M.J. \& Hamilton, P.B. Method for detecting production of zearalenone, zearalenol, T-2 toxin and deoxynivalenol by Fusarium isolates. Appl. Environ. Microbiol. 47, 643-646 (1984).

22. Steele, J.A. Mirocha, C.J. \& Pathre, SV. Metabolism of zearalenone by Fusarium roseum Graminearum. J. Agric. Food Chem. 24, 89-97 (1976). 
23. Takahashi-Ando, N., Kimura, M., Kakeya, H., Osada, H. \& Yamaguchi, I. A novel lactonohydrolase responsible for the detoxification of zearalenone: enzyme purification and gene cloning. Biochem. J. 365,1-6 (2002).

24.Tannous, B.A., Kim, D.E., Fernandez, J.L., Weissleder, R. \& Breakefield, X.O. Codon-optimized Gaussia luciferase cDNA for mammalian gene expression in culture and in vivo. Mol. Ther. 11:435-443 (2005).

25. Vanyi, A., Bata, A. \& Kovacs, F. Perinatal oestrogen syndrome in swine. Acta Vet. Hung. 42, 433-446 (1994).

26. Zinedine, A., Soriano, J.M., Moltó, J.C. \& Mañes, J. Review on the toxicity, occurrence, metabolism, detoxification, regulations and intake of zearalenone: an oestrogenic mycotoxin. Food Chem. Toxicol. 45, 1-18 (2007). 


\title{
Chapter 6:
}

\section{Benchmarks}

\section{Quantification of green fluorescent protein fluorescence using real-time PCR thermal cycler}

\author{
Jan Utermark and Petr Karlovsky \\ Goettingen University, Goettingen, Germany \\ BioTechniques 41:150-154 (August 2006) \\ doi 10.2144/000112221
}

Fluorescent proteins have become a widely used transgenic marker in the last decade because they spontaneously form fluorophores without the need for other gene products, they do not require external substrates, and they enable real-time monitoring in intact organisms. The currently available fluorescent proteins belong to either one of two families: the green fluorescent protein (GFP) family, originating from the jellyfish Aequorea victoria, and the reef coral fluorescent protein (RCFP) family, originating from reef corals. These fluorescent proteins and their mutants with altered spectral characters span emission spectra from $480-620 \mathrm{~nm}$.

There are two broad groups of applications for fluorescent proteins as transgenic markers. The first group includes the labeling of whole organisms (1), the subcellular localization of cells and proteins (2), the analysis of tissue specificity of gene expression, and fluorescence-activated cell sorting. These applications require semiquantitative detection in space or time and use imaging technologies, such as macroscopic fluorescence imaging systems (3) and confocal fluorescence microscopy (4), to detect the fluorescent targets. The second group of applications consists of bioassays that require accurate quantification of fluorescence in either solution or in living cells. For example, bacteria and yeast that synthesize GFP after contact with chemicals that bind to human estrogen receptors have been developed as bioassays for environmental estrogens (5-7). Such bioassays are usually applied to a large number of samples, requiring the use of a fluorometer that can read microtite plates. Since microtiter plate fluorometers are not common equipment found in a molecular biology laboratory, we determined that real-time thermal cyclers can replace fluorometers for the quantification of fluorescent proteins.

Real-time thermal cyclers monitor the progress of PCR by measuring the fluorescence of an intercalating dye or a fluorophore attached to a DNA hybridization probe. Most thermal cyclers use heating blocks that have a standard 96-well microtiter dish format, so they also can be used as microtiter plate fluorometers-provided that the excitation and emission wavelengths of the fluorescent protein in question match the specification of the thermal cycler, and that the fluorescence reading is returned in a digital form. Thermal cyclers that have monochromatic light sources are inherently limited in their excitation wavelength. Systems with a halogen lamp for its light source are more flexible, having full control of the spectral characters possible through the choice of filter sets. Regardless of the light source, the suitability of any real-time thermal cycler for the quantification of a particular fluorescent protein can be evaluated by comparing the spectral characters of the fluorescent protein with those of the DNA fluorophores for which the thermal cycler was designed. The most widely used fluorescent proteins are listed in Table 1 along with their matching DNA fluorophores.

We compared the ability of a standard microtiter plate fluorometer (Synergy $^{\mathrm{TM}}$ HT, Bio-Tek Instruments $\mathrm{GmbH}$, Friedrichshall, Germany) and a real-time thermal cycler (iCycler $\mathrm{iQ}^{\circledR}$, Bio-Rad Laboratories, Hercules, CA, USA) to detect GFP (Roche Diagnostics GmbH, Penzberg, Germany) ( Figure 1). The sensitivity of both systems was similar to the lower limit of detection at approximately 1 $\mathrm{mg} / \mathrm{mL}$. Although a limited solubility of

Table 1. Matching Fluorescent Proteins with DNA Fluorophores

\begin{tabular}{|c|c|c|}
\hline Fluorescent Protein & Source of Wild-Type Gene & Matching DNA Label \\
\hline $\begin{array}{l}\text { rGFP, GFP } \\
\text { EGFP (488/507), Class } 2 \text { GFPs }{ }^{a}\end{array}$ & jellyfish Aequorea victoria & СуТМ2 (489/506) \\
\hline S65T-GFPb $(489 / 509)$ & jellyfish $A$. victoria & $\begin{array}{l}\text { 6-FAM (494/516), } \\
\text { Oregon Green }{ }^{\circledR} 500(499 / 519), \\
\text { SYBR Green I (497/520) }\end{array}$ \\
\hline Ds Red Monomer (556/586) & Discoma sp. reef coral & Су3 (552/570), TAMRA (565/580) \\
\hline ZsGreen1 (493/505) & Anthozoa reef coral & Cy2 (489/506) \\
\hline AsRed2 (576/592) & Anthozoa reef coral & Суз.5 $(581 / 596)$ \\
\hline HcRed1 (588/618) & Heteractis crispa reef coral & $\operatorname{ROX}^{\mathrm{TM}}(581 / 607)$, Texas $\operatorname{Red}^{\circledR}(589 / 610)$ \\
\hline
\end{tabular}


GFP has been encountered frequently in published reports, we were able to generate a calibration curve up to the concentration of $10 \mathrm{mg} / \mathrm{mL}$. The form of the curves was slightly sigmoidal, rather than linear, for both systems (Figure 1).

In many applications, GFP has to be measured in heterogeneous systems such as tissue cultures or bacterial cells rather than in cell-free solutions. In order to ensure that real-time thermal cycle is suitable for this task as well, we measured fluorescent signal generated by germinating spores of a filamentous fungus responding to the mycotoxin zearalenone (Figure 2). The bioassay exploits the ability of Gliocladium roseum to sense and respond to the presence zearalenone by synthesizing a zearalenone-specific lactonase. The bioassay strain was constructed by fusing the esterase gene in G. roseum with a GFP gene (Utermark and Karlovsky, unpublished). The fluorescence signal can be quantified by any real-time thermal cycler able to detect FAM and/or SYBR ${ }^{\circledR}$ Green dyes. Unlike fluorometers, real-time thermal cyclers are available in many molecular biology laboratories.

According to our findings, real-time thermal cyclers are a viable alternative to microtiter plate-compatible fluorometers for measuring the amount of GFP and other fluorescent proteins within living cells and as purified proteins.

\section{ACKNOWLEDGMENTS}

We thank Dr. Ingo Heilmann, Goettingen University, for allowing us to use a fluorometer in his laboratory.

\section{COMPETING INTERESTS STATEMENT}

The authors declare no competing interests.

\section{REFERENCES}

1.Van den Wymelenberg, A.J., D. Cullen, R.N. Spear, B. Schoenike, and J.H. Andrews. 1997. Expression of green fluorescent protein in Aureobasidium pullulans and quantification of the fungus on leaf surfaces. BioTechniques 23:686-690.

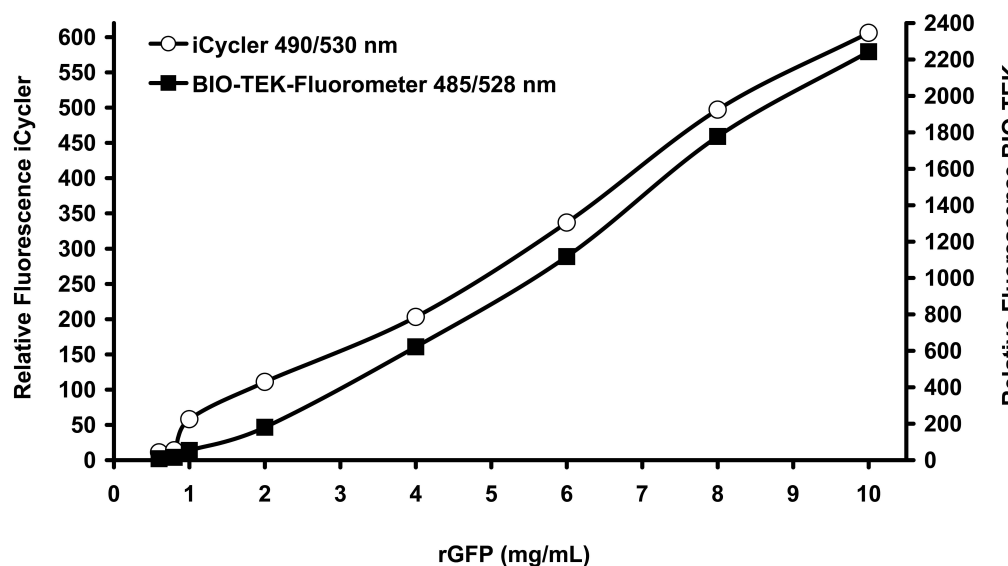

Figure 1. Comparison of green fluorescent protein (GFP) determination with the help of a fluorometer and real-time thermal cycler. Solutions of purified recombinant GFP (rGFP) were analyzed in fluorometer Synergy HT with published excitation and emission wavelength for the fluorophore and in an iCycler real-time thermal cycler with excitation and emission filters for SYBR Green I.

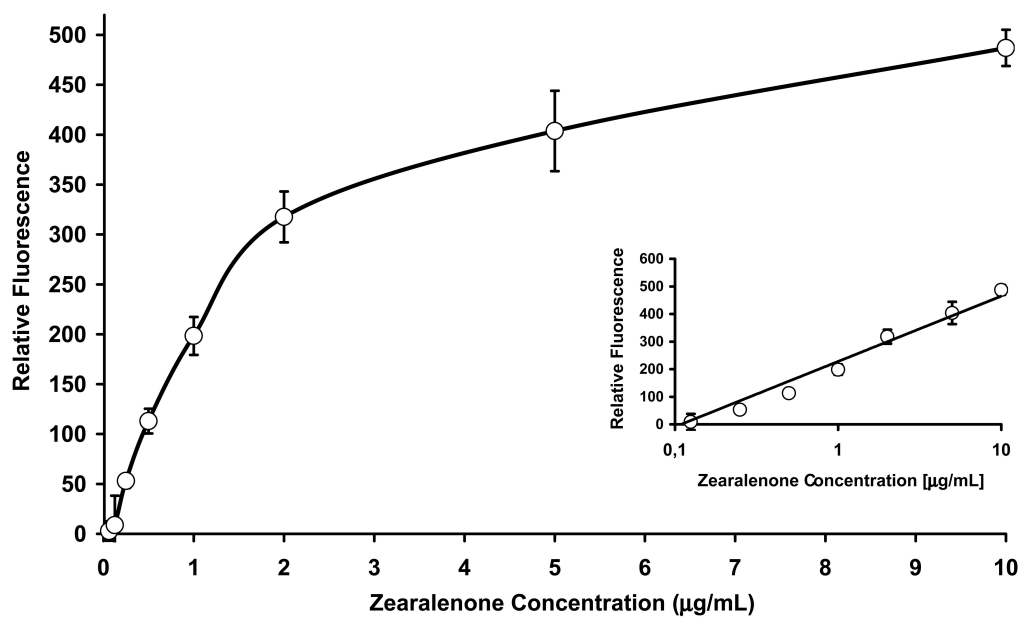

Figure 2. Determination of zearalenone using a bioassay based on a green fluorescent protein (GFP) fusion. Gliocladium roseum strain carrying a fusion of zearalenone esterase with GFP was incubated with increasing concentrations of zearalenone. The fluorescence of GFP was measured in an iCycler real-time thermal cycler. Inset: the same data plotted on a semilogarithmic scale. Points are averages of 5 measurements with error bars of \pm 1 standard deviation.

2. Eggink, L.L., R. LoBrutto, D.C. Brune, J. Brusslan, A. Yamasato, A. Tanaka, and J.K. Hoober. 2004. Synthesis of chlorophyll $\mathrm{b}$ : localization of chlorophyllide a oxygenase and discovery of a stable radical in the catalytic subunit. BMC Plant Biol. 4:1-16.

3. Millwood, R.J., M.D. Halfhill, D. Harkins, R. Russotti, and C.N. Stewart. 2003. Instrumentation and methodology for quantifying GFP fluorescence in intact plant organs. BioTechniques 34:638-643.

4. Kwok, E.Y. and M.R. Hanson. 2004. In vivo analysis of interactions between GFP-labeled microfilaments and plastid stromules. BMC Plant Biol. 4:1-9.

5. Beck, V., A. Pfitscher, and A. Jungbauer. 2005. GFP-reporter for a high-throughput assay to monitor estrogenic compounds. J. Biochem. Biophys. Methods 64:19-37.

6. Bovee, T.F., R.J. Helsdingen, I.M. Rietjens, J. Keijer, and R.L. Hoogenboom. 2004. Rapid yeast estrogen bioassays stably expressing human estrogen receptors $\alpha$ and $\beta$, and green fluorescent protein: a comparison of different compounds with both receptor types. J. Steroid Biochem. Mol. Biol. 91:99-109. 


\title{
Benchmarks
}

\author{
7. Mitterbauer, R., H. Weindorfer, N. Safaie, \\ R. Krska, M. Lemmens, P. Ruckenbauer, \\ K. Kuchler, and G. Adam. 2003. A sensitive \\ and inexpensive yeast bioassay for the myco- \\ toxin zearalenone and other compounds with \\ estrogenic activity. Appl. Environ. Microbiol. \\ 69:805-811. \\ 8. Heim, R., A.B. Cubitt, and R.Y. Tsien. \\ 1995. Improved green fluorescence. Nature \\ 373:663-664. \\ 9. Tsien, R.Y. 1998. The green fluorescent pro- \\ tein. Annu. Rev. Biochem. 67:509-544.
}

Received 10 April 2006; accepted 23 May 2006.

Address correspondence to Petr Karlovsky, Molecular Phytopathology and Mycotoxin Research Section of the Department of Crop Sciences, Goettingen University, Grisebachstrasse 6, D-37077 Goettingen, Germany.e-mail: pkarlov@gwdg.de

To purchase reprints of this article, contact: Reprints@BioTechniques.com 


\section{Chapter 7: General discussion}

Mycotoxins are secondary metabolites produced by filamentous fungi that cause a toxic response (mycotoxicosis) when ingested by mammals and humans. Aspergillus, Fusarium, and Penicillium are the primary fungal genera that produce these toxins in the human and animal food chain (Christensen et al., 1974; 1982).

Mycotoxins can accumulate in human foods and animal feeds through fungal growth prior to and during harvest, or from incorrect storage following harvest. For example, crop losses due to diseases caused by mycotoxin producing fungi have put a tremendous economic burden on U.S. Agriculture (U.S. Food and Drug Administration [http://www.fda.gov]).

\section{Biological function of mycotoxins}

Despite of their economic importance and the impact on the health of humans and farm animals, the biological function of most mycotoxins remains elusive. Likewise, the biological function of mycotoxin detoxification activity in nature is a subject of speculations.

Størmer and Høiby (1996) reported that the mycotoxins ochratoxin A (producing organisms: Aspergillus and Penicillium spp.) and citrinin (producing organisms: Aspergillus, Penicillum, and Monascus spp.) inhibit the growth of the bacterium Neisseria meningitidis.

Other mycotoxins seem to play a role in the phytopathogenicity. For example, the Fusarium mycotoxins trichothecenes may act as virulence factors to enhance the spread of $F$. graminearum in maize (Harris et al., 1999). The role of the Fusarium trichothecene deoxynivalenol (DON) in plant disease is still a matter of discussion (McCormick, 2003), but most of the evidence supports the hypothesis that its function as a virulence factor. Fusarium mutants with a disrupted trichodiene synthase (Tri5) gene, involved in trichothecene biosynthesis, are still pathogenic but they exhibit reduced virulence on wheat (Desjardins et al., 1996); they are unable to spread from the infection site (Bai et al., 2002). Deoxynivalenol is diffusible in plants, suggesting a role in conditioning host tissue for colonization (Kang and 
Buchenauer, 1999). Results of several studies indicate that the in vitro resistance of wheat cultivars towards deoxynivalenol correlates with Fusarium resistance in the field (Mesterhazy, 2003).

Recently, Williams et al. (2007) have shown that fumonisins produced by Fusarium verticillioides are inhibitors of ceramide synthase and play a major role in fungal pathogenicity. They demonstrated that fumonisin production is required for the induction of leaf lesions indicative of $F$. verticillioides maize seedling disease and that it is an important contributor to the degree of disease expression.

Inspired by the idea that the sexual reproduction of fungi is controlled by hormones (Machlis, 1966) and by the estrogenic properties of zearalenone, Nelson (1971) and Wolf and Mirocha (1973) postulated that zearalenone might play a role as a sexual pheromone in F. graminearum. However, this assumption has not been proven. Furthermore, the fact that $F$. culmorum produces large amounts of zearalenone while not having any sexual stage poses a serious challenge to the sexual pheromone hypothesis.

G. roseum produces an esterase which hydrolyzes zearalenone. The high substrate specificity of this enzyme indicates that its interaction with Fusarium spp. producing zearalenone is frequent enough to maintain the selection pressure for the detoxification of zearalenone. This reasoning is in line with the findings that Gliocladium spp. have most frequently been found among fungal antagonists of $F$. culmorum in wheat and that it has outperformed other species in biocontrol activity against $F$. culmorum in both greenhouse tests and field experiments (Teperi et al., 1998).

We demonstrated that zearalenone acts as an agent of interference competition, suppressing the growth of fungi competing with or antagonizing Fusarium spp.. The finding that the growth of many filamentous fungi was inhibited by zearalenone provides a strong support for this hypothesis. Furthermore, we demonstrated that the inactivation of the zearalenone detoxifying esterase in the mycoparasite G. roseum reduces the resistance of the fungus to zearalenone. The increased susceptibility of the zearalenone lactonase disruption mutant of $G$. roseum to zearalenone further corroborates the ecological role of the mycofungicide zearalenone (chapter 2). The zearalenone detoxification gene zes2 provides a promising genetic resource in order 
to investigate the biological function of zearalenone lactonase in G. roseum and the mycotoxin zearalenone itself in situ.

\section{Reduction of zearalenone contamination in agricultural commod- ities by enzymatic detoxification}

Efficient prevention of mycotoxin contamination in the food chain of humans and productive livestock is not always feasible or practical. Therefore, there is a need for novel methods for the elimination of zearalenone from contaminated grain.

Significant proceedings have been made in establishing various control strategies, such as prototypes of genetically engineered crops which contain genes for resistance to mycotoxins (Igawa et al., 2007; Hohn T., Peters C. and J. Salmeron.19 February 2004, U.S. Patent application number US2004034884).

Regarding zearalenone, the reduction of its content in feedstuffs is particularly important, because high-quality grains are selected for human consumption. As a decontamination strategy, feed additives that bind zearalenone by adsorption are widely used. However, the use of mycotoxin sorbents imposes additional costs on meat production leading to environmental pollution. Furthermore, these sorbents are not entirely safe because adsorption is reversible and mycotoxins can be released during their passage through the digestive tracts of animals (Voelkl and Karlovsky, 1999). Finally, sorbents may bind nutrients and/or dietary compounds, resulting in a reduced performance of livestock.

One promising strategy for reducing zearalenone contamination is its enzymatic degradation. The commercial product Mycofix ${ }^{\circledR}$ Plus (Biomin $\mathrm{GmbH}$, Herzogenburg, Austria) has been sold as a feed additive and is supposed to eliminate mycotoxins within the digestive tract. According to the manufacturer, Mycofix ${ }^{\circledR}$ Plus consists of adsorbing and enzymatic components which have the function to adsorb and degrade Fusarium toxins (http://www.biomin.at). The product has been tested for in vivo activity (Weiß et al., 1999; Hoppenbrock, 2002; Danike et al., 2004; Karlovsky, 1999) and was shown to be ineffective in diminishing the growth depressing effects of mycotoxin-contaminated diets. Recently, a novel yeast strain, Trichosporon mycotoxinivorans with the capability of degrading zeralenone has been isolated and charac- 
terized (Molnar et al., 2004). It is expected that this organism will provide future versions of Mycofix ${ }^{\circledR}$ Plus with genuine zearalenone-hydrolyzing activity.

In addition to the use of intact microorganisms or cell-free enzymatic preparations as feed additives, the heterologous expression of the respective genes in genetically engineered organisms opens new avenues for the reduction the risks of mycotoxin contamination. In chapter 3 , a transgenic detoxification system for the elimination of zearalenone was developed using the zearalenone-degrading enzyme Zes2 from G. roseum. Transgenic Arabidopsis plants indicated a feasible way of mitigating mycotoxin problems caused by Fusarium spp. (chapter 3 ). Thus, the availability of a gene which encodes a zearalenone-detoxifying enzyme suggests a new transgenic strategy for the efficient decontamination of zearalenone in feeds and foods.

\section{Biosensors for zearalenone - ready for environmental application?}

New detections methods using fiber optics, hyperspectral, and near infrared imaging as well as microbial biosensors for rapid and sensitive detection of mycotoxins or toxigenic fungi (Maragos and Thompson, 1999; Grow et al., 2003; Berardo et al., 2005). Biosensors have major advantages over chemical or physical analyses with regard to specificity, sensitivity, and portability.

Due to recent advances in cell biology, fluorescent probe chemistry, miniaturization and automation, many types of living cell biosensors allowing detection of the estrogenic activity of zearalenone have been developed using recombinant DNA technology (Mitterbauer et al., 2003; Bovee et al., 2004; 2006). Yeast strains were genetically engineered to respond to the presence of zearalenone by using a cloned human estrogen receptor alpha (ER- $\alpha)$ or estrogen receptor beta (ER- $\beta)$ and synthesizing a reporter protein, such as luciferase or the green fluorescent protein (GFP).

However, the yeast-based bioassays only enable detection of the estrogenic activity in cereal extracts and are not able to distinguish between zearalenone and other estrogens. This makes the screening of zearalenone contaminations by this approach fairly difficult because phytoestrogens and steroids (e.g. 17- $\alpha$ - or $\beta$-estradiol and estrone) are also present in plant-based or animal food-producing samples. Hence, the use of yeast biosensors will not permit detailed analyses of samples. 
The ability of the mycoparasite G. roseum to sense zearalenone in growth medium and to respond by producing a detoxification enzyme (Woerfel and Karlovsky, 1998) inspired us to exploit zearalenone sensing ability of $G$. roseum as a basis for a zearalenone-specific biosensor. Thus, a G. roseum-based bioassay that possesses a high specificity for zearalenone and its derivatives was developed. Translational fusions of zearalenone-sensing promoter-element of the zearalenone lactonase gene zes2 with either green fluorescent protein (GFP) or Gaussia princeps lucifease were constructed. The high sensitivity makes this assay suitable for low cost monitoring of contaminations of small grain cereals with estrogenic Fusarium mycotoxins, but is also attractive as a tool for basic research. We have successfully used a G. roseum indicator strain to screen for zearalenone producing Fusarium spp.. Furthermore, we applied the strains for real-time macroscopic imaging of zearalenone biodistribution which actually occurred in Fusarium spp. infected maize tissue (chapter 5). In further applications, its use in screening to find microorganisms that are able to convert zearalenone into less estrogenic compounds would be conceivable.

\section{Luciferase- and GFP-marker in functional genomics in fungi}

Fluorescent and bioluminescent proteins play a major role in advancing our understanding of biological processes. Reporter proteins belonging to fluorescent proteins (green fluorescent protein (GFP) and reef coral fluorescent protein (RCFP) or luciferases can be transgenically expressed in filamentous fungi.

The use of fluorescent protein markers in filamentous fungi allows applications in biochemical assays (Utermark and Karlovsky, 2006) and cell screening (Helber and Requena, 2007). Eynck et al. (2007) have used a constitutively GFP-expressing Verticillium strain to monitor the various stages of fungal infection and to demonstrate the development of Verticillium longisporum on Brassica napus. In vivo biochemical assays using GFP reporter gene technique are usually applied to a large number of samples, requiring the use of a fluorometer which can accurately quantify fluorescence generated on the scale of microtiter plates. However, microtiter plate fluorometers do not belong to the common equipment found in a molecular biology laboratory. To overcome this limitation in our laboratory, we used a real-time thermal cycler 
to measure GFP expression in G. roseum strains.

However, bioluminescent imaging which is based on the endogenous production of light by the expression of the enzyme luciferase has led to significant advances in comparison to GFP expression. Eynck et al. (2007) demonstrated that the level of GFP expression depends on the physiologic state of fungal mycelium in Verticillium spp.. With advanced age of the fungal hyphae, the GFP fluorescence decreased. Furthermore, bioluminescent imaging was shown to be more sensitive than fluorescent GFP imaging (Choy et al., 2003).

Fluorescence applications of "whole body" imaging (e.g. tissue screening of whole mice or plants) required the use of a hardware capable to emit excitation light to raise the fluorophore to a higher energy state, followed by emission at a longer wavelength (e.g. Molecular Light Imager (Berthold Technologies, Germany) coupled to excitation filter and emission filter). This is a big drawback because these devices are not a common equipment found in a biology laboratory.

Luciferases occur in lower organisms such as bacteria, fungi, insects, and marine crustaceans. Thus, these enzymes fall into many unrelated classes with different evolutionary origins. For example, firefly luciferase (FLuc), found in the light-emitting organ of the firefly Photinus pyralis, is one of the best studied luciferases due to its high quantum yield (>88\%; Lembert and Idahl, 1995) generated by oxidation of its substrate, beetle d-luciferin. FLuc requires ATP and $\mathrm{Mg}^{2+}$ as cofactors for its activity. Another well-studied luciferase is that from the sea pansy, Renilla reniformis (RLuc) which uses coelenterazine as a substrate. Like all coelenterazine luciferases, it does not require ATP for activity; however, RLuc has a low enzymatic turnover and quantum yield (6\%; Matthews et al., 1977).

So far, only a few researchers demonstrated in vivo the expression of firefly and Renilla luciferase activity in filamentous fungi and it remained problematic due to its poor translation (Morgan et al., 2003).

In order to sense zearalenone in Fusarium infected plant tissue a luciferase from the marine copepod Gaussia princeps was used. Gaussia luciferase is the smallest luciferase known and is naturally secreted (Bakhos et al., 2005). The native gene has been humanized (Nanolight, Pinetop, USA) by codon optimization for mammalian cell 
expression. After the addition of the substrate coelenterazine, the enzyme emits light at a peak of $480 \mathrm{~nm}$ with a broad emission spectrum extending to $600 \mathrm{~nm}$. Gaussia luciferase has been cloned, overexpressed in bacteria, and used as a sensitive analytical reporter for hybridization assays (Verhaegent and Christopoulos, 2002).

Up to now, this reporter gene had not been used for monitoring fungal cell expression in culture or in vivo. We describe the construction of a genetically engineered fusion of the zearalenone-sensing promoter-element and the codon-modified Gaussia princeps lucifease in G. roseum (chapter 5). Real-time luciferase imaging demonstrated that this gene is a sensitive reporter useful for a variety of experimental uses in G. roseum.

\section{Conclusion and future work}

During this work, the biological role of the fungal secondary metabolite zearalenone in interactions among microorganisms and plants was studied using tools of analytical chemistry and molecular genetics. The objectives of this work were to demonstrate the growth inhibition of filamentous fungi by zearalenone and to evaluate the effect of disruption of the zearalenone lactonase gene of $G$. roseum on the ability of the fungus to hydrolyze zearalenone and the resistance of $G$. roseum to zearalenone. Zearalenone acts as an agent of interference competition and the zearalenone specific and inducible lactonase of $G$. roseum protects the fungus from the fungitoxic effect of the mycotoxin.

However, to address the ecological role of zearalenone in detail, the effect of zearalenone and its degradation on fungal fitness needs to be evaluated in highly complex systems (e.g. microcosms).

Furthermore, the role of zearalenone in plant-pathogen interactions and the relevance of the phytotoxic potential as well as the mode of action remain also subjects for further studies.

The existence of the functional gene zes2 encoding a zearalenone-specific lactonase and the inducibility of this gene by zearalenone and its derivatives has only been studied in G. roseum so far. It is likely that the mechanisms of regulation of zes2 expression in G. roseum is still waiting to be discovered. The goal of future studies 
should be the cloning of entire genes which are responsible for zes2 regulation. With the utmost probability these genes contain a zearalenone receptor and at least parts of zes2 transcription factors. Strains of G. roseum carrying gene fusions of zes 2 with reporter genes (GFP or luciferase) will facilitate these studies. This would be the first time that a biological system is utilized for the specific detection of a mycotoxin. The practical use of this genetic system offers innovative opportunities. The isolation of a zearalenone receptor would pioneer the development of a new, improved and highly specific biosensor for zearalenone. 


\section{References (cited in introduction and general discussion)}

1. Ahamed, S., Foster, J. S., Bukovsky, A. and J. Wimalasena. 2001. Signal transduction through the Ras/Erk pathway is essential for the mycoestrogen zearalenone-induced cell-cycle progression in MCF-7 cells. Mol. Carcinog. 30:88-98.

2. Allen, N.K., Peguri, A., Mirocha, C.J. and J.A. Newman. 1983. Effects of Fusarium cultures, T-2 toxin and zearalenone on reproduction of turkey females. Poultry Sci. 62:282-289.

3. Altalhi, A.D. 2007. Plasmid-mediated detoxification of mycotoxin zearalenone in Pseudomonas Sp. ZEA-1. Am. J. Biochem. Biotechnol. 3:150-158.

4. Arora, R.G., Frolen, H. and H. Fellner-Feldegg. 1983. Inhibition of ochratoxin and teratogenesis by zearalenone and diethylstilboestrol. Food Chem. Toxicol. 21:779-783.

5. Bai, G.H., Desjardins, A.E. and R.D. Plattner. 2002. Deoxynivalenol nonproducing Fusarium graminearum causes initial infection, but does not cause disease spread in wheat spikes. Mycopathologia 153:91-98.

6. Becci, P.J., Johnson, W.D., Hess, F.G., Gallo, M.A. and R.A. Parent. 1982b. Combined two-generation reproduction-teratogenesis study of zearalenone in the rat. J. Appl. Toxicol. 2:201-206.

7. Becci, P.J., Voss, K.A., Hess, F.G., Gallo, M.A., Parent, R.A., Stevens, K.R. and J.M. Taylor. 1982a. Long-term carcinogenicity and toxicity study of zearalenone in the rat. J. Appl. Toxicol. 2:247-254.

8. Bennett, G.A., Nelsen, T.C. and B.M. Miller. 1994. Enzyme-linked immunosorbent assay for detection of zearalenone in corn, wheat, and pig feed: collaborative study. J. AOAC Int. 77:1500-1509.

9. Bennett, J.W. 1987. Mycotoxins, mycotoxicoses, mycotoxicology and mycopathology. Mycopathologia 100:3-5.

10. Bennett, J.W. and M.A. Klich. (2003) Mycotoxins. Clin Microbiol. Rev. 16:497-516.

11. Berardo, N., Pisacane, V., Battilani, P., Scandolara, A., Pietri, A. and A. Marocco. 2005. Rapid detection of kernel rots and mycotoxins in maize by near-infrared reflectance spectroscopy. J. Agric. Food Chem. 53:8128-8134. 
12.Berger, T., Esbenshade, K.L., Diekman, M.A., Hoaglund, T. and J. Tuite 1981. Influence of prepubertal consumption of zearalenone on sexual development of boars. J. Animal Sci. 53:1559-1563.

13. Bovee, T.F., Bor, G., Heskamp, H.H., Hoogenboom, R.L. and M.W. Nielen. 2006 Validation and application of a robust yeast estrogen bioassay for the screening of estrogenic activity in animal feed. Food Addit. Contam. 23:556-568.

14.Bovee, T.F., R.J. Helsdingen, I.M. Rietjens, J. Keijer, and R.L. Hoogenboom. 2004. Rapid yeast estrogen bioassays stably expressing human estrogen receptors $\alpha$ and $\beta$, and green fluorescent protein: a comparison of different compounds with both receptor types. J. Steroid Biochem. Mol. Biol. 91:99-109.

15. Brachmann, C.B., Sherman, J.M., Devine, S.E. and E. E. Cameron. 1995. The SIR2 gene family, conserved from bacteria to humans, functions in silencing, cell cycle progiression, and chromosome stability. Genes \& Dev. 9:2888-2902.

16. Bundesministerium für Gesundheit, Sport und Konsumentenschutz. 1993. Richtwerte für Mykotoxine in Getreide für den menschlichen Genuß (GZ 32.110/1-III/B/ 1b/93). Mitt. Oesterr. Sanitaetsverwalt. (Vienna) 94:360.

17. Campbell, H.M. and J.F. Armstrong. 2007. Determination of zearalenone in cereal grains, animal feed, and feed ingredients using immunoaffinity column chromatography and liquid chromatography: interlaboratory study. J. AOAC Int. 90:1610-1622.

18. Christensen, C.M., Kaufmann, H. and B. Mieroflora. 1974. In: Christensen, C.M. (ed), Storage of Cereal Grains and their Products, St. Paul: American Association of Cereal Chemists, 1974: 158-192.

19. Ciegler, A. 1986. Mycotoxins: a new class of chemical weapons. NBC Defense \& Technol. Int.52-57.

20. Coe, J. E., Ishak, K. G., Ward, J. M. and M. J. Ross. 1992. Tamoxifen prevents induction of hepatic neoplasia by zeranol, an estrogenic food contaminant. Proc. Natl. Acad. Sci. USA 89:1085-1089.

21. Coulombe, R.A. 1993. Biological action of mycotoxins. J. Dairy Sci. 76:880-891. 
22. Choy, G., O'Connor, S., Diehn, F.E., Costouros, N., Alexander, H.R., Choyke, P. and S.K. Libutti. 2003. Comparison of noninvasive fluorescent and bioluminescent small animal optical imaging. Biotechniques 35:1022-1026.

23. Creppy, E.E. 2002. Update of survey, regulation and toxic effects of mycotoxins in Europe. Toxicol. Lett. 127:19-28.

24.D'Mello, J.P.F., Placinta, C.M. and A.M.C. MacDonald. 1999. Fusarium mycotoxins: a review of global implications for animal health, welfare and productivity. Anim. Feed Sci. Tech. 80:183-205.

25. Dacasto, M., Rolando, P., Nachtmann, C., Ceppa, L. and C. Nebbia. 1995. Zearalenone mycotoxicosis in piglets suckling sows fed contaminated grain. Vet. Hum. Toxicol. 37:359-361.

26.Desjardins, A.E. and R.H. Proctor. 2007. Molecular biology of Fusarium mycotoxins. Int. J. Food Microbiol. 119:47-50.

27.Desjardins, A.E., Hohn, T.M. and S.P. McCormick. 1993. Trichothecene biosynthesis in Fusarium species: chemistry, genetics, and significance. Microbiol. Rev. 57:595-604.

28. Desjardins, A.E., Procter, R.H., Bai, G., McCormick, S.P., Shaner, G., Buechley, G. and T. Hohn.1996. Reduced virulence of trichothecene-nonproducing mutants of Gibberella zeae in wheat field tests. Mol. Plant Microbe Interact. 9:775-781.

29. Dewick, P. N. 2001. The actetate pathway: fatty acids and polyketides, p. 35-117. In P. N. Dewick (ed.), Medicinal natural products. A biosynthetic approach, 2nd ed. John Wiley \& Sons Ltd, West Sussex, England.

30.Diekman, M.A. and M.L. Green. 1992. Mycotoxins and reproduction in domestic livestock. J. Anim. Sci. 70:1615-1627.

31. El-Sharkawy, S. and Y. Abul-Hajj. 1987a. Microbial transformation of zearalenone I. Formation of zearalenone 4-0- $\beta$-glucoside. J. Nat. Prod. 50:520-521.

32. El-Sharkawy, S. and Y. Abul-Hajj. 1987b. Microbial transformation of zearalenone. 2. Reduction, hydroxylation, and methylation products. J. Org. Chem. 53:515-519. 33. El-Sharkawy, S. and Y. Abul-Hajj. 1988. Microbial cleavage of zearalenone. Xenobiotica 18:365-371. 
34. Engelhardt, G., Zill, G., Wohner, B. and P. R. Wallnöfer. 1988. Transformation of the Fusarium mycotoxin zearalenone in maize cell suspension cultures. Naturwissenschaften 75:309-310.

35. Etiene, M. and M. Jemmali. 1982. Effects of zearalenone on estrous activity and reproduction in gilts. J. Animal Sci. 55:1-10.

36. Etienne, M. and J.Y. Dourmad. 1994. Effects of zearalenone or glucosinolates in the diet on reproduction in sows: a review. Livest. Prod. Sci. 40:99-113.

37.FAO. 1997. Food and Nutrition Paper 64, Worldwide regulations for Mycotoxins 1995, a compendium, Rome.

38. Fink-Gremmels, J. 1999. Mycotoxins: their implications for human and animal health. Vet. Quat. 21, 115-120.

39. Flannigan, B. 1991. Mycotoxins. In: D’Mello, J.P.F., Duffus, C.M., Duffus, J.H. (Eds.), Toxic Substances in Crop Plants. The Royal Society of Chemistry, Cambridge: 226-257.

40. Flipphi, M., Kocialkowska, J. and B. Felenbok. 2003. Relationships between the ethanol utilization (alc) pathway and unrelated catabolic pathways in Aspergillus nidulans. Eur. J. Biochem. 270:3555-3564.

41. Gaffoor, I. and F. Trail. 2006.Characterization of two polyketide synthase genes involved in zearalenone biosynthesis in Gibberella zeae. Appl. Environ. Microbiol. 72:1793-1799.

42. Gaffoor, I., Brown, D.W., Plattner, R., Proctor, R.H., Qi, W. and F. Trail. 2005. Functional analysis of the polyketide synthase genes in the filamentous fungus Gibberella zeae (anamorph Fusarium graminearum). Eukaryot Cell 4:1926-1933.

43. Gao, H.P. and T. Yoshizawa. 1997. Further study on Fusarium mycotoxins in corn and wheat from a high-risk area for human esophageal cancer in China. Mycotoxins 45:51-55.

44. Ghedira-Chekir, L., Zakhama, A., Ellouz, F., Dhouib, S., Creppy, E.E. and H. Bacha. 1998. Induction of SOS repair system in lysogenic bacteria by zearalenone and its prevention by vitamin E. Chem. Biol. Interact. 113:15-25.

45. Gilbert, J. 1989. Current views on the occurrence and significance of Fusarium toxins. Soc. Appl. Bacteriol. Symp. Ser., 18:89S-98S. 
46. Glass, C. K. 1996. Some new twists in the regulation of gene expression by thyroid hormone and retinoic acid receptors. J. Endocrinol. 150:349-357.

47. Goswami, R.S. and H. Kistler. 2004. Heading for disaster: Fusarium graminearum on cereal crops. Mol. Plant Pathol. 5:515-525.

48. Graessle, S., Loidl, P. and G. Brosch. 2001. Histone acetylation: plants and fungi as model systems for the investigation of histone deacetylases. Cell. Mol. Life Sci. 58:704-720.

49. Grow, A.E., Wood, L.L., Claycomb, J.L. and P.A. Thompson. 2003. New biochip technology for label-free detection of pathogens and their toxins. J. Microbiol. Methods 53:221-233.

50. Harris, L.J., Desjardins, A.E., Plattner, R.D., Nicholson, P., Butler, G., Young, J. C., Weston, G., Proctor, R. H. and T.M. Hohn. 1999. Possible role of trichothecene mycotoxins in virulence of Fusarium graminearum on maize. Plant Dis. 83:954-960.

51. Helber, N. and N. Requena. 2007. Expression of the fluorescence markers DsRed and GFP fused to a nuclear localization signal in the arbuscular mycorrhizal fungus Glomus intraradices. New Phytol. 177, 537-548.

52. Hidy, P.H., Baldwin, R.S., Greasham, R.L., Keith, C.L. and J.R. McMullan. 1977. Zearalenone and some derivatives: Production and biological activities. Adv. Appl. Microbiol. 22:55-82.

53. Hilakivi-Clarke, L., Onojafe, I,. Raygada, M., Cho, E., Skaar, T., Russo, I. and R. Clarke. 1999. Prepubertal exposure to zearalenone or genistein reduces mammary tumorigenesis. Br. J. Cancer 80:1682-1688.

54. Hussein, H.S. and J.M. Brasel. 2001. Toxicity, metabolism, and impact of mycotoxins on humans and animals. Toxicology 167:101-134.

55. IARC. 1999. Overall evaluations of carcinogenicity to humans. IARC monographs, 76: 1-36.

56. Igawa, T., Takahashi-Ando, N., Ochiai, N., Ohsato, S., Shimizu, T., Kudo, T., Yamaguchi, I. and M. Kimura. 2007. Reduced contamination by the Fusarium mycotoxin zearalenone in maize kernels through genetic modification with a detoxification gene. Appl. Environ. Microbiol. 73:1622-1629. 
57.Ito, Y. and K.I. Ohtsubo. 1994. Effects of neonatal administration of zearalenone on the reproductive physiology of female mice. J. Vet. Med. Sci. 56:1155-1159.

58. Kaliamurthy, P., Geraldine, P. and P.A. Thomas. 1997. Effects of zearalenone on food consumption, growth, organ weight and serum testosterone level in male rats. J. Environ. Biol. 18:115-120.

59. Kang, Z. and H. Buchenauer. 1999. Immunocytochemical localization of Fusarium toxins in infected wheat spikes by Fusarium culmorum. Physiol. Mol. Plant Path. $55: 275-288$.

60. Karlovsky, P. 1999. Biological detoxification of fungal toxins and its use in plant breeding, feed and food production. Nat. Toxins 7:1-23.

61. Kiessling, K.H., Pettersson, H., Sandholm, K. and M. Olsen. 1984. Metabolism of aflatoxin, ochratoxin, zearalenone, and three tricothecenes by intact rumen fluid, rumen protozoa, and rumen bacteria. Appl. Environ. Microbiol. 47:1070-1073.

62. Kim, Y.T., Lee, Y.R., Jin, J., Han, K.H., Kim, H., Kim, J.C., Lee, T., Yun, S.H. and Y.W. Lee. 2005. Two different polyketide synthase genes are required for synthesis of zearalenone in Gibberella zeae. Mol. Microbiol. 58:1102-1113.

63. Klang, D.T., Kennedy, B.J., Pathre, S.V. and C.J. Mirocha. 1978. Binding characteristics of zearalenone analogs to estrogen receptors. Cancer Res. 38:3611.

64. Kuiper -Goodman, T., Scott, P.M. and H. Watanabe. 1987. Risk assessment of the mycotoxin zearalenone. Regul. Toxicol. Pharm. 7:253-306.

65. Kuiper Goodman, T. 1991. Risk assessment to humans of mycotoxins in animalderived food products. Veterinary and Human Toxicol. 33:325-332.

66. Labuda, R., Parich, A., Berthiller, F. and D. Tancinova. 2005. Incidence of trichothecenes and zearalenone in poultry feed mixtures from Slovakia. Int. J. Food Microbiol. 105:19-25.

67. Lattanzio, V.M., Solfrizzo, M., Powers, S. and A. Visconti. 2007. Simultaneous determination of aflatoxins, ochratoxin $A$ and Fusarium toxins in maize by liquid chromatography/tandem mass spectrometry after multitoxin immunoaffinity cleanup. Rapid Commun. Mass Spectrom. 21:3253-3261. 
68. Lauren, D.R. and M.A. Ringrose. 1997. Determination of the fate of three Fusarium mycotoxins through wet-milling of maize using an improved HPLC analytical technique. Food Addit. Contam. 14:435-443.

69. Lembert, N. and L.A. Idahl. 1995. Regulatory effects of ATP and luciferin on firefly luciferase activity. Biochem. J. 1: 929-933.

70. Lioi, M.B., Santoro, A., Barbieri, R., Salzano, D. and M.V. Ursini. 2004. Ochratoxin and zearalenone: a comparative study on genotoxic effects and cell death induced in bovine lymphocytes. Mutat. Res. 557:19-24.

71. Logrieco, A., Mulè, G., Moretti, A. and A. Bottalico. 2002. Toxigenic Fusarium species and mycotoxins associated with maize ear rot in Europe. Eur. J. Plant Path.108:597-609.

72. Long, G.G. and M.A. Diekman. 1989. Effect of zearalenone on early pregnancy in guinea pigs. Am. J. Vet. Res. 50:1220-1223.

73. Machlis, L. 1966. Sex hormones in fungi, p. 415-433. In G. C. Ainsworth and A. S. Sussman (ed.), The fungi. Academic Press, New York, USA.

74. Maragos, C,M. and V.S. Thompson. 1999. Fiber-optic immunosensor for mycotoxins. Nat. Toxins 7:371-376.

75. Marasas, W.F.O., Rensburg, S.J. and C.J. Mirocha. 1979. Incidence of Fusarium species and the mycotoxins, deoxynivalenol and zearlenone, in corn produced in esophagealcancer areas in Transkei. J. Agric. Food. Chem. 27:1108-1112.

76. McCormick, S.P. 2003. Fusarium head blight of wheat and barley, pp. 165-183, American Phytopathological Society, St. Paul, Minnesota, USA

77. McLean, M. 1996. The phytotoxicity of selected mycotoxins on mature, germinating Zea mays embryos. Mycopathologia 132:173-183.

78. Mesterhazy, A. 2003. Fusarium head blight of wheat, pp. 363-380, American Phytopathological Society, St. Paul, Minnesota, USA.

79. Molnar, O., Schatzmayr, G., Fuchs, E. and H. Prillinger. 2004. Trichosporon mycotoxinivorans sp. nov., a new yeast species useful in biological detoxification of various mycotoxins. Syst. Appl. Microbiol. 27:661-671. 
80. Morgan, L.W., Greene, A.V. And D.Bell-Pedersen. 2003. Circadian and lightinduced expression of luciferase in Neurospora crassa. Fungal Genet. Biol. 38:327-332.

81. Moss, M.O. 1984. Conditions and factors influencing mycotoxin formation in the field and during the storage of food. Chem. Ind. 15:533-536.

82. Nelson, R. R. 1971. Hormonal involvement in sexual reproduction in the fungi, with special reference to F-2, a fungal estrogen, p. 181 - 200. In S. Akai and S. Ouchi (ed.), Morphological and Biochemical events in plant-parasite interaction, The Phytopathological Society of Japan, Tokyo.

83. Nikolaev, I., Cochet, M.F. and B. Felenbok. 2003. Nuclear import of zinc binuclear cluster proteins proceeds through multiple, overlapping transport pathways. Eukaryot. Cell 2:209-221.

84. Nilsson, N., Lindahl, O. and L. Lindwall.1987. The effect of fungal toxins on the sexual behaviour of rabbits. Nutr. Health. 5:95-97.

85. Nuryono, N., Noviandi, C.T., Böhm, J. and E. Razzazi-Fazeli. 2005. A limited survey of zearalenone in Indonesian maize-based food and feed by ELISA and high performance liquid chromatography. Food Control 16:65-71.

86. Palyusik, M., Hagler, W.M., Horváth, L. and C.J. Mirocha. 1980. Biotransformation of zearalenone to zearalenol by Candida tropicalis. Acta Vet. Acad. Sci. Hung. 28:159-166.

87.Park, J.W., Shoi, S.Y., Hwang, H.J. and Y.B. Kim. 2005. Fungal mycoflora and mycotoxins in Korean polished rice destined for humans. Int. J. Food Microbiol. 103:305-314.

88. Pfohl-Leszkowicz, A., Chekir-Ghedira, L. and H. Bacha. 1995. Genotoxicity of zearalenone, an estrogenic mycotoxin: DNA adduct formation in female mouse tissues. Carcinogenesis 16:2315-2320.

89. Pietri, A., Bertuzzi, T., Pallaroni, L. and G. Piva. 2004. Occurrence of mycotoxins and ergosterol in maize harvested over 5 years in Northern Italy. Food Addit. Contam. 21:479-487. 
90. Placinta, C.M., D’Mello, J.P.F. and A.M.C. Macdonald. 1999. A review of worldwide contamination of cereal grains and animal feeds with Fusarium mycotoxins. Anim. Feed Sci. Technol. 78:21-37.

91. Reza Oveisi, M., Hajimahmoodi, M., Memarian, S., Sadeghi, N. and S. Shoeibi. 2005. Determination of zearalenone in corn flour and a cheese snack product using high-performance liquid chromatography with fluorescence detection. Food Addit. Contam. 22:443-448.

92. Richard, J.L. 2007. Some major mycotoxins and their mycotoxicoses-An overview. Int. J. Food Microbiol. 119:3-10.

93. Rotter, B.A., Prelusky, D.B. and J.J. Pestka. 1996. Toxicology of deoxynivalenol (vomitoxin). J. Toxicol. Environ. Health 48.1-34.

94.Ruhr, L.P., Osweiler, G.O. and C.W. Foley. 1983. Effect of the estogenic mycotoxin zearalenone on reproductive potential in the boar. AJVR 44:483-485.

95. Ryu, D., Jackson, L.S. and L.B. Bullerman. 2002. Effects of processing on zearalenone. Adv. Exp. Med. Biol. 504:205-216.

96. Saenz de Rodriguez, C.A., Bougiovanni A.M. and L. Conde de Borrego. 1985. An epedemic of precocious development in Puerto Rican children. J. Pediatr. 107:393-396.

97. Schoental, R. 1985. Trichothecenes, zearalenone and other carcinogenic metabolites of Fusarium and related microfungi. Adv. Cancer Res. 45:217-290.

98. Schollenberger, M., Müller, H.M., Rüfle, M., Suchy, S., Planck, S. and W. Drochner. 2006. Natural occurrence of 16 Fusarium toxins in grains and feedstuffs of plant origin from Germany. Mycopathologia 161:43-52.

99. Shaner, G. 2003. Epidemiology of Fusarium Head Blight of Small Grain Cereals in North America, p. 512, In K. J. Leonard and W. R. Bushnell, eds. Fusarium Head Blight of Wheat and Barley. The American Phytopathological Society, St. Paul, Minnesota, USA.

100.Starkey, D.E., Ward, T.J., Aoki, T., Gale, L.R., Kistler, H.C., Geiser, D.M., Suga, H., Tóth, B., Varga, J. and K. O'Donnell. 2007. Global molecular surveillance reveals novel Fusarium head blight species and trichothecene toxin diversity. Fungal Genet. Biol. 44:1191-1204. 
101.Steele, J.A., Mirocha, C.J. and S.V. Pathre. 1976. Metabolism of zearalenone by Fusarium roseum Graminearum. J. Agric. Food Chem. 24:89-97.

102.Stob M., Baldwin R.S., Tuite J., Andrews F.N. and K.G. Gillette. 1962. Isolation of an anabolic, uterotrophic compound form corn infected with Giberella zeae. Nature 196:1318.

103.Stoermer, F.C., Sandven, P., Huitfeldt, H.S., Eduard. W. and A. Skogstad. 1998. Does the mycotoxin citrinin function as a sun protectant in conidia from Penicillium verrucosum? Mycopathologia 142: 43-47.

104.Størmer, F.C. and B. Høiby. 1996. Citrinin, ochratoxin A and iron. Possible implications for their biological function and induction of nephropathy. Mycopathologia 134:103-107.

105.Teperi, E., Keskinen, M., Ketoja, E. and R. Tahvonen. 1998. Screening for fungal antagonists of seed-borne Fusarium culmorum on wheat using in vivo tests. Eur. J. Plant Pathol. 104:243-251.

106.Tomaszewski, J., Miturski, R., Semczuk, A., Koarski, J. and J. Jakowicki. 1998. Tissue zearalenone concentration in normal hyperplasic and neoplastic human endometrium. Gynakologe 69:363-366.

107.Ueno, Y. and K. Kubota. 1976. DNA-attacking ability of carcinogenic mycotoxins in recombination-deficient mutant cells of Bacillus subtilis. Cancer Res. 36:445-451.

108.Urry, W.H., Wehrmeister, H.L., Hodge, E.B. and P.H. Hidy. 1966. The structure of zearalenone. Tetrahedron Let. 27:3109-3114.

109.Vanyi, A., Bata, A. and F. Kovacs. 1994. Perinatal oestrogen syndrome in swine. Acta Vet. Hung. 42:433-446.

110.Vanyi, A., Timar, I. and A. Szeky. 1980. Fusarium-toxicosis. The effect of F-2 toxin (zearalenone) on the spermatogenesis of rams and bulls. Magy. Allattorv. Lapja 35:777-780.

111.Varga, J., Péteria, Z., Katalin, T., Térenb, J. and C. Vágvölgyia. 2005. Degradation of ochratoxin A and other mycotoxins by Rhizopus isolates. Int. J. Food Microbiol. 99:321-328. 
112.Varga, J., Rigó, K. and J. Téren. 2000. Degradation of ochratoxin A by Aspergillus species. Int. J. Food Microbiol. 59:1-7.

113.Verhaegent, M. and T.K. Christopoulos. 2002. Recombinant Gaussia luciferase: overexpression, purification and analytical application of a bioluminescence reporter for DNA hybridization. Anal. Chem. 74: 4378-4385.

114. Völkel, A. and P. Karlovsky. 1999. Hefen und Tonminerale binden Mykotoxine: Wirksamkeit mineralischer und organischer Substanzen unterschiedlich. Agrarzeitung Ernährungsdienst, 24. April 1999, p. 10.

115.Völkl, A., Woerfel, G., Häußermann, T., Vogler, B., Klaiber, I. and P. Karlovsky. 1997. Biotransformation von Mykotoxinen von Fusarium spp. 19. MykotoxinWorkshop, München. Proceedings pp. 45-49.

116.Weaver, G.A., Kurtz, H.J., Behrens, J.C., Robinson, T.S., Seguin, B.E., Bates, F.Y. and C.J. Microcha. 1986. Effects of zearalenone on the fertility of virgin dairy heifers. Am. J. Vet. Res. 47:1395-1397.

117.Williams, L.D., Glenn, A.E., Zimeri, A.M., Bacon,C.W., Smith, M.A. and R.T. Riley. 2007. Fumonisin disruption of ceramide biosynthesis in maize roots and the effects on plant development and Fusarium verticillioides-induced seedling disease. J. Agric. Food Chem. 55:2937-2946.

118.Windels, C.E. (2000). Economic and social impacts of Fusarium Head Blight: changing farms and rural communities in the northern great plains. Phytopathology 90:17-21.

119.Woerfel, G. and P. Karlovsky. 1998. Hydrolyse von Zearalenon durch Gliocladium roseum, p. 189-192. In J. Wolff and T. Betsche (ed.), 20th Mycotoxin Workshop. Gesellschaft für Mykotoxinforschung, Detmold, Germany.

120.Wolf, J. C. and C.J. Mirocha. 1973. Regulation of sexual reproduction in Gibberella zeae (Fusarium roxeum "graminearum") by F-2 (Zearalenone). Can. J. Microbiol. 19:725-734.

121.Yu, J., Cleveland, T., Wilkinson, J., Campbell, B., Kim, J.H., Kim, H., Bhatnager, D., Payne, G. and W. Nierman. 2006. Aflatoxin control through targeting mechanisms governing aflatoxin biosynthesis in crops. Mycotoxin Research 22:16-21. 
122.Yu, J., Cleveland, T.E., Nierman, W.C. and J.W. Bennett. 2005. Aspergillus flavus genomics: gateway to human and animal health, food safety, and crop resistance to diseases. Rev. Iberoam. Micol. 22:194-202.

123.Zill, G., Engelhardt, G., Wohner, B. and P. R. Wallnhöfer. 1990. The fate of the Fusarium mycotoxin zearalenone in maize suspension cultures. Mycotoxin Res. 6:31-48.

124.Zinedine, A., Brera, C., Elakhdari, S., Catano, C., Debegnach, F., Angelini, S., De Santis, B., Faid, M., Benlemlih, M., Minardi, V. and M. Miraglia. 2006. Natural occurrence of mycotoxins in cereals and spices commercialized in Morocco. Food Control 17:868-874.

125.Zwierzchowski, W., Przybylowicz, M., Obremski, K., Zielonka, L., SkorskaWyszynska, E., Gajecka, M., Polar, M., Jakimiuk, E., Jana, B., Rybarczyk, L. and M. Gajecki. 2005. Level of zearalenone in blood serum and lesions in ovarian follicles of sexually immature gilts in the course of zearalenone micotoxicosis. Pol. J. Vet. Sci. 8:209-218. 


\section{Summary}

Fungal secondary metabolites can not only cause toxic effects in animals and humans, but also exhibit toxic properties to microorganisms and plants. The mycotoxin zearalenone is a resorcylic lactone derivative produced by plant pathogenic Fusarium species, which exerts estrogenic and anabolic effects on mammals.

The biological role of zearalenone in fungal biology has been unknown. We established that zearalenone and its derivatives inhibit the growth of filamentous fungi. Only the mycoparasitic ascomycete Gliocladium roseum, which is known to hydrolyse zearalenone to a far less estrogenic product by the activity of a zearalenonespecific lactonase, was not affected by zearalenone. The zearalenone lactonase encoding gene zes2 in G. roseum was inactivated using Agrobacterium tumefaciensmediated genetic transformation. The mutants were unable to hydrolyse the lactone bond of zearalenone and displayed an increased susceptibility to zearalenone. Thus it appears that zearalenone acts as an agent of interference competition (active protection of substrate from colonization by competitors) and that zearalenone lactonase protects $G$. roseum from its fungitoxic effect.

To assess the effect of zearalenone on plants a sensitive in vitro seedling growth assay was used to investigate the phytotoxic effect of zearalenone on Arabidopsis thaliana wild type and transformants expressing the gene zes2 from G. roseum. While wild type plants after exposure to zearalenone exhibited dwarfism. The transgenic plants were more tolerant to zearalenone showing almost no symptoms. These data indicate that zearalenone lactonase protects transgenic Arabidopsis plants from the toxic effects of this mycotoxin.

Genetic and methodical requirements for the $A$. tumefaciens-mediated transformation of $G$. roseum and the identification of mutants deficient in zearalenone lactonase production were developed. We further applied the protocol to transform different species of filamentous fungi (Leptosphaeria maculans, Verticillium longisporum, Fusarium verticillioides and Trichoderma harzianum). In order to maximize the number of transformants, the ratio of $A$. tumefaciens cells to fungal spores and the duration of the co-cultivation was optimized. A practical method for suitable saturation 
mutagenesis is described that can be used to generate hundreds of independent transformation events in one experiment.

Specific knowledge of concentrations which actually occur in the infected tissue would facilitate the understanding of the phytotoxic effects caused by zearalenone. We harnessed the zearalenone-sensing ability of G. roseum to develop a novel kind of biosensor for zearalenone. Genetically engineered fusions of the zearalenonesensing promoter-element and reporter genes encoding Green Fluorescent Protein (GFP) and Gaussia princeps lucifease were constructed. G. roseum strains harbouring the fusion constructs act as specific and highly sensible systems in a bioassay which exhibit fluorescence (GFP) or emit light (luciferase) upon exposure to zearalenone. The strains were used for real-time macroscopic imaging of zearalenone biodistribution on Fusarium infected maize tissue. Based on these imaging properties, the place of origin of native zearalenone synthesis in target tissue was discovered.

Fluorescent proteins like the green fluorescent protein (GFP) have become enormously popular as tools for monitoring gene expression in filamentous fungi. Biochemical assays using GFP reporter gene technique are usually performed in 96-well microtiter plates and the fluorescence is determined with a fluorometer. A new method was developed which uses a real time thermal cycler to measure GFP expression. In this way, fluorometers which are not commonly encountered in molecular biology laboratories, can be replaced by widely accessible thermal cyclers. 


\section{Danksagung}

Die vorliegende Arbeit wurde von Januar 2004 bis März 2008 am Department für Nutzpflanzenwissenschaften in der Abteilung "Molekulare Phytopathologie und Mykotoxinforschung" an der Universität Göttingen angefertigt.

Mein besonderer Dank gilt meinem Doktorvater Herrn Prof. Dr. Petr Karlovsky für die Überlassung des Themas. Ich bedanke mich für den regen Austausch an fachlichen Informationen sowie für die stete Diskussionsbereitschaft und konstruktive Kritik.

Bei Herrn Prof. Dr. Andreas von Tiedemann bedanke ich mich für die bereitwillige Übernahme des Korreferates.

Bei Christina Eynck und Andres Schützendübel möchte ich mich ganz herzlich für die kurzfristige Korrektur der Dissertation bedanken.

Mein Dank gilt auch Frau Dr. Ursula Hettwer und Astrid Ratzinger für die gewährte Unterstützung bei der HPLC.

Meiner Familie danke ich für die bedingungslose Unterstützung und Geduld während meiner Dissertation. 


\section{Publications and conference contributions}

Utermark J. and Karlovsky, P. 2008. Genetic transformation of filamentous fungi by Agrobacterium tumefaciens. Nature Protocols, DOI: 10.1038/nprot.2008.83.

Utermark J. and P. Karlovsky. 2007. Detoxification of zearalenone by Gliocladium roseum: biological function and regulation of zearalenone lactonase synthesis. $29^{\text {th }}$ Mycotoxin-Workshop, Stuttgart-Fellbach, Germany 14.-16.05. 2007.

Utermark, J. and P. Karlovsky. 2007. Role of zearalenone lactonase in protection of Gliocladium roseum from fungitoxic effects of the mycotoxin zearalenone. Appl. Environ. Microbiol.73:637-642.

Utermark, J. and P. Karlovsky. 2006. Biosensor for zearalenone based on the mycoparasitic fungus Gliocladium roseum. $55^{\text {th }}$ German Congress of Plant Protection. Goettingen, Germany, 25.-28.09.2006.

Utermark J. and P. Karlovsky. 2006. Quantification of green fluorescent protein fluorescence using real-time PCR thermal cycler. BioTechniques 41:50-54.

Utermark, J. and P. Karlovsky. 2006. Bioassay for zearalenone and related mycotoxins based on fusion of GFP with zearalenone esterase in Gliocladium roseum. Annual Conference of the Association for General and Applied Microbiology (VAAM). Jena, Germany, 19.-22.03.2006.

Utermark, J. and P. Karlovsky. 2005. Biological function of zearalenone lactonase in Gliocladium roseum. VAAM-Symposium "Molecular Biology of Fungi", Bochum, Germany, 04.-07.09.2005

Utermark, J. Koopmann, B. and P. Karlovsky. 2004. Agrobacterium tumefaciens mediated transformation of the ascomycete Leptosphaeria maculans, the causal agent of Blackleg disease of oilseed rape. $54^{\text {th }}$ German Congress of Plant Protection. Hamburg, Germany, 20.-23.09.2004. 


\section{Curriculum vitae}

\section{Personal Details}

Name and Surname: Jan Utermark

Address:

Oberer Waldweg1, 37186 Moringen, Germany

Tel:

+4917662025696

Email:

j.utermark@gmx.de

Date of Birth: 23.10.1977

Place of Birth: Goettingen

Nationality: German

Status: unmarried

Work Experience and Education

01/05 - today Georg-August University of Goettingen

Dissertation (Dr. sc. agr.) at the Department of Crop

Sciences, Section Molecular Phytopathology and

Mycotoxin Research, finished degree: 01/2008

07/04-12/04 Georg-August University of Goettingen

Graduate assistant at the Department of Crop Sciences,

Section General Plant Pathology and Crop Protection

10/97 - 07/04 Georg-August University of Goettingen

Study of agricultural science, Master of Science (M. Sc.),

degree 01.07.2004

08/94-06/97 Geschwister-Scholl-Gesamtschule, Goettingen.

Diploma 23.06.1997 


\section{Eidesstattliche Erklärung}

Hiermit erkläre ich eidesstattlich, dass diese Dissertation selbständig und ohne unerlaubte Hilfe angefertigt wurde.

Göttingen, im April 2008 